\title{
BALANCS HÍDRICO E ENERGÉTIICO NA CULTURA IRRIGADA DO FEIJOEIRO EM LATOSSOLO ROXO
}

\author{
EMILIO SAKAI \\ Engenheiro Agrônomo
}

Orientador: Dr. ORIVALDO BRUNINI

Dissertação apresentada à Escola Superior de Agricultura "Luiz de Queiroz" da Universidade de São Paulo, para obtenção do título de Mestre em Agronomia. Ārea de Concentração: "Solos e Nutrição de Plantas". 
Ficha catalográfica preparada pela Seção de Livros da Divisão de Biblioteca e Documentação - PCAP/USP

\section{Sakai, Emilio}

S158b Balanço hídrico e energético na cultura irrigada do feijoeiro em latossolo roxo. Piracicaba, 1989. $121 \mathrm{p}$.

Diss.(Mestre) - ESALQ

Bibliografia.

1. Feijão - Irrigação - Balanço de energia 2. Fei jão - Irrigação - Balanço hidrico 3. Latossolo roxo Irrigação I. Escola Superior de Agricultura Luiz de Queiroz, Piracicaba.

CDD $\quad 635.652$ 


\section{BALANÇO HÍDRICO E ENERGÉTICO NA CULTURA IRRIGADA DO FEIJOEIRO EM LATOSSOLO ROXO}

\section{EMÍLIO SAKAI}

Aprovado em: '19.03.1990

Comissão julgadora:

Prof. Dr. Klaus Reichardt

ESALQ/USP

Prof. Dr. Paulo Leonel Libardi

ESALQ/USP

Prof. Dr. Orivaldo Brunini

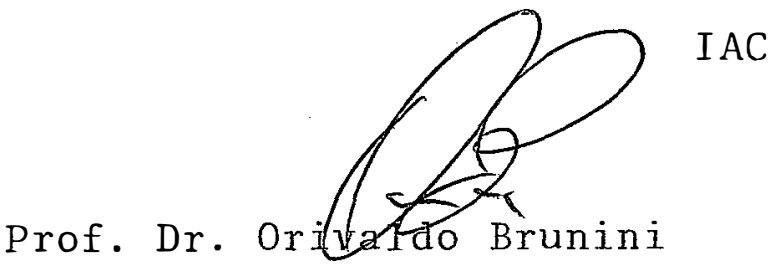

- Orientador - 
A meus pais

Coro Takeca

OFEREGO 
A minha esposa Sônia

e. a meus filhos

Gisele, Vivien e Rafael

DEDICO 
Ao Dr orivaldo Brunini, pela amizade, orientacăo precisa e apoio irrestrito durante o curso de Pos-Graduacáo $E$ elaboracáo desta:

Aos Drs. Altino Aldo Ortolani, Rogério Remo Alfonsi, Mario José Pedro Junior e Marcelo Paes de Camargo, pesquisadores cientificos da Segäo de Climatologia Agrícola do Instituto Agronômico, pelo constante $e$ inestimável apoio e sugestöes na execucấo deste trabalho?

Ao pesquisador cientifico Dr Flávio Arruda Bussmeyer, pe-las sugestöes, colaboracáo e revisấo dos tentos;

Aos Drs. Klaus Reichardt e Paulo Leonel Libardi, professores do Departamento de Física e Meteorologia da ESALQ e do Centro de Energia Nuclear na Agricultura, pelas facil idades oferecidas;

Aos professores do Curso de Pós-Graduacä́o em Solos e Nutricáo de Plantas, pelos ensinamentos:

Aos colegas do Curso de Pós-Graduacáo, pelo convívio agradave1:

Aos colegas Luis Alberto Sáes, Issao Ishimura, Kiyoshi Yanai, Mauro Sakai, Mamor Fujiwara, Regina, Célia de Matos Pires Silva, pelo excelente ambiente de trabalho, amizade, Estimulo e colaboraçỡ

A professora Ligia Abramides Testa, pela correcáo de ver-กล์ำ 
A desenhista Liliana Solha, pelo esmero na confectä́ das figuras;

Ao Instituto Agronômico do Estado de Sấo Paulo (IAC), pela oportunidade concedida"

Ao Curso de Pósmgraduacáo em Solos e Nutricáó de Plantas da ESALQ/USP, pela possibilidade en realizar o curso:

a CAPES, pela concessáo de bolsa de estudos:

is minha esposa e aos meus filhos, companheiros e amigos de todas as horas, razáo maior dos meus esforcos;

E a todos que, direta ou indiretamente, contribuiram para realizaçấo deste trabalho, mels muito obrigado. 


\section{SUMARIO}

página

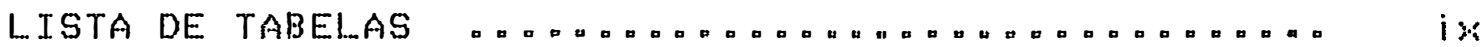

LISTA DE FIGURAS $"$ " RESUMO $\quad \ldots \ldots \ldots a n$ a

SUMMARY

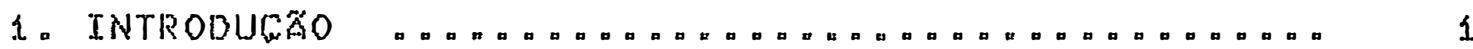

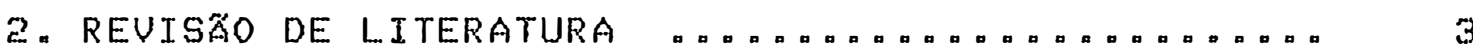

2.1. Consideracótes sobre o feijoeiro .........

2.1.1. Irrigacăo do feijoeiro \#......... A

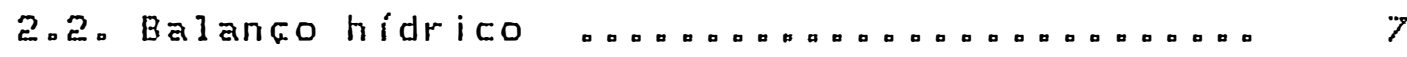

2. 2.1 . Balango hidrico de campo manan...

2.2.1.1. Drenagem profunnda $\ldots=n . . \quad 8$

2.2.1.2. Evapotranspiragáo ........ 9

2.2.1.2.1. Coeficiente de cultura a........

2.3. Balangó de energia $\ldots \ldots \ldots \ldots \ldots \ldots \ldots \ldots \ldots \ldots \ldots \ldots$ at

2..3.1. Resistência da planta ao fluxo trans-

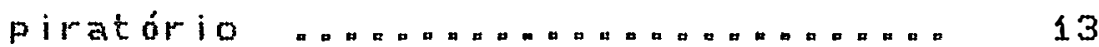

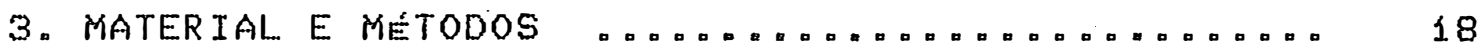

3.1. Caracteriąăo da área experinental ....... 18 3.1.1. Local $\quad \ldots \ldots \ldots \ldots \ldots \ldots \ldots \ldots \ldots \ldots \ldots \ldots \ldots \ldots \ldots \ldots \ldots$

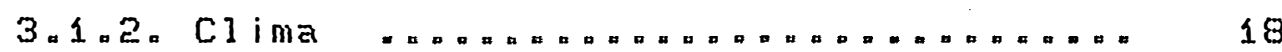

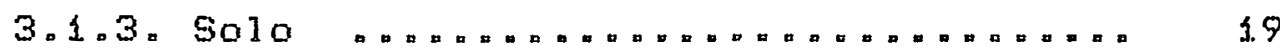

3.1.3.1. Textura $\ldots \ldots \ldots \ldots \ldots \ldots \ldots \ldots$ 19

3.1.3.2. Densidade e porosidade a. a 20

3.1.3.3. Velocidade de infiltracăo da água no $5010 \quad \ldots \ldots \ldots \ldots=0$ 21

3.1.3.4. Curva de retengấo da żgua : ét

3.1.3.5. Condutividade hidráulica. ". 24

3.2. Esquema experimental $\ldots \ldots \ldots \ldots \ldots \ldots \ldots \ldots \ldots \ldots \ldots$ z.

3.3. Caracter istica da cultura $\ldots \ldots \ldots \ldots \ldots \ldots \ldots \ldots \ldots$ a 30 
Página

3.4. Instrumental $\ldots \ldots \ldots \ldots \ldots \ldots \ldots \ldots \ldots \ldots \ldots 0.0 \ldots$ 3e

3.4.1. Anemômetro "..

3.4.2. Temperatura do ar e abrigo termometri...

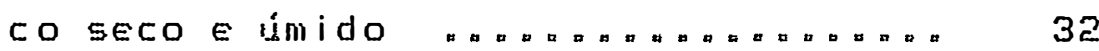

3.4.3. Radiômetro liquido " ".............. 33

3.4.4. Radiąắ global $\ldots \ldots \ldots \ldots \ldots \ldots \ldots \ldots$

3.4.5. Radiacåo fotossinteticamente ativa. 33

3.4.6. Placas medidoras do fluxo de calor no $5010 \quad$ "

3.4.7. Sistema de aquisicắo de dados ".... 34

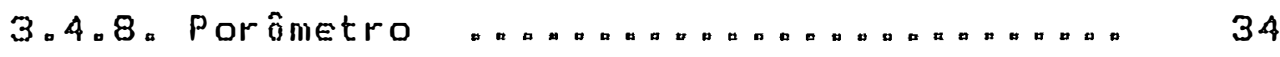

3.4.9. Evaporacắ

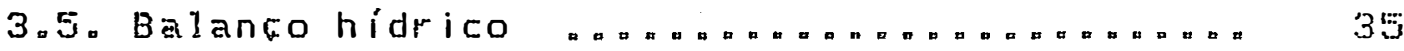

3.5.3. Variaçóo no armazenamento de água no 5010 व

3.5.2. Precipitacäo pluvial e irrigacăo : : 37

3.5.3. Drenagem profunda $\ldots \ldots \ldots \ldots \ldots \ldots \ldots$

3.5.4. Evapotranspiracä́o $\ldots \ldots \ldots \ldots \ldots \ldots$

3.6. Coeficiente de cultura ".................. 39

3.7. Balanco de energia n................. 40

3.8. Aspectos fisiológicos da cultura w....... 42

3.8.1. Resistência estomática à difusăo de vapor d’água, temperatura $e$ transpi-racăo foliar $\ldots \ldots \ldots \ldots \ldots \ldots \ldots \ldots \ldots$ \&

3.8.2. Eficiência no 150 da água \#........ 43

4. RESULTADOS E DISCUSSÃo $\ldots \ldots \ldots \ldots \ldots \ldots \ldots \ldots \ldots \ldots \ldots \ldots$

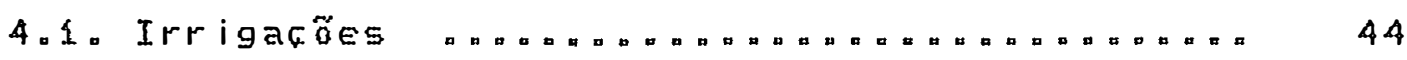

4. 2 . Comportamento estomático do feijoeiro "... 46

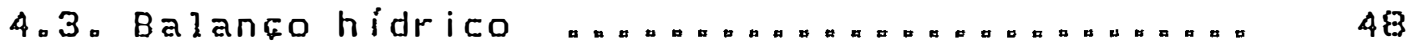

4.3.1. Adicắo de água no sistema "........ 57

4.3.2. Variacăo de armazenamento de água no $5010 \quad$ a

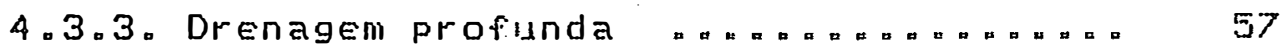

4.3.4. Evapotranspirąấo $\ldots \ldots \ldots \ldots \ldots \ldots \ldots \ldots$ 
Página

4.4. Balanco de energia wan

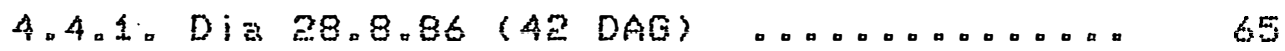

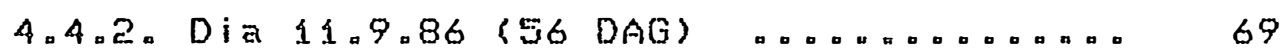

$4.4 .3 . D i a 16.9 .86$ (61 DAG) $\ldots \ldots \ldots 70$

4.4.4. Dia 23.9.86 (6B DAG) n.........

A.4.5. Dia 10.10.86 (76 DAG) \#......... 76

4.5. Coeficiente de cultura .............. 84

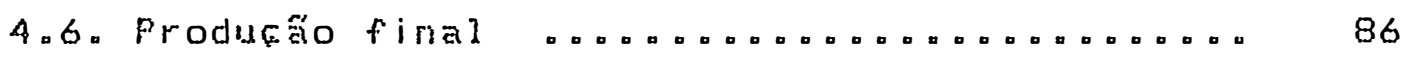

4.6.l. Beneficio da irrigacáo e uso da água. 86

4.6.2. Relaçóo entre a producáo $e$ a evapotranspiraçáo $\ldots \ldots \ldots \ldots \ldots \ldots$

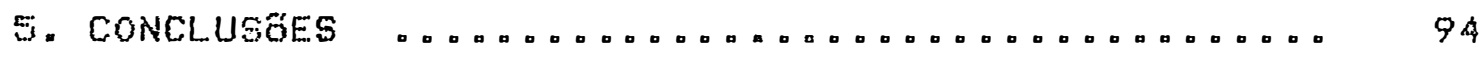

REFERENCIAS BIBLIOGRAFICAS $\ldots \ldots \ldots \ldots \ldots \ldots \ldots$

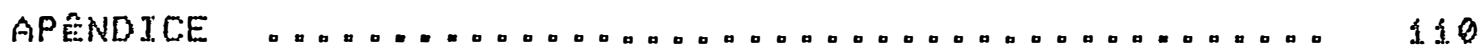




\section{LISTA DE TABELAS}

Tabela

Página

1. Resultados de análise granulométrica, fracionamento segundo escala de Atterberg, do la… tossolo roxo eutrófico, Campinas, realizada pela sefáco de Pedologia do IAC. ............

2. Resultados da densidade global e da partícula E porosidade total do solo, ao longo do per... fil do latossolo roxo eutrófico, na área experimental. Cada valor é média de oito re-.. peticöes.

3 Nimero, lâminas e intervalo médio nas irriga coóes aplicadas após o florescimento no ensaio com feijoeiro, em Campinas, SP. ........" " 46

4 Resistência estomática total d difusâo de vapor d'água ( $r_{g}$ ), nos tratamentos de irrigacăo do feijoeiro medida no periodo da manhá (8h30n-10h) E da tarde(14-15h). Cada valor é média tomada de dez folhas totalmente expostas e recém-amadurecidas.

5 Valores dos componentes do balanco hidrico de campo - precipitacăo, irrigaç̃o, variaçăo no armazenamento da água no solo ( $\triangle A$ ), drenagem profunda $e$ evapotrainspiracăo real (ETr), na cultura do feijoeiro para o tratamento $100 \% A D$ em 1986, Campinas, SP. 
Tabela

Prigina

6 Valores dos componentes do balanco hidrico de campo - precipitacăo, irrigocán. variacto no armazenamento da água no solo ( $\triangle A$ ), drenagem profunda evapotranspiracăo real (ETr), na cultura do feijoeiro para o tratamento 75\%AD, em 1996, Campinas, SP.

7 Valores dos componentes do balanco hidrico de campo - precipitacăo. irrigacto, variacáo no armazenamento da água no solo ( $\triangle A$ ), drenagem profunda e evapotranspiracăo real (ETr), na cultura do feijoeiro para o tratamento $50 \% A D$, Em 1986, Campinas, SP.

8 Valores dos componentes do balango hidrico de campo - precipitacăo, irrigacăo, variagăo no armazenamento da água no solo $(\triangle A)$, drenagem profunda e Evapotranspiracăo real (ETr), na c.ultura do feijoeiro para o tratamento $25 \% A D$, Em 1986, Campinas, SP.

9 Valores dos componentes do balango hidrico de campo - precipitaço, irrigacăo, variąăo no armazenamento da água no solo ( $\triangle A$ ), drenagem profunda e evapotranspiracăo real (ETr), na cultura do feijoeiro para o tratamento DHI, em 1986, Campinas, SP.

10 Valores dos componentes do balango hidrico de campo - precipitacăo, irrigacăo, variagăo no armazenamento da água no solo ( $\triangle A$ ), drenagem profunda e evapotranspiraço real (ETr), na cultura do feijoeiro para o tratamento $M 75 \%$, em 1986, Campinas, SP. 
Tabela

11. Valores dos componentes do balanco hidrico de campo - precipitaço, irrigacăo, variaşăo no armaženamento da água no solo ( $\triangle A$ ), drenagem profunda e evapotranspiracấo real (ETr), na cultura do feijoeiro para o tratamento En \{986, Campinas, SP.

12 Valores dos componentes do balancio hidrico de campo - precipitacăo, irrigagăo, variagáo no armazenamento dágua no solo ( $\triangle A$ ), drenagem profunda E Evapotranspiracăo real (ETr), na cultura do feijoeiro para o tratamento DHN, Em 1986, Campinas, SP.

13 Resultados do coeficientede cultura (Kc) obtidos nos tratamentos de irrigacáo ao longo do ciclo da cultura do feijoeiro, de 10.8 a 16.10.86, Em Campinas, SP. A ETo foi calculada a partir da evaporacáo de tanque classe A, $E$ a ETr, pelo método do balanco hidrico de campo, em períodos de quatro dias. ......

14 Comparacäo entre coeficientes de cultura (Kc) calculados pelo método do balanco hídrico de campo ( $\left.{ }_{*} H_{0}\right)$, em perílodos de quatro dias, E pelo método do balango de energia ( $B_{0} E_{\text {. }}$ ) ao curso do dia indicado, em seis diferentes épocas e em trếs tratamentos de irrigacấo do feijoeiro. ETó evapotranspiracáo de referência, calculada pelo tanque classe A - C.A (média de quatro dias), e por penman no dia indicado. 
Tabela

Págin a

15 Valores acumulados de irrigacáo, intervalo niédio entre irrigacóeg, producăo final de grắos e eficiência no 150 da água (EUA), Em funfáo dos tratamentos de irrigacóo na cultu-.. ra do feijoeiro, Campinas, SP. 


\section{LISTA DE FIGURAS}

Figura

página

1. Velocidade de infiltracăo e infiltracăo acumulada en funcăo do tempo, observada na área experimetal, pelo método do anéis concentri$\cos$ :

2. Curva caracteristica da rigua no solo, obtida em laboratório, para a camada de $0-60 \mathrm{~cm}$ da área experimental.

3 Infiltraçón horizontal da água para a camada - -30cm, em funcáo da raiz quadrada do tempo, na área experimental.

4 Condutividade hidráulica em funcăo da umidade do solo, determinada em laboratório, a partir da infiltraçáo horizontal da água em coluna de solo.

5. Representacấo esquemática da área experimental com feijấo localizacăo dos mastros (M), com instrumental micrometeorológico, o laboratório, como sistema de aquisicáo de dados, e a airea com os seis blocos de tratamentos de irrigaçắ ( 25 a $100 \%$ AD, DHI $\in$ DHN).

6 Esquema da armacáo de suporte para a protecáo de parcelas contra as precipitacóes, instalada nos tratamentos de irrigacáo.

7 Irrigacóes e precipitacóes (mm) ocorridas nos diferentes tratamentos da cultura do feijoeiro, no inverno de 1986 , Campinas, SP. . ..... 
Figura

Página

8 Evapotranspirąéo de referência e evapotranspiraço real (ETr) acumulada para diferentes niveis de aplicafáo de água na cultura do feijoeiro, determinadas no inverno de 1986. e:m Campinas, SP.

9 Variaça temporal da evapotranspiracäo de referência (ETo) e real (ETr), em periodos após a aplicacáo de água $(38 \mathrm{~mm}$ aos 36 DAG $E$ $70 \mathrm{~mm}$ aos 62 DAG) no tratamento DHI da cultura do feijoeiro, no inverno de 1986, Cam-... pinas, SP.

10 Variacăo horária da radiacăo líquida (RN), do fluxo de calor no solo $(-G)$, do fluxo de calor sensivel (-H) e latente (-LE) en cultura de feijâo, no dia 28.8 .86 , no tratamento 100\%AD.

11. Variagăo horária da radiąăo liquida (RN), do fluxo de calor no solo $(-G)$, do fluxo de calor sensivel (-H) e latente (-LE) en cultura de feijấ, no dia 28.8 .86 , no tratamento $M 75 \% . .68$

12 Variagăo horária da radiaçólo liquida (RN), do fluxo de calor no solo $(-G)$, do fluxo de calor sensivel (-H) e latente (-LE) en cultura de feijấ, no dia 11.9 .86 , no tratamento 100\%AD.

13 Variagăo horária da radiacăo liquida (RN), do fluxo de calor no solo $(-G)$, do fluxo de calor sensivel (-H) e latente (-LE) em cultura de feijäo, no dia 11.9 .86 , no tratamento $M 75 \%$. . 72 
Figura

Página

14 Variacấo horária da radiaçóo liquida (RN), do fluxo de calor no solo $(-G)$, do fluxo de calor sensivel ( $-H$ ) e latente (-LE) en cultura de feijấ, no dia 16.9.86, no tratamento 100\%AD. 73

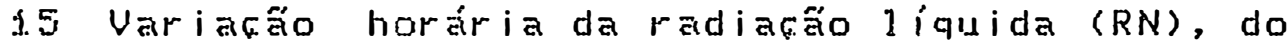
fluxo de calor no solo (-G), do fluxo de calor sensivel (-H) e latente (-LE) em cultura de feijấo no dia 16.9 .86 , no tratamento $M 75 \%$. " 74

16 Var iacăo horária da radiacăo líquida (RN), do fluxo de calor no solo $(-G)$, do fluxo de calor sensivel (-H) e latente (-LE) en cultura de feijăo, no dia 23.9 .86 , no tratamento $100 \%$ AD.

17 Variacăo horária da radiacăo liquida (RN), do fluxo de calor no $5010(-G)$, do fluxo de calor sensivel ( $-H$ ) e latente (-LE) em cultura de feijấ, no dia 23.9 .86 , no tratamento $M 75 \% . .78$

18 Variacấo horária da radiaçóo liquida (RN), do $f l u \times o$ de calor no $5010(-G)$, do fluxo de calor sensivel (-H) e latente (-LE) en cultura de feijâo, no dia 10.10 .86 , no tratamento $100 \%$ AD. 79

19 Variacăo horária da radiaçólo liquida (RN), do fluxo de calor no $5010(-G)$, do fluxo de calor sensivel (-H) e latente (-LE) en cultura de feijế, no dia 10.10 .86 , no tratamento $M 75 \%$. 
Figura

20 Producấo de gráos do feijoeiro en funcấo da irrigacáo acumulada nos tratamentos de irrigatå.

21 Producấo de grấos do feijoeiro em funcấo dă Evapotranspiractio (ETr) acumulada nos tratamentos de irrigacáo.

2e Relacáo entre a producấo de gráos do feijoeiro e o número de vagens por área obtida nos tratamentos de irrigacáo - DHI e de 25 a $100 \% A D$. 
BALANGO HIDRICO E ENERGÉTICO NA CULTURA IRRIGADA

DO FEIJOEIRO EM LATOSSOLO ROXO

Autor: EYILIO SAKAI

Orientador: ORIUALDO BRUNINI

RESUMO

O presente trabalho teve o objetivo de estudar - comportamento de alguns parâmetros que afetam o manejo das irrigagóes do feijoeiro (Phaseolus vulgaris L.) relacionados à disponibilidade de água no solo e às condicóes ambientais.

0 estudo foi realizado no Centro Experimental de Campinas - Instituto Agronônico do Estado de Sắo Paulo, (IAC), no inverno de 1986, en área de superfície plana de latossolo roxo. Inicialmente, determinaram-se os parâme-.. tros físico-hidricos do solo e, durante o desenvolvimento da cultura, acompanhou-se sistematicamente a umidade do solo, a abertura estonatica $e$ obalanco energético nos trat amentos de irrigas ấ.

A evapotranspiraçóo real (ETr), determinada atraves do balanco hidrico de campo emperíodos de quatro dias, foi relacionada com a evapotranspiracáo de referéncia, Estimada pela evaporacáo do tanque classe A, e com a ETr obtida $p \in l o$ balanco de energia (diária).

- consumo total de água $p \in l a$ cultura mostrou... se linearmente relacionado à porcentagen de água disponivel E à lâmina total de irrigacáo, ede forma assintótica con a produç̃o de grấos. 
Os resultados mostraram que o intervalo médio entre irrigacóses menor que nove dias, após o florescimento além de aumentar a perda de água por drenagem profunda, nẫo elevou significativamente a producấo final de gráos.

Houve recuperacấo total na abertura estomática dos folílolos do feijoeiro após estresse hidrico, porém, quando este foi severo, acarretou demora na resposta da tawa transpiratória.

- coeficiente de cultura mostrou-se relacionado com o desenvolvimento da cultura e das condicóes de umidade do solo: sob estresse moderado, foi afetado pela resistência estomática e pela evapotranspiracấo potencial e, sob estresse severo, praticamente, somente pela intensidade da evapotranspirafáo potencial. 
WATER AND ENERGY BALANCE OF IRRIGATED FIELD BEANS GROWN ON A DUSKY LATOSOL.

Author: EMILIO SAKAI

AdVISER: ORIVALDO BRUNINI

SUMMARY

This work investigates the water consumption and crop coefficient of field beans (Phaseolus vulgaris L.) as related to available water and environmental conditions.

A field experiment was conducted during the winter season of 1986, on a flat, well drained dusky latosol, in the Experimental Center of Campinas. Instituto Agronomico, State of Säo Paulo. Soil physical conditions, soil water profile, energy balance and estomatal resistance were monitored along the season of five irrigation time intervals.

Actual evapotranspiration (ETa) was determined by field water balance over periods of four days, and the results compared to daily ETa by Bowen ratio and reference evapotranspiration ( $E T_{0}$ ) estimated by pan.evaporation.

The water consumption was linearly related to percentage available water and irrigation depth, but asymptotically by to bean grain yield.

Stomatal resistance was reversely affected by water shortage. But water application after severe water stress did not show readly recover on transpiration rate.

The results showed that mean irrigation interval of nine days or less, after flowering, did not increa-se significantly grain yield eventhough increased losses of water by drainage. 
Crop coefficient (Kc) was dependent on crop development, environmental and soil water conditions under moderated stress. Kc was affected by stomatal resistance and reference evapotranspiration; under severe stress, Kc was mostly affected by reference evapotranspiration. 


\section{INTRODUCAO}

O feijäo, produto básico na dieta alimentar do povo brasileiro, é, para muitos, a principal fonte de proteínas. Hád décadas, a cultura do feijoeiro (Phaseolus vulgaris $\left.L_{a}\right)$ tem recebido a atencăo das diferentes áreas da pesquisa agronômica. Contudo, sua produtividade média se estabilizou em um patamar muito baixo em relacăo ao seu potencial genético.

Entre os fatores que afetam a producâo vegetal, destaca-se a água; é o meio de difusấo dos solutos nas células e solvente para a maioria das reacóes bioquimicas; funciona ainda como regulador da temperatura, pela alta capacidade calorifica, sendo básica na sustentacấo dos tecidos vegetais, dada a sua incompressibilidade.

Nas plantas em desenvolvimento, há uma continuidade no fluxo da água desde o solo até a atmosfera. A absorcấ, a translocacăo $e$ a transpiracấo da água pelas plantas dependem, além dos parâmetros inerentes ao solo, de certas caracteristicas fisiológicas próprias à planta e, principalmente, das condicóes micrometeorológicas ambientais. Entre as propriedades do solo que comandam esses movimentos, a condutividade hidráulica e o potencial da água no solo săo os principais, sendo regulados pelas suas caracteristicas fisicas: textura, estrutura e porosidade. Periodos de estiagem e alta demanda evaporativa da atmosfera sấ freqiientes e, muitas vezes, de consequências desastrosas, ocasionando deficit hidrico as plantas ediminuicáo na produtividade do feijoeiro. 
O conhecimento dos processos e fatores que in-.. fluenciam a demanda de água (evapotranspiracấo) $e$ a água norotida na camada de atuaçóo efetiva do sistema radicular das culturas no solo - drenagem profunda - constituem duas valiosas fases do balanco hidrico real.

A importância de conhecer a evapotranspiracấo de uma cultura resulta de uma estreita relacáo entre a transpiracáo e a producấo de biomassa da planta (WIT, 1958). A dificuldade de separar a transpiracáo da evaporaGấo do solo levou ao uso dos dois termos conjugados: evapotranspiracáo (ET).

Para um estudo detalhado das reais necessidades hidricas de um cultivo, é preciso conhecer os fatores fisicos do solo, particularmente no que se relaciona à disponibilidade hidrica, e os parâmetros da cultura: resistência estomática, potencial de água na folha, área $E$ temperatura da folha e eficiência do 150 da água, além dos elementos climáticos: radiacáo liquida, temperatura do ar, déficit de pressăo de vapor e velocidade do vento.

Nesse contexto, realizou-se o presente estudo com o feijấo cultivar Carioca-80-SH, em condicôes de camPo, com o objetivo de: (a) estudar o consumo e o efeito do manejo da irrigacấo para producăo de grấos, em condicợes variáveis de disponibilidade hidrica no solo: (b) correlacionar esse consumo hidrico com parâmetros climáticos $e$ fisiológicos, $E$ (c) comparar as estimativas da ET, pelo método do balango de energia e do balango hídrico no campo. 


\section{REUISÃO DE LITERATURA}

2.1. Consideragốs sobre o feijoeiro

Originário da região semitropical da América Central, onde a precipitacáo média varia entre 500 e $1800 \mathrm{~mm}$, E a temperatura média oscila de 17 a $30^{\circ} \mathrm{C}$, feijoeiro caracteriaa-se como planta herbácea, com sistema radicular de natureza pivotante e ciclo vegetativo de 75-120 dias: Consome, ao longo do ciclo, segundo as condiGôes edafoclimáticas, 300 a $500 \mathrm{~mm}$ de água, sobretudo nas fases de emergência, florescimento e formacăo dos legumes consoante DOORENBOS \& KASSAM (1979) E requer, para a germinacão, uma temperatura do solo acima de $15^{\circ} \mathrm{C}$. A $18^{\circ} \mathrm{C}$, a germinacáo leva cerca de doze dias e, a $25^{\circ} \mathrm{C}$, cerca de sete dias. As variedades, em geral, não são afetadas pela dur ąão do diă.

No Estado de São Paulo, o principal cultivar de feijâo recomendado para plantio pela secretaria da Agricultura, nas três épocas de cultivo, é o Carioca 80SH: apresenta alta produtividade, valor biológico e resistencia a muitas ragas do fungo da antracnose e da ferrugem E ao virus do mosaico comum (BULISANI \& ROSTON, 1987).

Segundo BULISANI (1987), o cultivo de feijäo de inverno irrigado expandiu-se nos ult imos anos, sobretudo nas regiốs Centro-Norte e Centro-Deste do Estado. A disponibilidade de recursos hidricos, energia elétrica e 
condicốs ecológicas favoráveis ao seu desenvolvimento, em" maio-setembro, com boa sanidade, veio solucionar a problemática de producấo de sementes, evitando a disseninacấo dos agentes causais de molestias limitantes.

Embora a cultura apresente sistena radicular de natureza pivotante, autores de regióes tropicais observaram que grande parte das raízes se encontram nos primei -ros 20 cm. INFORZATO \& MIYASAKA (1963) relatan que, En podzólico vermelho-anarelo, $74,5 \%$ do sistena radicular es.... tá contido nos primeiros $10 \mathrm{~cm}$ do perfil do 5010 e $83,6 \%$, nos primeiros 20 cm en podzolizado de lins e Marilia. $87,4 \%$ do sistema radicular concentra-se até a profundidade de $10 \mathrm{~cm} \in 97,4 \%$ até $20 \mathrm{~cm}$. REICHARDT et ali $\mathrm{c}(1974)$ verificaram, en experimentacăo de campo, que $90 \%$ das raízes se encontravan nos primeiros $30 \mathrm{~cm}$ do perfil do solo. ROUIRA (1975), estudando o cultivar Carioca, observou a totalidade do sistena radicular até $50 \mathrm{~cm}$ de profundidade, edeterminou que, lateralmente, a raiz do feijoeiro cultivado en espacamento de $50 \mathrm{~cm}$ chega a atingir $25 \mathrm{~cm}$. CAIXETA et ali i (1983) verificaram que o sistema radicular da planta se concentra na camada superficial $(\theta-2 \theta c m)$ do solo e responde a irrigacöes freqijentes. Para STANSELL \& SMITTLE (1980), o manejo de água no solo, na profundidade de $30 \mathrm{~cm}$, foi adequado para elevada produtividade de gráos. embora o feijoeiro tambén tenha extraido água de camadas abaixo dessa profundidade.

\subsubsection{Irriga६ล̃o do feijoeiro}

Segundo HAGAN et al i $i$ (1967), estresse de umidade é geralmente associado con redugấo do contelido de água no solo, na zona que compreende o sistema radicular. no ponto en que a taxa de evapotranspiraço excede a de absorkẫo das raízes elou transmissấo de água para as par-. 
tes da planta acima do solo. Estresse moderado denota mar-cante perda de turgor durante o dia, recuperando o estado integro à noite, porém sem danos à folna. Estresse severo se refere à falta de água na planta a ponto de, a noite, ela nấo se recuperar. Periodos longos de estresse na época de florescimento reduzem o nímero de vagens e de gráos por vagen e, antes do florescimento, retardam o desenvolvimento da planta. Estresse prolongado na maturacấo diminui a produtividade, ao reduzir o peso dos gráos. Conforme RoBINS et alii (1956), há decréscimo de $20 \%$ no rendimento de sementes, quando deficiências hidricas visiveis persistem antes ou durante a floracấo ou, ainda, antes da maturacấo das primeiras vagens.

LAMBERTH (1950), estudando os fatores que influenciam o pegamento das vagens, concluiu que a disponi-bilidade de água era o fator ambiental mais importante. BERNARDO et ali $i$ (1970) observaram as maiores producóes de feijấo nos tratamentos em que se irrigava quando a tensáo da água no solo atingia $0,05-0,065 \mathrm{MPa}$. Nos tratamentos mais úmidos, as plantas apresentavam maior precocidade e, acima de $0,075 \mathrm{MPa}$, sintomas de falta de água.

BURMAN \& BOLMONT (1961), Em pesquisas en casa de vegetacão, realizaram experimento onde as parcelas de feijấo recebiam irrigacấo quando o potencial matricial da água no 5010 alcancava $-0,05 ;-0,10 ;-0,20 \in-0,40 \mathrm{MPa}$; no tratamento mais irrigado, em relacáo aos demais, houve resposta significativa sobre o peso de grấos por vagem, nímero de vagens por planta $e$ de grä́os por vagem.

MCMASTER Et ali $i$ (1965) E HORNER \& MOJTEHEDI. (1.970), entre outros, verificaram as maiores reducóes na producấo quando o déficit de água no solo ocorria no flo-. rescimento $e$ na frutificacáo

Para MAGALHÄES \& MILLAR (1978), houve decréscimo na producấo de grăos com o múmero de dias de déficit: de água a partir de uma semana antes do inicio da flora- 
Găo, com a diminuigấo do potencial matricial do solo. An-tes e após o período desse déficit, os tratamentos foram ef́tuados em condicóes ótimas de umidade até o final do ciclo da cultura.

Segundo MILLAR \& GARDNER (1972), o feijoeiro é afetado no crescimento e transpiracáo quando o potencial matricial é menor que $-0,025 \mathrm{MPa}$, sofrendo a $-0,04 \mathrm{MPa} u \mathrm{~m}$ decréscimo de $50 \%$ na taxa de transpiracấ.

De acordo com DAKER (1984), o nivel de tensấo da água no solo tolerado pelo feijoeiro para obter eleva-das produgöes é de 0.06 a $0.10 \mathrm{MPa}$. BULISANI (1987), em Sáo Paulo, propöe que se irrigue quando o solo atinge a tensấo de 0,07 MPa $e$ que se tenha cuidado especial nas fases de germinakấ, crescimento vegetativo, florescimento enchimento dos gräos, pois, caso ocorra déficit hidrico acentuado, as perdas de producăo poderáo ser elevadas $e$ irrecuperáveis.

DOORENBOS \& KASSAM (1979) recomendam que o suprimento de água para a maxima producăo de feijấo seja contínuo, desde o inicio do ciclo, suspendendo-se a irrigąấo cerca de 20-as dias antes da colheita. A deficiência hidrica severa no periodo vegetativo geralmente retarda o desenvolvimento do ciclo da cultura, e irrigacóes freqientes durante o florescimento e maturacấo elevam bastante a produgấo. DOORENBOS \& PRUITT (1977) apontaram o periodo critico à deficiência hidrica da cultura do feijấo da seguinte forma, por ordem de prioridades(1) periodo de florescimento e pegamento das vagens: (2) periodo vegetativo e (3) periodo de maturacâo. Entretanto, o último pode ser mais critico que o anterior, desde que nấo tenha ocorrido deficiência hídrica. 
2.2. BaIngo hidrico

Para a manutenfä́o da unidade do solo em niveis ót imos de armazenamento, através da irrigacáo ou da drenagem, é recessário caracterizar o sistema solowplantaatmosfera que interfere no balanco hidrico da cultura.

No estudo da determinacấo do consumo de água pelos vegetais en áreas irrigadas, destacam-se os métodos do balanco hidrico de campo e do balanco de energia.

\subsubsection{Balanco hídrico de campo}

O balango hidrico de campo é um método para avaliar, em determinado período, os processos de flumos de água em um solo, cultivado ou nấo (HILLEL, 1971). Seus componentes sấo os seguintes: precipitąấo, irrigacấo, escoamento superficial, drenagen profunda, evapotranspiracáo e variacáo do armazenamento de água no solo. Cada un deles : apresentado en forma integral ou diferencial, numa equaGấ baseada no princípio da conservacáo da matéria (HILLEL, 1980, E OMETTO, 1981).

Na elaboracấo do balanco hidrico de campo, a maior dificuldade se encontra na estimativa da drenagem profunda obtida mediante a equacăo de Darcy. Muitas vezes, ela é negligenciada ou incluida como parte do armazenamento de água ou evapotranspiracấo da cultura (ROSE, 1966), embora, às vezes, seja responsável por grande parte da água perdida. Segundo REICHARDT et alii (1979), podem ocorrer erros na estimativa do gradiente do potencial hidráulico no solo. principalmente na determinacáo da condutividade hidráulica. Embora esta, quando obtida em laboratório, possa ser usada sem sérias restricóes (DANG, 1980), a exponencialidade da relagäo entre a condutividade hidráulica e a umidade do solo em base volumétrica faz com 
que um pequeno erro na estimativa da umidade possa resul ... tar num valor da condutividade hidráulica de outra ordem de grandeza.

\subsubsection{Drenagem profunda}

O movimento de água no solo, que preferencialmente ocorre na fase liquida, dáse em resposta a diferen-cas de potencial da água. Esse fluxo é igual ao produto da condutividade hidráslica pelo gradiente de potencial total, inicialmente determinado por Darcy em 1856. Assim, para o cálculo da drenagem profunda, é necessário a determinaçáo de ambos na profundidade do sistema radicular.

A condutividade hidráulica, apesar de ser diretamente proporcional à umidade do solo, nâo implica que o fluxo também o seja. Os fluxos de água no campo ocorrem, na maioria das vezes, em condicóes insaturadas.

OGATA \& RICHARDS (1957) determinaram a condutividade hidráulica no campo, através do perfil instantâneo em condicốes de nâo-saturacâo, modificando o método aplicado por RICHARDS et aliis (1956), mediante a cobertura da superficie do solo, e eliminando, assim, o fluxo ascendente. NIELSEN et alii (1962) utilizaram-se da mesma técnica, exceto na determinacáo da umidade, onde empregaram sonda de nêutrons, técnica introduzida por BELCHER et ali is (1950).

Através de medidas sucessivas do conteudo e do gradiente de potencial da água de un perfil do solo. HILLEL et alii (1972) observaram uma relacâo exponencial entre a umidade volumétrica e a condutividade hidráulica.

E:m vista das dificuldades envolvidas na-determinaçáo direta da condutividade hidráulica do solo, mutos pesquisadores procuram relaciona-la com outras propriedades fisicas de fácil medida. No método proposto por REI- 
CHARDT et ali is (1975), é preciso conhecer apenas a umida-de de saturacăo, a umidade seca ao ar e o coeficiente angular da curva da distância da fonte de água à frente de molhamento versus a raiz quadrada do tempo em experimentos de infiltracáo horizontal, em coluna de solo homogeneamen-te compactado em laboratórion

PAULA SOUZA et al i i (1979) calcularam a drenagem profunda en terra roxa estruturada numa cultura de feijăo, na profundidade de $l 20 \mathrm{~cm}$, observando que no periodo limido ela foi responsável por $58,7 \%$ da contabilidade da água $e$, no seco, por $6,6 \%$ apenas.

\subsubsection{Evapotranspiracăo}

A evapotranspiracăo (ET) de uma área cultivada consiste na evaporacăo do solo e transpiracăo pelas plantas, evaria com o estádio de desenvolvimento da cultura. Esses processos de evaporacăo e transpiracăo ocorrem simultânea e interdependentemente. A dificuldade em separá1 os levou ao uso dos dois termos conjugados: evapotranspiraçóo. A importância em conhecê-la é a estreita relacấo entre a transpiracăo e a producấo de biomassa da planta (WIT, 1958). Essa dependência da producăo final de biomas-sa e de gräos na evapotranspiraçóo total das culturas também é relatada por DOWNEY (1972).

A estimativa da evapotranspiraçó é primordial na agricultura, sobretudo ao planejamento da irrigacăo, à predicáo de produtividade e ao manejo da disponibilidade dos recursos hidricos (HAGAN et alii, 1967, e DOORENBOS \& KASSAM, 1979). Vários métodos foram desenvolvidos e técnicas introduzidas para a determinacáo da ćgua consumida pelas plantas, com base em conceitos físicos de transporte de vapor d'água e nas respostas fisiológicas dos vegetais em experimentacăo. 
Estudando a Evapotranspiracấo do algodão $E$ sorgo-uranifero cultivados em lisimetros, RITCHIE et alii (1972) observaram que a taxa de transpiracấo diminuiu quando $80 \%$ da água extraível do perfil do solo foi usada. RITCHIE (1973) notou o mesmo efeito com milho, e MEYER \& GREEN (1980) detectaram uma reducâo na tawa de transpiraGấo quando $70-80 \%$ da água disponível era consumida em tri... 90.

MILLAR \& GARDNER (1972) determinaram decréscimos curvilineares na transpiracấo e na taxa de producấo de matéria seca com o potencial de água do solo: quando este decrescia de $-0,028$ a $-0,04 \mathrm{MPa}$, a producâo de matéria seca diminuía em 47\%. Determinaram, também, que o fechamento dos estômatos pelo déficit de água resultou em maior reduGẩo na taxa de crescimento do que na transpiracâo.

Para COWAN \& MILTHORPE (1968) E KAUFMANN \& HaLl (1974), a taxa de perda de água através das plantas e os gradientes de potencial que geram o movimento da água sáo determinados, primariamente, pelos fatores atmosféricose da planta que interferem na passagem do vapor d'água da folha para a atmosfera. Já para GARDNER (1965), a evapotranspiraqấo em culturas sem deficiência hidrica é comandada muto mais pelas condicöes atmosféricas do que pelos fatores do solo e da planta, considerando que a radiaGấo solar é a forca motriz primária e que a taxa de escoamento da água depende do gradiente de pressáo de vapor d'água entre a superfície evaporante $e$ o ar.

SILUEIRA \& STONE (1979) realizaram o balango hidrico do feijoeiro em latossolo vermelho-amarelo em cerrado de Goiania. Considerando um volume de controle com $60 \mathrm{~cm}$ de profundidade, encontraram $220 \mathrm{~mm}$ de evapotranspiracâo $e 40 \mathrm{~mm}$ de drenagem profunda, ou equivalentes a b2 $e$ $11 \%$ da evaporacâo do tanque classe $A$, acumulada ao longo do ciclo da cultura. 
Em un experimento de três anos, na Costa Rica, GTRALT (1979) Estimou a Evapotranspiracáo total do feijoeiro em 360-371 mm, com média de $3,27-3,47 \mathrm{~mm}_{\text {. diat. }}^{-1}$.

GUIMARÄES et alii (1982), avaliando a evapotranspiracáo, em Goiñnia, de populacốes do feijoeiro, com E sem irrigac:áo, obtiveram valores de evapotranspiracáo de 1,96 a 2.,14 mmodia-1 nos primeiros dez dias após a germinậ́o: 5,27 a $7,26 \mathrm{~mm}_{\text {adi }}{ }^{-1}$ no periodo da floracáo, $E$ de 0,79 a $1,45 \mathrm{~mm}^{0} \mathrm{dia}^{-1}$ no inicio da maturacăo.

\subsection{Coeficiente de cultura}

A relacão entre a evapotranspiracáo real e a potencial ou de referência (ETr/ETo), denomina-se coeficiente de cultura (KC) (DOORENBOS \& PRUITT, 1977): tratase de un coeficiente complexo que envolve variáveis relacionadas ao desenvolvimento da planta e ao manejo da água. Em experimentacăo em terra roxa estruturada, em Piracicaba, LUCHIARI JUNIOR (1978) obteve Kc médio de Q 88, calculado pela estimativa da evapotranspirafáo real do feijoeiro, a partir da evaporacáo média diária corrigida do tanque classe A, para periodos de sete dias. Já DooRENBOS \& KASSAM (1979) recomendam valores diferentes de Kc para diferentes estádios de desenvolvimento da cultura. No estádio 1 , que vai da germinacáo até $10 \%$ de cobertura ve-getal (15 a 20 dias) - Ke de 0,3 a 0,4; no estádio 2 , de 10 a $80 \%$ de cobertura do solo pelas plantas ( 15 a 20 dias) - Kc de 0,7 a 0,$8 ;$ no estádio 3 , de $80 \%$ de cobertura vegetal até o início do amadurecimento (35 a 45 dias) - Kc de 1,05 a 1,$2 ;$ no estádio 4, do amadurecimento até a colheita (20 a 25 dias) - Kc de 0,65 a 0,75, e no estadio 5, periodo da colheita - Kc. de 0,25 a 0,30 . 
ENCARNAC\%O (1980), comparando os métodos de determinacáo do Kc em feijoeiro cultivar Goiano Precoce em terra roxa estruturada, em Piracicaba, concluiu que a es... t imativa de Kc através do tanque classe $A$ foi a única que nấ ifferiu estatisticamente do padrấo recomendado pela FAO (DOORENBOS \& KASSAM, 1979).

SANTOS (1985) comparou os valores medidos de ET com o calculado pelo método da radiąáo da FAO (Makkink modificado) recomendado por DOORENBOS \& PRUITT (1977), obtendo os seguintes resultados de Kc: periodo de 28.1 (ger... minacấo) a 6.2: 0,20; de 7 a $16.2: 0.67 ;$ de 17 a $26.2:$ $0.89 ;$ de 27.2 a $7.3: 1,43 ;$ de 8 a $17.3: 0.75 ;$ de 18 a 27.3: 0.99; de 28.3 a $3.4: 0.73 ;$ de 4 a $11: 4: 0.15$. O Kc médio foi de 0,73 .

Ds resultados de Kc relatados na literatura variam. Nem sempre sấo bem caracterizadas as condicốs ambientais onde foram determinados, resultando, mitas vezes,en valores discrepantes entre locais, épocas e auto$r \in S$.

Quando se tem um controle maior das condicóes que interferem no consumo de água, é importante a comparaGáko do Kc obtido a partir do balanco hidrico de campo com o do balango de energia diário ou pela equacấo de penman.

\subsection{Balango de energia}

o balanco de energia o somatório algébrico das energias que alcancam e deixam a superficie do solo, vegetada ou nấ, tendo como resultante a energia líquida disponivel ao meio. É utiliazdo no cálculo da evapotranspiracáo: os resilltados obtidos por esse método sấo semelhantes àqueles por lisimetro, porém sem seus gastos. Se -.. gundo PERRIER et ali $i(1975)$, ele é adotado para determinar os fluxos de calor latente e sensivel, a partir de me... 
didas da radiacấo líquida, do fluxo de calor no solo, dos gradientes de vapor d'água e da temperatura do ar acima da cultura. Agronomicamente, ét utilizado para quantificar o consumo d'água pela cultura (evapotranspiracấo), com grande precisấ, quando nâo há transporte advectivo. Na clas-.. sificacáo de TANNER (1968), o método do balanco de energia se destina d̀ determinacấo hor ária.

Alguns autores observaram que, em condicóes advectivas, o emprego do método é dificultado pela contri... buicấo de energia no.processo evaporativo, além daquelas determinadas no balanco vertical. No sorgo, por exemplo, HANKS et alii (1971) detectaram um incremento de até $30 \%$ na evapotranspiracấ, E CHIN CHOY \& KANEMASU (1974) obser... varam que $21 \%$ da energia utilizada na transpiracấo era proveniente da advectấo.

No Brasil, a técnica do balanco de energia foi adotada por alguns autores, como UILLA NOUA (1973) na cul-tura do arroz; PEDRO JR. (1977), na de soja, e BERGAMASCHI

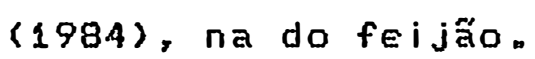

- consumo total de água da cultura sob vairios tratamentos de manejo de irrigafáo pode ser mais bem en-tendido pela análise do curso diário da particấo da energia e no seu uso para a vaporizacấo da água do solo e da planta..

2.3.1. Resistência da planta ao fluxo transpiratório

- movimento de água a partir do solo para a atmosfera, através da planta, é um processo contínuo e di-nẩmico que se dá ao longo de gradientes decrescentes de potencial d'água (GARDNER, 1960). A planta absorve água armazenada no solo em resposta a um gradiente de potencial da água no sistema solo-planta (GARDNER \& NIEMANN; 1964, RITCHIE, 1974). Esse gradiente resulta da transpiracáo. 
que desidrata as folhas, reduzindo o potencial da água na planta, em um processo essencialmente passivo. Com isso, as taxas de fiuxo de água do soin, através das raías, para as folhas, éproporcional à diferenca entre os potenciais da água na folha e no solo (RITCHIE, 1974)"

A água se move no sistema solo-planta-atmosfe-ra, passivamente, segundo un gradiente de potencial. Quan-to maior o gradiente, mais rapidamente ela se moverá. Esse movimento, todavia, é influenciado também pela resistência do percurso (HSIAO, 1973, E NOBEL, 1974).

o movimento da água da $r a i z$ até as folhas, que cocore, predominantemente, no xilema, é chamado fluxo transpiratório: por via de regra, é causado pela perda de água através da folha, mas pode ser aumentado pela pressáo radicular resultante de solutos no xilema das raizes. A principal forca motrizestá localizada fora, e náo dentro da planta, embora forcas osmóticas sejam responsáveis pelo acumulo de água nas células (SUTCLIFFE, 1980). Portanto, para manter o fluxo, o potencial da água na planta deve ser menor do que no solo (MILLAR Et ali $i$, 1971).

SEgundo JARUIS (1975), para uma planta cujo déficit hidrico se está desenvolvendo, a transpiraçó excede a absorfăo, e a água é retirada dos tecidos que circundam o xilema. Quando a transpirafấo se iguala à absormi Găo, observa-se que a água nos tecidos que envolven o lema $e$ a do próprio xilema estäo sob o mesmo potencial. Como o volume de água transpirada diariamente é grande em relaGåo à variąâo do seu teor na planta, o fluxo de água pode, para determinados intervalos de tempo, ser conside-rado como um processo en equilibrio dinâmico.

A resistência da planta ao fluxo d’água é de-.finida como a resistência ao fluxo liquido através de raizes, , ilema $e$ folhas (JONES et alii, 1982). 
Para solos limidos, tanto a resistencia total como a da planta podem ser consideradas iguais, ou seja, 0 Solo pouco contribui para a resistencia totai. No entanto. com o secamento do solo, a resistência total torna-se consideravelmente maior que a da planta, para os mesmos valo res de fluxo transpiratório (ZUR et ali $i, 1982$ ).

No que se refere ta resistencia do solo ao movimento da água, vários autores afirmam que a condutância do solo decresce exponencialmente com o decréscimo do teor da água SGARDNER, 1960; HSIAO et alii, 1979; LIBARDI et a1ii, 1980, E BRUNINT, 1981).

A trangfiracto das plantas envolve a evaporaEấo da água a partir de locais dentro das folhas ou outros tecidos e seus subseqiiente transporte como vapor d'agua, principalmente por difusăo, arravés de uma série de resis-. tências, até o ar externo. A maior parte do fluxo total ocorre pelos estômatos, e pequena porgão pela cuticula (JONES \& HIGGS, 1980 ).

SEgundo GATES (1980), usando a lei de Fick, é possivel definir a resistência d difusấo para os percursos estonatico, cuticular eda camada limite. A resistência total deste percurso representa a soma das resistencias da folha e da camadalimite, considerando que existen duag superficies foliares e que a difusão do vapor d'ágúa de ambas representa um circuito en paralelo.

A resistência do ar à troca gasosa varia com as dimensóes da folha e com a ventilacắo aumenta com o tamanho das folnas e diminui com a velocidade do vento. sendo esta ifltima a variável que mais a afeta (PARCEUAUX, 1972; ROSEMBERG, 1974, E GATES, 1980).

A abertura dos estomatose, portanto, a resistência que opöen ao fluxo de vapor d'água é funcấo de fatores internos e externos a folma, passiveis de medir por aparelhos próprios, possibilitando a descricấo do comportamento estomatico e estado hidrico da planta CBEGG \& 
TURNER, 1976; JARUIS, 1976: GATES, 1980), GEgundo GARDNER (1960), o decréscimo do contéldo de água no solo diminui o potencial da água no 5010 e nas folhas, que apresentam um déficit: as células-guarda perden a turgescência, causando - fechamento dos estômatos e, conseqijentemente, aumentando a resistência ao transporte de vapor d'água nas folhas. Esse aumento na resistência estomática ocasiona a redugấo da dissipacăo do calor latente pela transpiracấo, elevando, por conseguinte, a temperatura das folhas (BIDINGER, 1978). SLATYER (1967), complementando essa afirmacấo, acrescenta que a temperatura, a luze a concentracáo de Cog no ar ambiente também afetam a pressä́o de turgescência das células-guarda. KANEMASU \& TANNER (1969) concluíram que a resistência estomática, que é a principal resistên-cia d̀ difusấo do vapor d’água, age como una chave interruptora, Evitando uma diminuiçáo mais intensa no potencial da água na folha. Quando as plantas sấo submetidas a déficits hidricos graduais, poden ocorrer processos que as tornam menos sensiveis ao estresse de água por ajustamento osmótico, por influência na morfologia das folhas $e$ por mudangas na plasticidade das suas células (JENSEN, 1981).

A abertura estomát ica também depende de processos fotoquímicos, sendo uma funcáo da densidade de fluxo quântico, da diferenca de pressấo de vapor folha-ar, da temperatura da folha, do nível de cos; da velocidade do vento $E$ do estado hidrico da folha (JARUIS, 1976 : KAUFMANN, 1976, E SIUAKUMAR \& SHAW, 1979).

KANEMASU \& TANNER (1969) mediram a resistência Estomática abaxial e adaxial $e$ o potencial da água nas folhas expandidas do feijoeiro en condicóes de campo: obser-. varan eles comportamentos distintos entre as faces das foIhas, provavelmente pelo maior número de estômatos na su-perfície abaxial. Enquanto essa face nấo era afetada significativamente, pela mudanga do potencial da água na folha de $O$ a $-1,1$ MPa, só aumentando rapidamente com o in- 
cremento do potencial de $-1,1$ para -1,2 MPa, na face adaxial esse aumento na resistência ocorreu gradativamente a partir de $-0,8$ até $-1,2$ MPa. MILLAR \& GARDNER (1972) ob… servaram elevacấ na resistência estomática adaxial à difusão de vapor a um potencial da água na folha menor que $-0,8 \mathrm{MPa}$. Coincidentemente, detectaram diminuicấo mais rápida na taxa de producâo de matéria seca que na de trans.-. piracáo quando esse nivel foi alcancado.

Um aumento nos valores da resisténcia estomá-. tica com a diminuicăo da disponibilidade hidrica no solo, foi observado por HSIAO (1973). EsSE efeito, mais pronunc. iado quando o contelido de água no solo era inferior a $80 \%$ da água disponivel, levou-o a coneluir que a determinacáo da resistência do estômato ̀े difusâo de vapor é um excelente critério para a estimativa do déficit hidrico na produtividade das plantas.

BASCUR et alii (1985) demonstraram a possibilidade de, por meio da termometria infravermelha $e$ de um indice de secamento que representa o estado hidrico da planta, identificar cultivares de feijấo com genótipo para maior tolerância à deficiência hídrica. KRETCHMER et alii (1980), por sua vez, utilizaran a diferenga acumulada da temperatura do dossel aferida em torno das 13 h, entre parcelas irrigadas e näo-irrigadas, para identificar genóti-. pos de feijấo-tolerantes à seca. 
3. MATERIAL E MÉTODOS

3.1. Caracterizą̧̃o da área experimental

\subsubsection{Loca 1}

- Experimento foi realizado no Centro Experimental de Campinas - Instituto Agronômico do Estado de São Paulo (IAC), cujas coordenadas são $22^{\circ} 53^{\prime} \mathrm{S}$. $E 47^{\circ} 04^{\prime} \mathrm{W}$., e altitude de 706 metros, en área aproximada de 18.000 metros quadrados.

\subsubsection{Clima}

- clima regional é do tipo "CWA", conforme classificagäo de Koppen, definido como inverno seco e temperatura do mês mais quente superior a $22^{\circ}$ e do mês "mais frio inferior a $18^{\circ} \mathrm{C}$. Os valores normais de precipitacão anual são de $1.365 \mathrm{~mm}$, Evapotranspirąăo potencial anual, de $955 \mathrm{~mm}$, com excedente hidrico de $433 \mathrm{~mm}$, E deficiencia hidrica de $23 \mathrm{~mm}$, obtidos pelo balango hidrico de THORNTHWAITE \& MATTER (1955), considerando-se um armazenamento de $125 \mathrm{~mm}$ de água no solo (dados fornecidos pela Secão de Climatologia Agrícola do IAC). 


\subsubsection{Solo}

O solo foi classificado como latossolo roxo eutrófico, argiloso, localizado em relevo plano a suave ondulado, com declividade do terreno na área experimental inferior a $2 \%$.

\subsubsection{Textura}

Determinou-se a textura através da análise granulométrica, pelo método da pipeta na quantificacáo do teor de argila; tamisamento para a separacáo da fracáo areia e, por diferenca, o teor de silte, após dispersáo da terra fina seca ao ar (TFSA) com hidróxido de sódio e agitaçáo mecânica. Os resultados da análise granulométricar. média de quatro perfis, encontram-se na Tabela 1.

Tabela 1 - Resultados de análise granulométrica, fracionamento segundo escala de Atterberg, do latossolo roxo eutrófico, Campinas, realizada pela Segáo de Pedologia do IAC.

Areia

Profundidade Grossa Fina Argila

$\begin{array}{ccccc}\mathrm{cm} & 21 & 18 & 05 & 56 \\ 0-20 & 18 & 15 & 06 & 61 \\ 20-40 & 17 & 12 & 06 & 65 \\ 40-60 & 16 & 13 & 06 & 65 \\ 60-80 & 16 & 13 & 07 & 64 \\ 80-100 & 16 & 7 & \end{array}$




\subsubsection{Densidade e porosidade do solo}

Determinou-se a densidade global do solo a ca... da $10 \mathrm{~cm}$, até a profundidade de $50 \mathrm{~cm}$, ut ilizando-se amostras indeformadas coletadas em anéis volumétricos de $100 \mathrm{~cm}^{3}, e$, nas mesmas profundidades, estabeleceu-se a densidade da partícula pelo método do picnômetro.

A porosidade total foi estimada pela relaçáo entre a densidade do solo e a da particula:

Espaco poroso $(\%)=100 \quad$ densidade do solo densidade da particula $100(1)$

Essas densidades foram determinadas na Secẫo de Irrigacáo $E$ Drenagem do IAC, encontrando-se os resultados na Tabela 2 .

Tabela 2 - Resultados da densidade global e da partícula porosidade total do solo, ao longo do perfil do latossolo roxo eutrófico, na área experimental. Cada valor é média de oito repeticóes.

Densidade

Profindidade $\quad$ Global . Particula $\quad$ Porosidade

\begin{tabular}{|c|c|c|c|}
\hline$c m$ & $-\cdots-\cdots--$ & $9.6 \mathrm{~m}-3$ & $\%$ \\
\hline 10 & 1,24 & 2,61 & 52,7 \\
\hline 20 & 1,30 & $\ldots$ & $\cdots$ \\
\hline 30 & 1,33 & 2,65 & 50.4 \\
\hline 40 & 1.27 & $=$ & $\cdots$ \\
\hline 50 & 1,21 & 2,65 & 54,5 \\
\hline
\end{tabular}


3.1.3.3. Velocidade de infiltraçỗo da água no 5010

Determinou-se a velocidade de infiltracáo da água no solo pelo infiltrômetro de anéis concêntricos, utilizando-se dois deles de 30 e $60 \mathrm{~cm}$ de diânetro, en sete repeticóes. Após encravados ao solo, esses anéis foram alimentados e mantidos com uma lâmina constante de água de $4 \mathrm{~cm}$, por $1 \mathrm{~m}$ sigtema de válvulas bóias conectadas a cilindros reservatórios, onde se efetuaram as leituras do volume infiltrado no solo, em funcấo do tempo, em periodos va-riáveis, de acordo com a velocidade com que a água penetrava no solo, porém os mesmos para cada local, até esta... biliaar-se, admitindo um valor constante, denominado infiltrąấo básica $\left(K_{0}\right)$.

Os resultados médios obtidos encontram-se na Figura 1. A infiltracăo básica (Ko) observada foi de

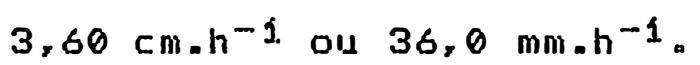

\subsubsection{Curva de retenção da água}

Determinou-se a curva caracteristica de unidade de solo mediante extratores de placa porosa.

As amostras da camada superficial de 0-5 cm, de vários locais na área de ensaio, foram preparadas em laboratório, passando em peneiras de $2 \mathrm{~mm} e$ as de 20,40 e $60 \mathrm{~cm}$ de profundidade eram indeformadas $e$ coletadas em anéis volumétricos de $100 \mathrm{~cm}^{3}$.

As amostras foram submetidas às pressóes de 0.1 a 15,0 atm, na panela e na câmara de Richards, com três repeticóos para cada profundidade, podendo, assim, determinar-se a dependência entre a umidade do solo e o potencial matricial. Os resultados das características de retençáo da água no solo, para a camada de $0-60 \mathrm{~cm}$, achamse na Figura 2 . 
(

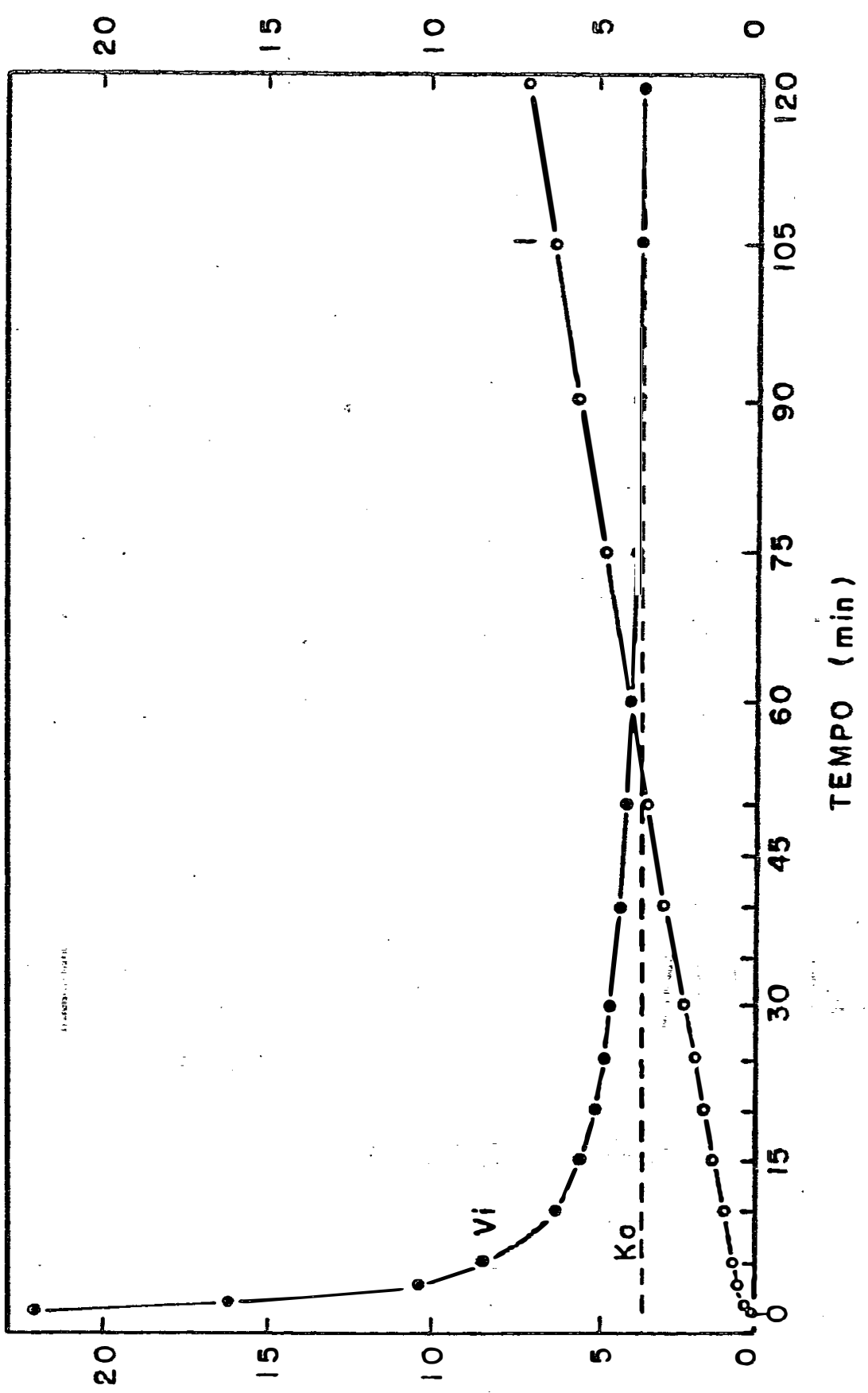

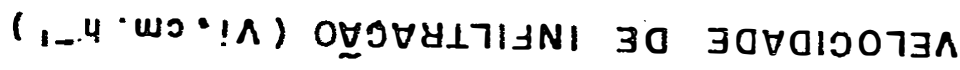




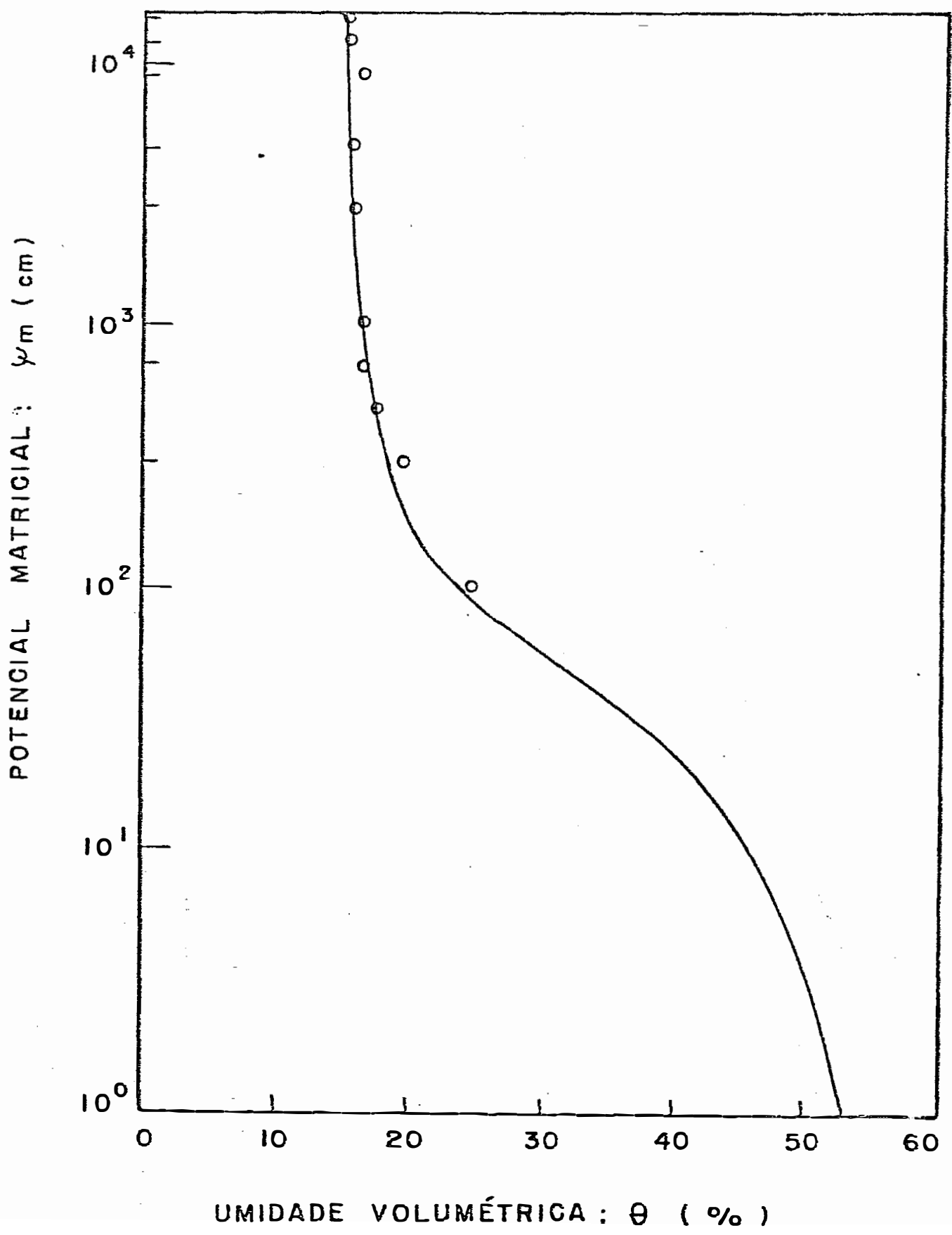

Figura 2 - Curva característica da água no solo, obtida em laboratörio, para a camada 0-60 cm da área experimental. 


\subsubsection{Condutividade hidráulica}

A condistividade hidrálslica do solo (K), em funcáo de sua umidade ( $\theta$ ) foi determinada em laboratório, com base na análise de infiltracăo horizontal da água em coluna de solo, no Departamento de Física e Meteorologia da ESALQ.

Uma coluna, constituida de um tubo de acrílico de $30 \mathrm{~cm}$ de comprimento ${ }^{5}, 7 \mathrm{~cm}$ de diâmetro interno, $1 \mathrm{i}-$ gada em uma das extremidades a um reservatório de água de nivel constante, foi preenchida com amostra de TFSA de diâmetro inferior a $1 \mathrm{~mm}$ e compactada homogeneamente até a densidade observada no campo.

A análise do processo de infiltraçáo da água no solo, neste método, consiste na determinacáo do avango da frente de molhamento no tempo, a qual é proporcional a raiz quadrada do tempo. Esses valores sáo dispostos em um sistema de eißos cartesianos, onde é graficamente determinada a tangente formada pela reta que une esses pontos $e$ tempo de observacáo. Como valor da tangente, a condutividade da água no solo foi determinada a partir da expressäo proposta por REICHARDT \& LIBARDI (1973), a saber:

$$
K(w)=1,542 \times 10^{-12} \times \mathrm{m}^{4} \mathrm{e}^{\left(-12,235 w^{2}+28,061 w\right)}
$$

onde m é a inclinagáo da reta formada pela frente de molhamento e a raia quadrada do tempo, e w, uma unidade adimensional dada pela relacáon

$$
W=\frac{\theta-\theta_{0}}{\theta_{E}-\theta_{0}}
$$

sendo $\theta$ a umidade volumétrica do solo para um instante qualquer, $e \theta_{0} \in \theta_{\text {sij }}$ respectivamente, as umidades do solo seco ao ar (TFSA) E, do solo saturado. 
Inicialmente, determinou-se a umidade da amostra de solo com trếs repeticốs, obtendo-se o valor médio de $0.0229 .9^{-1}$. A partir dele, calculou-se a umidade volumétrica, seguida da compactacăo homogênea da coluna de so-10, obtendo-se uma densidade global de $1,285 \mathrm{gam}^{-3}$ na coluna, semelhante à do campo.

Na Figura 3 - resultados da infiltracăo horiiontal - observa-se a relacăo linear entre o caminhamento da frente em funcáo da raiz quadrada do tempo decorrido de infiltrą̧óo $(R=2=0,999)$.

Após a infiltraḉo, desmontou-se a coluna $E$ determinou-se a umidade do solo sob condicốs de saturacáo $\left(0-2 \mathrm{~cm}\right.$ da coluna), obtendoise o indice $0.445 \mathrm{~cm}^{3} \mathrm{~cm}^{-3}$.

Para o cálculo da condutividade hidráulica do solo em funcăo de sua umidade, $k(\theta)$, basta obter o valor de $W$ correspondente ao de $\theta$ desejado pela eq.(3) e aplicar na $E q .(2)$, apresentando os resultados em $\mathrm{cm}_{.} \mathrm{s}^{-1}$.

Variando a umidade volumétrica do solo entre a saturacẫo $e$ a da amostra seca ao ar, obtém-se o gráfico semilogaritmico da condutividade hidráulica em funGẫo da umidade, com os resultados expressos em cmadia-1 ... Figura 4.

\subsection{Esquema experimental}

A Figura 5 mostra a disposicấo esquemática do campo experimental e das parcelas onde se fizeram as medicoóes necessárias ao cálculo do balango hidrico e de energia.

Dada a impossibilidade de efetuar estudos de balanco de energia em áreas reduzidas, sem incorrer em problemas de efeitos de bordadura, e considerando que tratamentos de irrigacóes em grandes áreas incorreriam em di- 
ficuldades de equipamento e interferência da precipitacăo natural, optou-se por dividir o ensaio em dois tipos de parcela.

- estudo de irrigacáo consistiria em parcelas menores, para melhor controle da aplicacáo de água e pro... tęăo contra a precipitacăo natural. De acordo com a freqiîñcia de irrigąâo e disponibilidade hidrica no solo, os tratamentos foram os seguintes:
a: déficit hidrico natural (DHN):
b: sem déficit hidrico ( $100 \% A D)$ :
c: déficit hidrico leve (75\%AD):
d: déficit hidrico moderado ( $50 \% A D)$;
e: déficit hidrico acentuado (25\%AD), e
f: déficit hidrico severo (DHI).

- Estudo de balango de energia foi realizado em parcelas maiores, cerca de $7.000 \mathrm{~m}^{2}$ cada uma, com os seguintes tratamentos:

$$
\begin{aligned}
& \text { g: similar ao } 50 \% A D(M 50 \%) \text {, e } \\
& \text { h: similar ao } 75 \% \text { AD (M75\%). }
\end{aligned}
$$

A manutencăo do armazenamento de água no solo. nos niveis estipulados nos tratamentos a a f, foi feita por um sistema de irrigacăo por microaspersäo e, nos tratamentos $g e h$, por $u m$ sistema convencional por aspersáo. Efetuou-se o controle das irrigacóses por amostragens gravimétricas do solo, sistematicamente, everificando-as pela evaporacáo de um tanque classe A dentro da área da cultura.

- tratamento DHN foi executado sem cobertura plástica, similar às condicốs normais de lavoura comercial, em que o estresse se desenvolve naturalmente e as irrigacöes săo realizadas quando as plantas apresentam visivel sintoma de sua necessidade. 


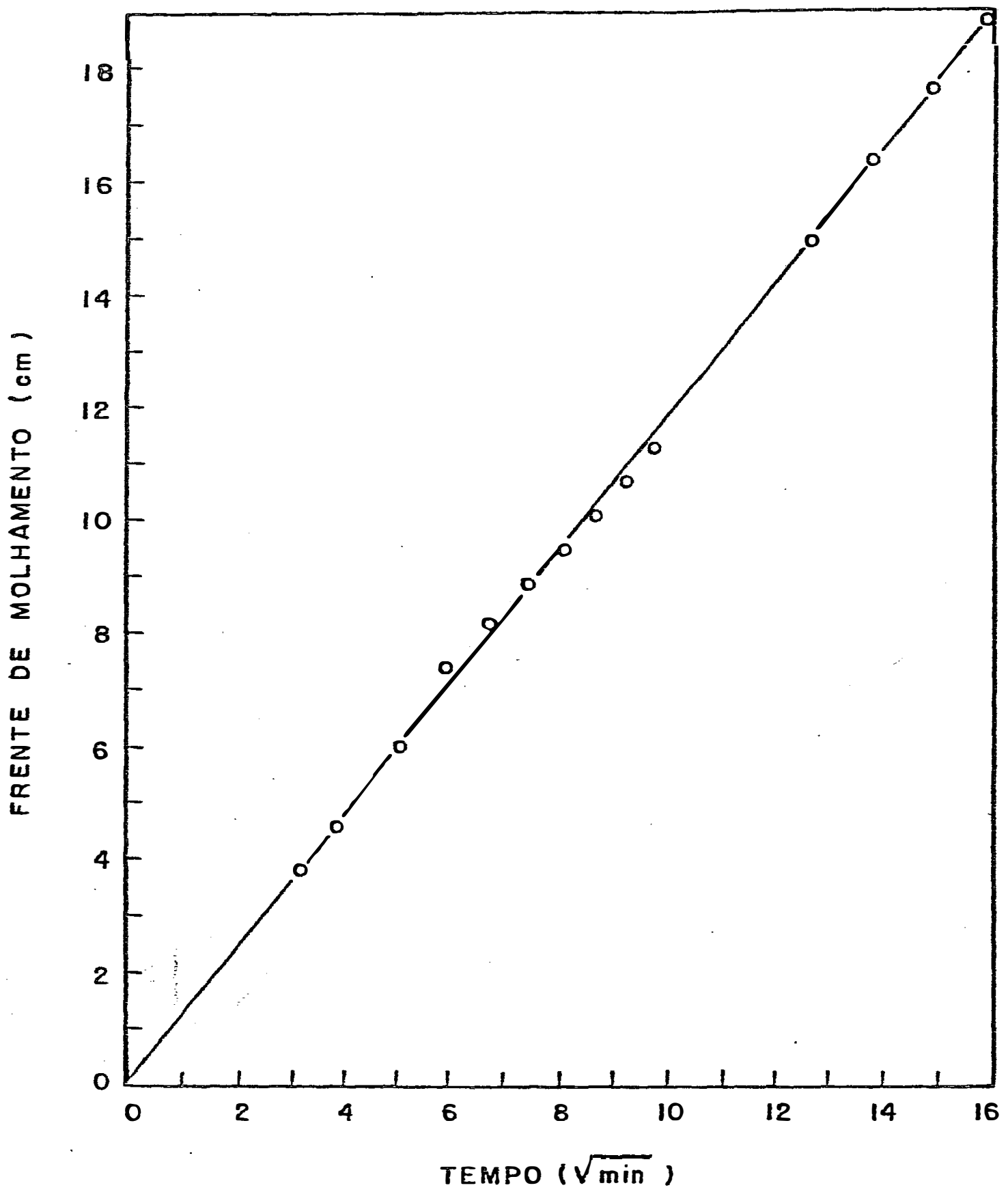

Figura 3 - Infiltração horizontal da água no solo para a camada 0-30cm, en função da raiz quadrada do temp̧o, na área experimental. 


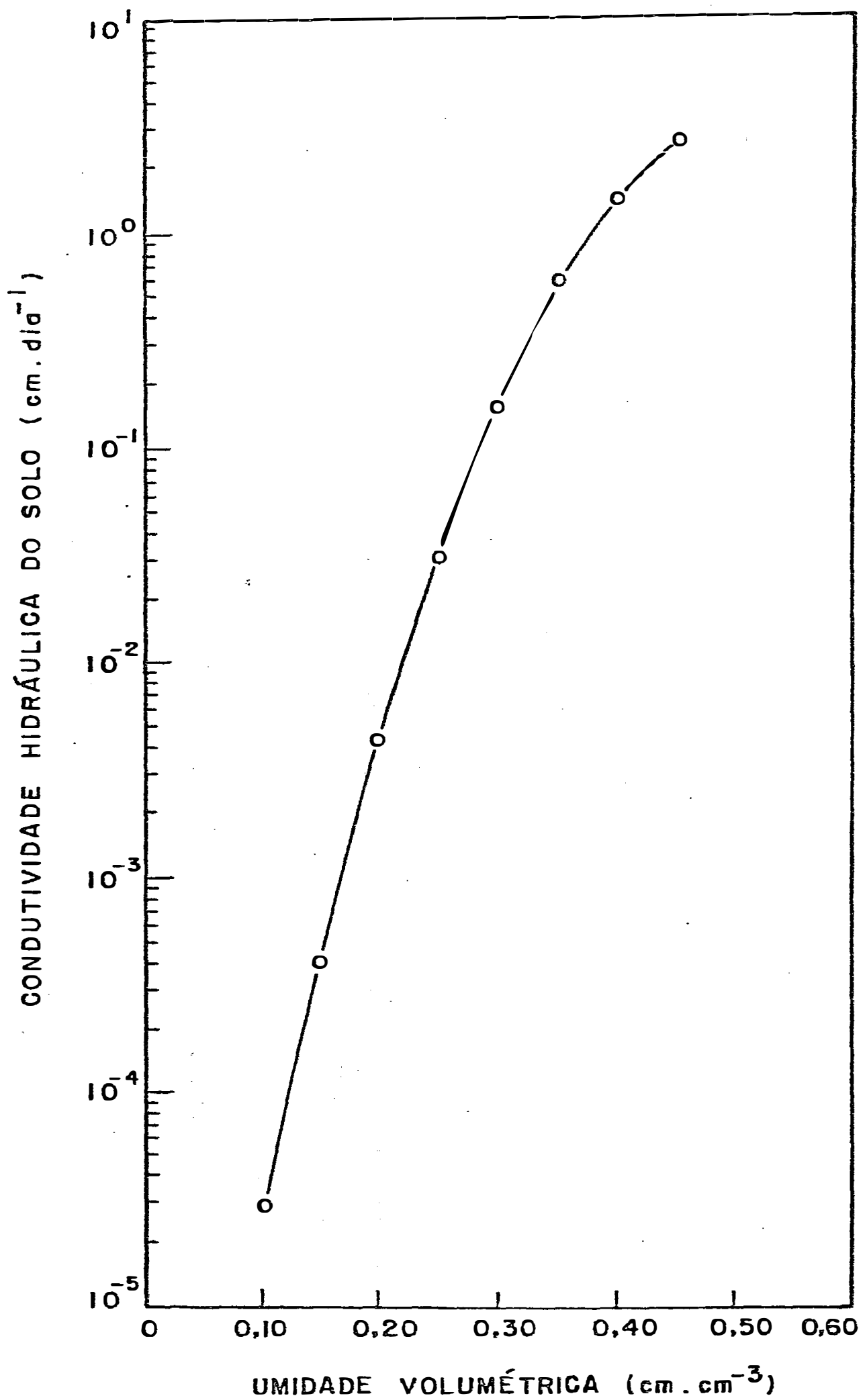

Figura 4 - Condutividade hidráulica em função da umidade do solo, determinada em laboratório, a partir da infiltração horizontal da água en coluna de solo. 


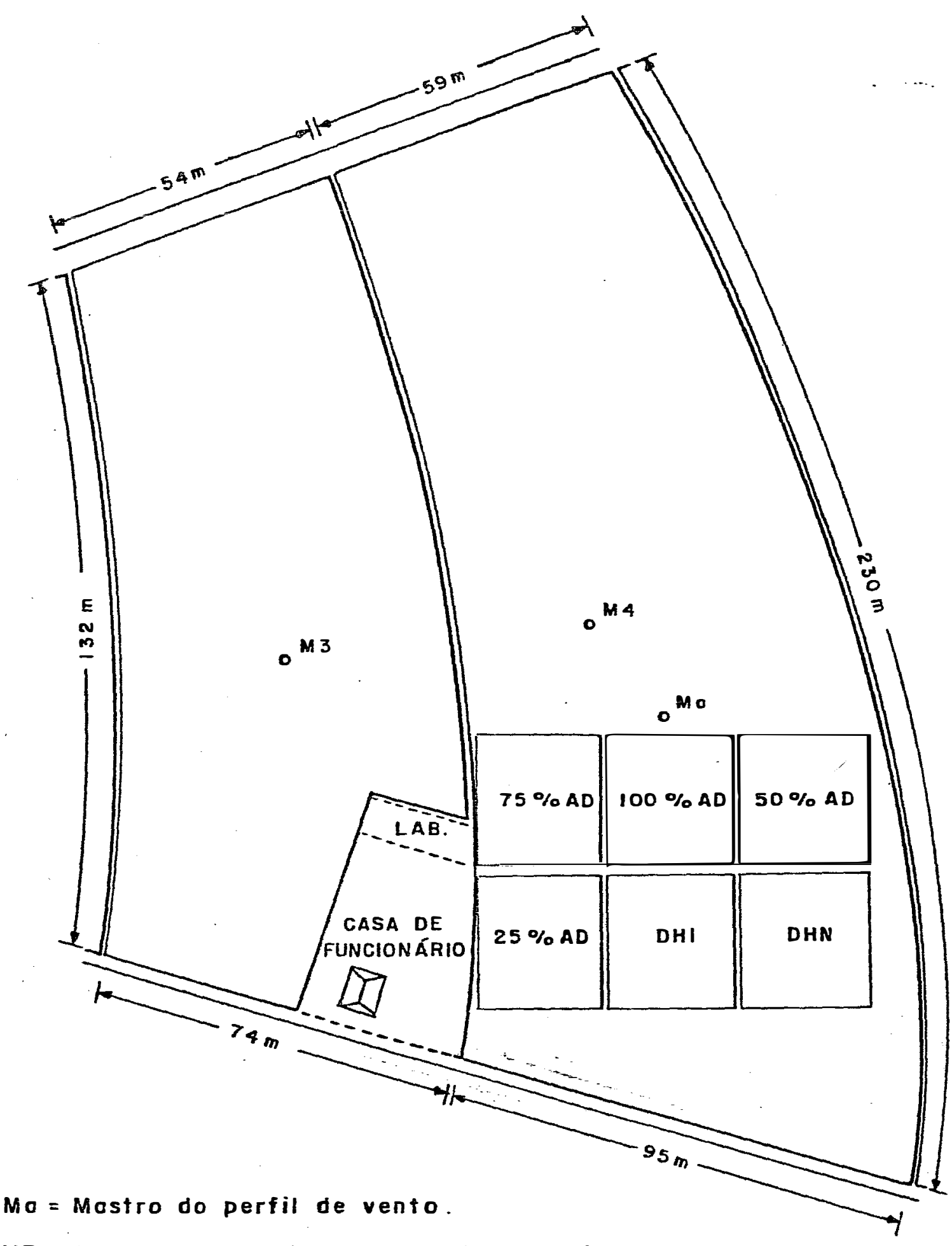

M3 e M4 = Mastros do balanco de energia.

LAB. = Laboratório

Figura 5 - Representação esquenática da área experimental corn feijão: localizaçōes dos mastros (M), com instrumental micrometeorológico, o laboratōrio, com o sistema de aquisição de dados, e a área com seis blocos de tratamentos de irrigação (25 a 100Aㅁ, DHI e DHN) . 
A imposicão do déficit hidrico no tratamento DHI refere-se à suspensão das irrigagốs e controle das precipitacốes aré o aparecimento de sintomas visiveis de estresse hidrico no meio do dia. Nesse ponto, era realizada a irrigacão, deixando-se a seguir a repetigão de novo ciclo de déficit seguido de nova aplicagâo de água.

A protegäo das parcelas contra eventuais precipitacốes e influencia da irrigacâo geral do campo foi feita por uma cobertura plástica de $3 \times 6 \mathrm{~m}$, esquematicamente apresentada na Figura 6 .

\subsection{Caracteristicas da cultura}

Plantou-se o cultivar Carioca-80-SH, recomendado para o Estado de São Paulo, a 8 de julho de 1986, em toda a área experimental de $1,8 \mathrm{ha}$, no espacamento entre linhas de $50 \mathrm{~cm}$ e doze a treze sementes por metro linear. Para garantir o estabelecimento da cultura, efetuou-se, antes e depois do plantio, uma irrigacâo de $30 \mathrm{~mm}$.

Realizou-se a adubacâo na semeadura, com 300 $\mathrm{kg} / \mathrm{ha}$ da fórmula 4-22-12, complementando-a com $150 \mathrm{~kg} / \mathrm{ha}$ de sulfato de amônio, 25 dias após a germinąâo.

A emergencia ocorreu em 17 de julho e o encerramento das análises microclimáticas em 13 de outubro, com colheita do ensaio em 20-21 de outubro. Nesse periodo, executaram-se duas capinas mecânicas, complementadas manualmente nas áreas de maior incidência de ervas daninhas, e controle semanal de saúvas. 
I. VISTA LATERAL

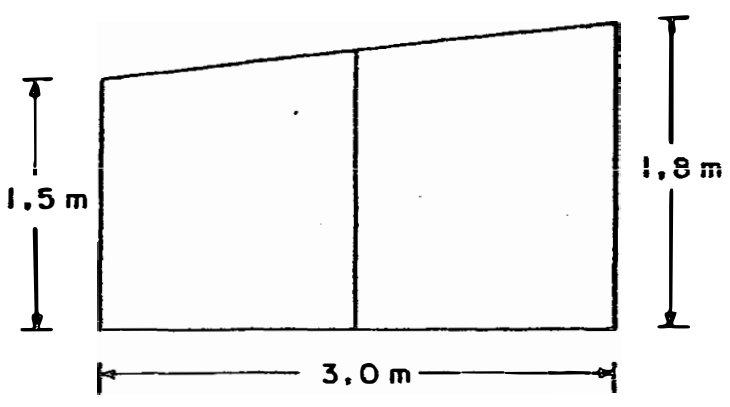

2. VISTA FRONTAL

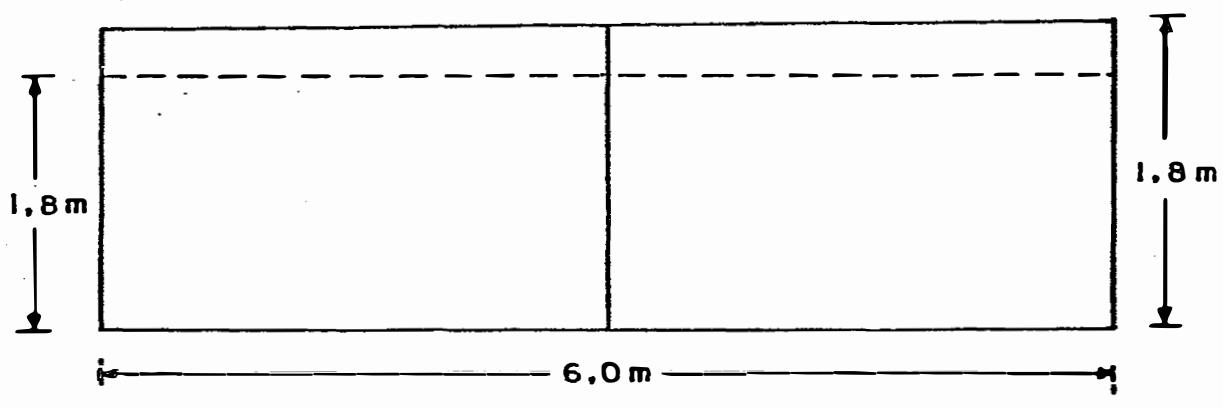

\section{VISTA ESPACIAL}

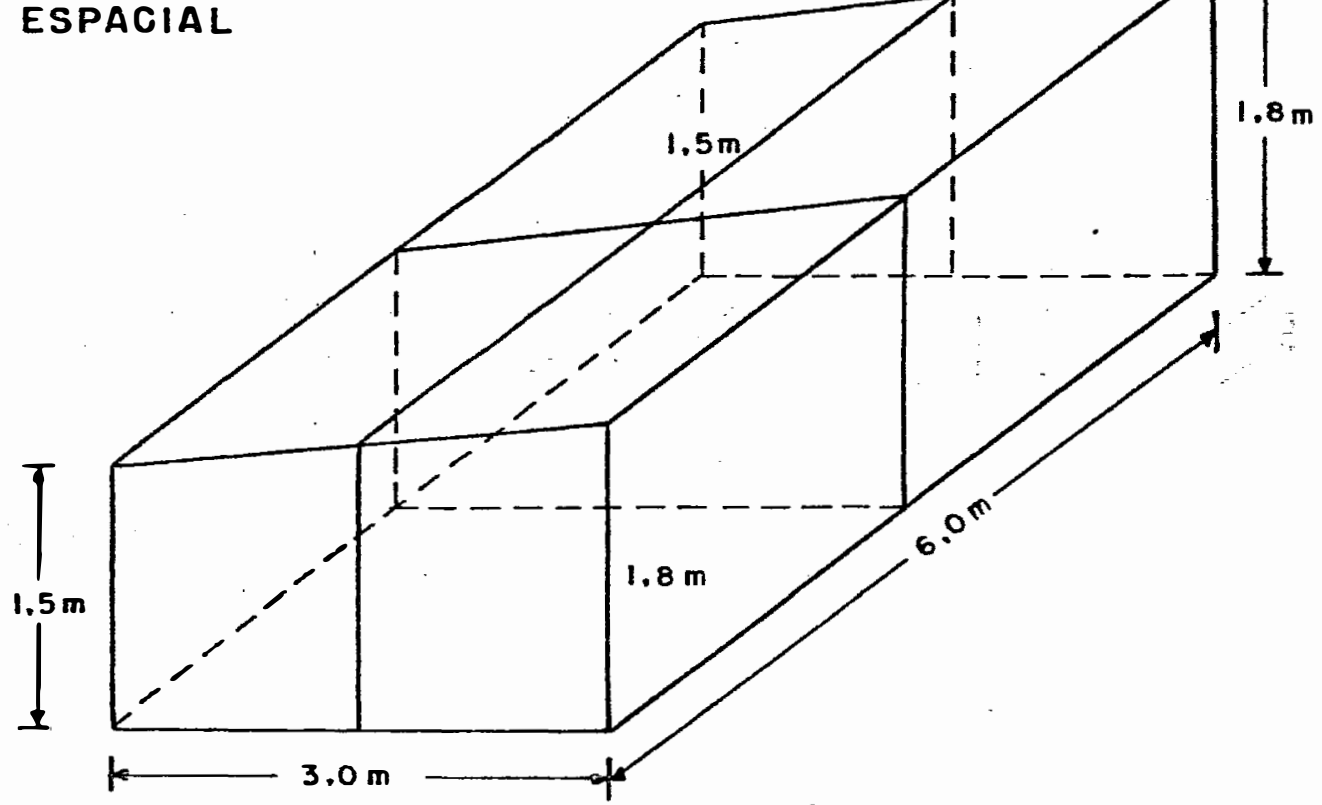

Figura 6 - Esquema da armação de suporte para a proteção de parcelas contra as precipitações, instalada nos tratamento de irrigação. 


\subsection{Instrumental}

O instrumental micrometeorológico foi instalado en diferentes pontos do campo, em mastros para avalia-Gấo da radiaçáo, do perfil de vento e dos gradientes de temperatura $e$ umidade do ar.

\subsubsection{Anemômetro}

- perfil da velocidade clo vento acima da cultura foi determinado com anemômetros tipo caneca, montados no mastro a $0,80,1,40,2,40,3,35,4,50 \in 6,05 \mathrm{~m}$ do nivel do solo, foram obtidos valores médios horários da veloci-dade horizontal do vento.

\subsubsection{Temperatura do ar e abrigo termométrico seco e limido}

A temperatura do ar foi determinada através de termopares de cobre constantã número 24 AGW, instalados em mastros nas duas áreas maiores e nos tratamentos extremos de armazenamento de água no solo, seus valores sendo integrados e registrados a intervalos de 150 segundos.

Esses termopares, instalados à altura do dossel e a 50,100 e $150 \mathrm{~cm}$ acima, serviram para determinar os gradientes de temperatura seco e ímido, necessários ao cálculo do balango de energia.

As partes sensíveis (juncấo de medida) foram colocadas no interior de abrigos micrometeorológicos especiais, Evitando a Exposicấo direta da radiacấo solar. Esses microabrigos sấo semelhantes aos utilizados no Brasil por PEDRO JR. (1977) E BERGAMASCHI (1984). As jungöes de referências foram colocadas em gelo fundente (OOC) e ava-l iadas periodicamente. 


\subsubsection{Radiômetro 1 iquido}

Para as determinacốs do fluxo de radiacão liquida, empregaram-se radiômetros liquidos, con modificacôes semelhantes ass usadas por LOURENCE et ali is (1970): inflando a clípula plástica do radiômetro por una bomba de aquário $e$ passando o fluxo de ar por um dessecador. A constante de resposta do radiômetro é de $30,85 \pm 2,5 \% \mathrm{mU}$. cal. $\mathrm{Cm}^{-2}$ " $\mathrm{min}^{-1}$.

Os aparelhos foram mantidos a $1,50 \mathrm{~m}$ de altura acima do topo do cultivo, nos tratamentos $M 50 \% \in M 75 \%$.

\subsubsection{Radią ão global}

A radiaç̃o global foi medida por radiômetros instalados a $1,5 \mathrm{~m}$ de altura do dossel, acoplados a um po-... tenci ógrafo.

\subsubsection{Radiaç̃o fotossinteticamente ativa}

Mediu-se a radiacão fotossinteticamente ativa (PAR) com un sensor quântico pontual, acoplado ao porômetro: este mede o quantum de fotons en $\mu E .5^{-1} m^{-2}$ na faixa de 400-700 $\mathrm{nm}$, com resolucão de $5 \%$.

3.4.6. Placas medidoras do fluxo de calor no solo

Mediu-se o fluxo de calor no solo por quatro placas de fluxo montadas a $5 \mathrm{~cm}$ de profundidade, na projec:ão do radiômetro liquido, e posicionadas nas linhas e nas entrelinhas da cultura. Essas placas, de $17 / 8 \times 11 / 8 \%$ 3/16", apresentaram as seguintes respostas: 


$$
\begin{aligned}
& \text {. F-253-18,74 } 23 \% \mathrm{mV} / \mathrm{cal}, \mathrm{cm}^{-2}, \mathrm{~min}^{-1} \text {; } \\
& \text {. F-223-18,91 } 13 \% \mathrm{mV} / \mathrm{cal} \mathrm{cm}^{-2}, \mathrm{~min}^{-1} \text {; }
\end{aligned}
$$

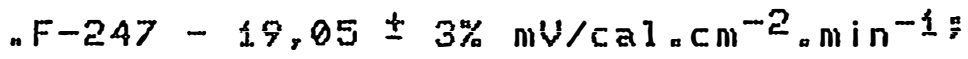

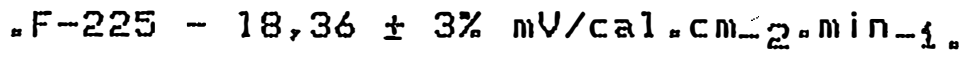

As placas foram ligadas en paralelo e conectaclas ao sistema de aquisicấo de dados. A resposta média do conjunto foi de $18,76 \pm 3 \%$ mU/cal.cm-2. $\mathrm{min}^{-1}$.

\subsubsection{Sistena de aquisigâo de dados}

- sistema foi projetado e construido na secấo de Climatologia Agricola do IAC, para o presente experimento, E sua capacidade padrấ, projetada para 40 canais, con duas faixas de tensấo: 2 e $50 \mathrm{~mW}$.

Ele possibilita atender às necessidades de monitorar os sensores meteorológicos, registrando os impulsos numa impressora ou num registrador gráfico, continuamente, con valores médios integrados a periodos desejados.

\subsubsection{Porômetro}

Foi utilizado: un porômetro de equilibrio dinânico, onde a resistência estonática é obtida diretämente, medindo a taxa de transpirąấo en equilibrio de una folha dentro de uma cânara. En sua constituiçốo, há um termopar de crônel-constantä para a leitura da temperatura de folha, em ambas as faces. 


\subsubsection{Evaporąẫo}

Determinou-se a evaporacăo pelo tanque classe A modificado (AMORIM NETO \& UILLA NOVA, 1983), de nivel de água constante, instalado em superfície gramada prókima à área experimental.

\subsection{Balanco hidrico}

Avaliou-se o consumo de água pela cultura através do balango hidrico de campo.

A equacäo do balanco hídrico de una camada de solo de profundidade $Z$ num intervalo de tempo $t_{2}-t_{1}$, fundamenta-se no princípio da conservacão de massa"

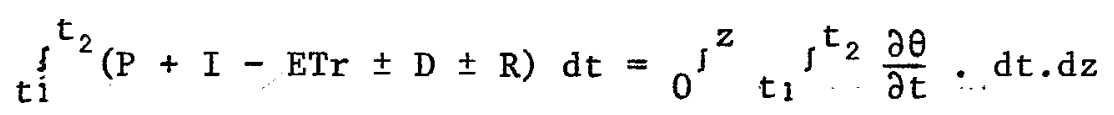

onde $P, I, E T r, D \in R$ représentam, respectivamente, os fluxos de precipitacão, irrigąấo, Evapotranspiracão, drenagem profunda e deflúvio superficial, (mmodia-1); e $\theta$ representa a umidade volumétrica do solo $\left(\mathrm{cm}^{3} . \mathrm{cm}^{-3}\right)$. 0 segundo membro da equaçóo corresponde à variaço no armazenamento da água na camada de solo de profundidade $Z$ num período de tempo $t=\left(t_{2}-t_{1}\right)$.

Essa mesma equacấo pode ser escrita de maneira mais simplificada, integrando-a com relacăo ao tempo $e$ à profundidade:

$$
P+I-E T R \pm D \pm R \pm \Delta A=0
$$

onde $\triangle A$ representa a variąấo no armazenamento de água no solo $(\mathrm{mm})$. 
- deflívio superficial nấo foi considerado na análise dos componentes do balango hidrico. Isso é possivel pelos seguintes fatoresa pouca declividade do terreno (menor de a\%) : armazenamento de água na superficie pelos sulcos de plantio, e alta velocidade de infiltracấo do so... $10\left(k_{0}=36 \mathrm{~mm}^{-1} \mathrm{~h}^{-1}\right.$, Figura 1$)$, associados a precipitacóes pouco intensas. Assim, a expressáo utilizada para a determinacấo da evapotranspiracâo foi:

$$
E T R=P+I \pm D \pm \Delta A
$$

Na avaliąâo dos componentes do balanco hidri-.. co, considerou-se um volume de controle de profundidade igual a $40 \mathrm{~cm}$, em virtude da maior concentracáo do sistema radicular ficar nos primeiros $30 \mathrm{~cm}$ (INFORZATO \& MIYASAKA, 1963).

t.3.5.1. Variacâo no armazenamento de água no solo

A variacăo no armazenamento de água no solo foi estimada a partir de perfis consecutivos de umidade em volume $(\theta)$, obtidos em dias alternados.

Para a determinacấo de $\theta$, empregou-se o método gravimétrico, através de amostras coletadas com trado nas profundidades de $0-5,5-20,20-40 \in 40-60 \mathrm{~cm}$, com duas repeticöes por parcela. As amostras eram acondicionadas em latas de aluminio e secas em estufa a 1050 C por 48 horas. para a estimativa do armazenamento no solo (A), foi empregada a expressåon

$$
A=\theta \cdot Z
$$

onde $\theta$ é a umidade média do perfil do solo até a profundi... dade $Z$, igual a $40 \mathrm{~cm}$. 
A variaçó nesse armazenamento ( $\triangle A$ ) num pe-.. ríodo ta - t 1 foi determinada por:

$$
\Delta A_{1}=A_{2}-A_{1}
$$

onde $A_{2} e A_{1}$ sấo os armazenamentos de água no solo (mm) nos tempos considerados. 4

\subsubsection{Precipitacåo pluvial e irrigacăo}

A precipitaçáo pluvial foi obtida com dados diários observados en pluviômetros junto à cultura.

As irrigacöes foran realizadas por meio de aspersores instalados na área, no espacamento de 12 x $12 \mathrm{~m}$ e, a vazáo, foi medida com hidrômetro na linha mestre do encanamento. Nos tratamentos especificos de balanco hidrico, efetuaram-se as irrigacóes com microaspersores, no espacamento de $1,20 \times 1,15 \mathrm{~m}$. As lâminas foram determinadas por pluviômetros, dentro da cultura.

\subsubsection{Drenagem profunda}

Determinou-se o fluxo vertical de água no so10, na profundidade $Z$ de $40 \mathrm{~cm}(q 2)$, pela equacáo de Darcy:

$$
q z=-K(\theta) \frac{\partial \Psi}{\partial z}
$$

onde $\frac{\partial \Psi}{\partial z} \dot{e}$ o gradiente potencial hidráulico (matricial + gravitacional), $\left.e K_{(} \theta\right)$, é a condut ividade hidráulica como uma funcấo de $\theta$. 
O potencial matricial e a condutividade hidráulica de cada camada foram calculados a partir da mediGăo da umidade do solo e da curva caracteristica ifigura 2) E da relacáo $K(\theta)$ da Figura 4 .

Para cada intervalo de retirada de amostra, determinou-se um valor médio da condutividade hidráulica, de modo que:

$$
\bar{k}=\frac{K\left(\theta_{2}\right)+K\left(\theta_{2}\right)}{2}
$$

onde, $K_{\left(\theta_{2}\right)} \in K_{\left(\theta_{2}\right)}$ foram obtidas através das umidades volumétricas $\theta_{1} \in \theta_{2}$, que correspondem a valores médios de umidade no pérfil do solo, para cada amostragem.

A drenagem total em determinado periodo foi calculada por:

$$
D=q z \cdot \Delta t
$$

onde Dé a drenagem total no periodo (mm); qz, o fluxo de água na profundidade de $40 \mathrm{~cm}\left(\mathrm{~mm}=\mathrm{ci}^{-1}\right), \in \Delta t$, o intervalo em dias entre duas amostragens.

\subsubsection{Evapotranspirąão}

Estimou-se a evapotranspiragáo potencial (ETo), (mmadia-1), pelos resultados da evaporaçóo do tanque classe $A$ (ECA), $p \in l a$ relaGăo:

$$
E T_{Q}=E C A \cdot K \dot{p}
$$

onde ECA É a Evaporacẫo do tanque Classe A (mm.dia ${ }^{-1}$ ), representada pelo valor médio diário do periodo considerado, e Kp, é o coeficiente do tanque, variável em funcáo da umidade relativa do ar, da velocidade do vento junto ao 
tanque e da sua localiazắo. Para facilidade da contabili-dade da ETo, adotou-se um valor médio para o Kp de 0,8 durante todo o ciclo da cultura.

Calculou-se a evapotranspiracâo real (ETr) dos tratamentos submetidos ao balanco hidrico de campor pela expressä́o b, isto é, pela diferenga entre a variagáo do armazenamento da água $e$ as adicóes e/ou subtracóes obser... vadas en cada periodo: precipitacóes, irrigacóes, drenagem profunda. Nesse estudo, a duracăo de cada periodo foi de quatro dias, ao longo do ciclo da cultura, enquanto a evapotranspiracấo real calculada pelo método do balanco de energịa foi diária $e$ obtida através da razáo de Bowen ( $\beta$ ), (ver item 3.6).

Portanto, a comparacáo entre a evapotranspiraGấo diária, calculada pelos dois métodos, pode resultar em valores bastante diferentes, pelo amaciamento dos resultados do balango hidrico.

\subsection{Coeficiente de cultura}

A quantidade de água necessária à cultura, $E$ que se pode aplicar na forma de irrigacăo, foi calculada, est imando-se a evapotranspiracáo potencial de referência $e$ mutiplicando-a por um fator (KC), que representa a demanda ideal.

Esse coeficiente é obtido pela relacăo:

$$
K c=\frac{E T r}{---}
$$

onde ETr é a Evapotranspiracäo real medida no tratamento de irrigacăo e ETor a evapotranspiracăo potencial ou de referência, que depende exclusivamente das condicốes climát icas. 
Vários métodos podem ser adotados na sua determinacăo: no presente estudo, eles foram estimados indiretamente pela evaporagâo do tanque classe A e pelo balan-.. 6. o de energia.

\subsection{Balanco de energia}

- método utilisado neste trabalho para analisar a energia colocada à disposicáo da cultura foi o balanco de energia. Essa técnica quantifica os fluxos energéticos verticais incidentes e emergentes sobre o dossel, apresentando facilidade na execucăo $e$, segundo TANNER (1968), nấo há perda de detalhes significativos.

o balanco de energia consistiu nas medicöes diretas da radiacăo líquida (RN) e do fluxo de calor no solo (G); através do gradiente de concentracấo de vapor d'água $e$ da temperatura do ar acima do topo da culturay determinou-se o fluxo de calor latente (LE) e sensivel (H), de acordo com o modelo utilizado por TANNER (1968) e UILLA NOUA Et ali is (1975):

$$
R N+G+L E+H+P=0
$$

onde RN é a radiacăo líquida disponivel à superfície; G, fluxo de calor para o solo; LE, fluxo convectivo de calor latente; $H$, fluxo convectivo de calor sensivel, $E$, energia utilizada nos processos fotossintéticos, todos en cal. $c m^{-2} \mathrm{~min}^{-1}$.

Segundo VILLA NOVA et ali i (1975), a energia utilizada nos processos fotossintéticos (P) raramente superior a $2-5 \%$ da radiacáo liquida, podendo ser desprezada sem causar erros significativos. 
Assim, a equacăo do balango de energia passa a

$$
R N+G+L E+H=O
$$

Essa equacăo pode ser resolvida de maneira mais simples, segundo BOWEN (1526), que definiu a relacấo (razão de Bowen) entre os fluxos He LE de tal modo que:

$$
B=\frac{H}{L E}
$$

e.

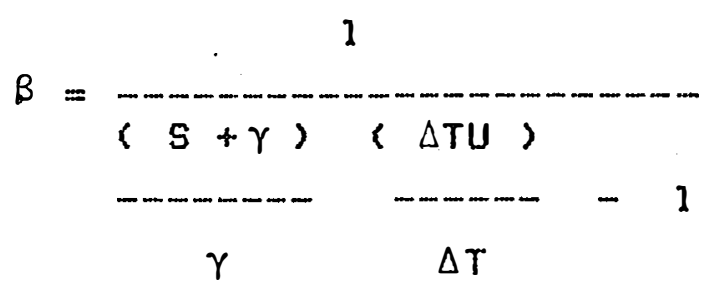

onde $\gamma$ é a constante psicronétrica; $S$, a derivada da tensåo de vapor eni relacåo à temperatura: $\Delta$ TU, a diferenca de temperatura de bulbo limido entre dois niveis: $\Delta T$, a diferenca da temperatura do bulbo seco entre dois niveis.

Inicialmente, calcula-se a razâo de Bowen, obtendo-se os valores de LE $E H$, $E$, substituindo-se a $E q$. ib En $17:$

$$
L E=-\frac{R N+G}{1+\beta}
$$

As $E q . \quad(16),(17) \in(18), q u \in$ constituen a formacăo do método do balanco de energia, permitem estimar os fluxos turbulentos de calor latente e de calor sensivel sobre una superficie natural evaporante. 


\title{
3.8. Aspectos fisiológicos da cultura
}

\author{
3.8.i. Resistência estomática à difusấo de vapor \\ d'água, temperatura e transpiracấo foliar
}

Para caracteriaar o comportamento fisiológico do feijoeiro, efetuaram-se amostragens sazonais da resistência estomática nas parcelas experimentais, nos dias 4 . 8, 10, 11, 16 e 23 de setembro.

Essas medidas foram feitas nos primeiros foliolos totalmente expandidos da planta, na superficie ada-.. xial e abaxial, ao acaso, en dez plantas por parcela, para garantir a representatividade dos dados.

Tais parâmetros foram avaliados através de um porômetro, que mede diretamente a resistência estomática, sem necessidade de curvas de calibracăo: mede a taxa de transpiracăo em equilibrio dinâmico de uma folha dentro de uma câmara, mantendo-se constante a densidade de vapor d'água. Isso é alcangado pelo bombeamento de ar seco da câmara, resultando num balanco entre o fluxo de água transpirada pela folha $e$ o fluxo de ar ĺmido saindo da câmara.

Mediu-se a temperatura da folha por um termopar de crômel-constantá em contato com a folha.

A resistência estomática total ( $r_{s t}$ ) foi estimada, admitindo que as duas superficies da folha atuem como resistores em paralelo PTURNER \& BEGG, 1973, e MONTEITH, 1975), assim:

$$
r_{s t}=\frac{r_{\text {sad }} \cdot r_{\text {sab }}}{r_{\text {sad }}+r_{\text {sab }}}
$$

onde rsad e rsab sấo resistências, respectivamente, da superficie adaæial e abaxial da folha. 
3.8.2. Eficiência no uso da água

Para a producấo final de grấos a $13 \%$ de umidade, determinou-se a eficiência no uso da água (EUA), pela relacão entre o peso de grấos $\left(\mathrm{kg}_{\mathrm{n}} \mathrm{ha}^{-4}\right)$ e o consumo de Figua (mm), transformando-se o resultado $E m g a m^{-2} \cdot m^{-1}$.

A colneita foi realizada aos 95 dias após a germinacáo, en todas as parcelas, embora tentam ocorrido variacốes no grau de maturaça eno entre tratamentos. 


\section{REsultados E discussäo}

\subsection{Irrigaföes}

As irrigacóes foram realizadas de acordo com as condicóes de umidade observadas no solo e grau admissí... vel de secamento programado para cada tratamento. Antes do preparo do solo e logo após o plantio, efetuaram-se irrigacóes gerais no ensaio, suficientes para elevar a umidade do solo à capacidade de campo e garantir o bom estabelecimento da cultura.

A Figura 7 apresenta as irrigacóes e precipitacốes durante a condugấo do ensaio. Aos 25 dias após a germinacấo (DAG), irrigaram-se todos os tratamentos, cuja diferenciacấo a ocorrência natural de chuvas até 0540 DAG nấo permitiu. Por essa época, instalaram-se armacóes metálicas com cobertura plástica para evitar o efeito das chuvas nos tratamentos DHI, $25,50,75 \in 100 \% A D$.

Efetuou-se a primeira irrigacấo diferenciada no tratamento $100 \% A D$, aos 42 DAG, quando as plantas estavam en pleno florescimento e a cobertura vegetal, quase completa. Os outros tratamentos comecaram após essa data. - DHI (déficit hidrico imposto) recebeu uma única irrigaGấo de $70 \mathrm{~mm}$ aos 61 DAG para amenizar o efeito de um severo estresse hidrico. Mesmo assim, suas plantas, bem como as do $25 \% A D$, mostraram-se de menor porte, com folhas pequenas, e nunca completaram o recobrimento do solo. 


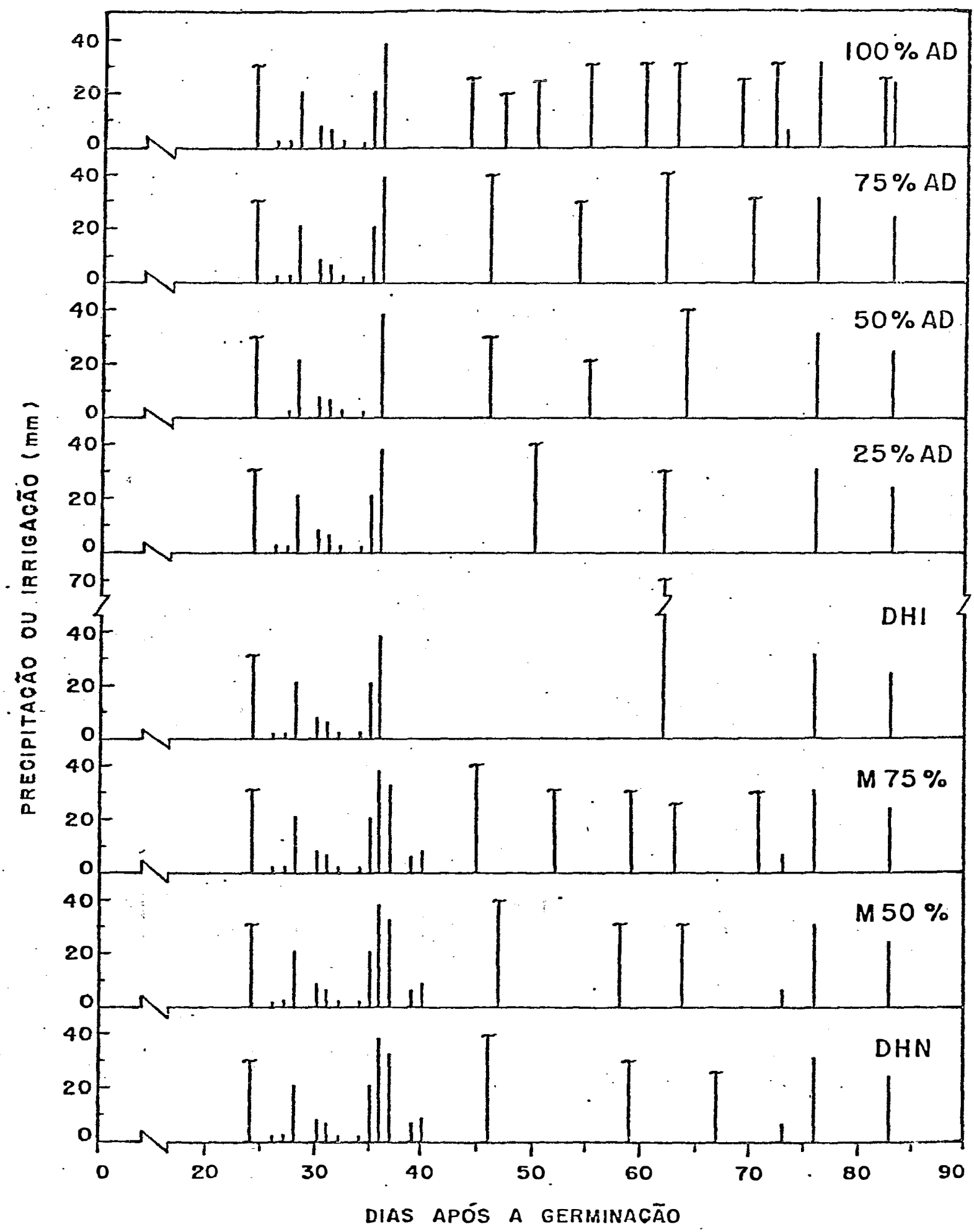

Figura 7 - Irrigações e precipitações (nm) ocorridas nos diferentes tratamentos da cultura do feijoeiro, no inverno de 1986, em Campinas, SP. 
No final do ciclo, aos 76 DAG, un vendaval danificou completamente todas as coberturas plásticas, seguido de duas precipitacóes de cerca de 30 mir cada uma. Com excegáo do 100\%AD, que a inda vegetava, todos os outros se mostravam visivelmente senescentes, năo se tendo beneficiado, talvez, da umidade adicional.

- número, as lâminas e o intervalo de irriga-(: ấo aplicados após o florescimento ( 42 DAG), nos tratamentos, encontram-se na Tabela 3 , onde se pode ver que o $M 75$ e o $M 50 \%$ se aproximaram dos obtidos no 75 e 50\%AD resPectivamente: no entanto, por seren realizados a céu aberto, - consumo de água foi ligeiramente maior e o intervalo entre irrigacóes, ligeiramente menor, quando comparados com $75 \%$ e 50\%AD, sob plástico.

Tabela 3 - Nímero, lâminas e intervalo médio nas irrigacóes aplicadas após o florescimento no ensaio con feijoeiro, en Campinas, sp.

$\begin{array}{lllllll}\text { Tratamento } & 100 \% & 75 \% & 50 \% & 25 \% & \text { DHI } & \text { DHN } \\ \text { M } 75 \% & M 50 \%\end{array}$

\begin{tabular}{|c|c|c|c|c|c|c|c|c|}
\hline No. irrig. & 9 & 4 & 3 & 2 & 1 & 3 & 5 & 3 \\
\hline L. ap 1 ic. $(\mathrm{mm})$ & 240 & 140 & 90 & 70 & 70 & 95 & 155 & 100 \\
\hline Interv. (dia) & 3 & 7 & 9 & 12 & 18 & $10 \div$ & 6 & 8 \\
\hline
\end{tabular}

4.2. Comportamento estomático do feijoeiro

A resistência estomática à difusăo de vapor de água ( $r_{s}$ ) nas folhas do feijoeiro foi tomada dos tratamentos mais representativos do efeito da água no solo $100 \% A D ; M 75 \%, M 50 \% \in D H I-n 05$ dias $4,8,10,11,16 \in$ 23/9/86, respectivanente, $49,53,55,56,61 \in$, 68 DAG. 
Realizaram-se as medicốes en foliolos expostos que haviam atingido recentenente a maturacáo e, sempre que possivel, posicionadas horizontalmente. Seus resultados se encontram na Tabela 4 .

Tabela 4 - Resistência estomática total ḋ difusáo de vapor d'água ( $r_{s}$ ), nos tratanentos de irrigacáo do feijoeiro medida no periodo da manhä (Bh30m 10h) E da tarde $(14-15 h)$. Cada valor é média tomada de dez folhas totalmente expostas e recém-anadurecidas.

Dias após

a germinacăo DAG

Periodo da manhá

Periodo da tarde

$\begin{array}{rrrrrrrrr}\text { DAG } \ldots & \ldots & \ldots & \ldots & 1,6 & 1,1 & \ldots \\ 49 & \ldots & 0,9 & 1,2 & \ldots & \ldots & 1,6 \\ 53 & \ldots & \ldots & \ldots & \ldots & 1,3 & 0,9 & 1,3 & 2,1 \\ 55 & \ldots & 1,0 & 0,9 & 1,3 & \ldots & 2,6 & 5,1 & 5,5 \\ 56 & 0,6 & 0,9 & 1,2 & 2,9 & 0,6 & 0,9 & 1,3 & 3,5 \\ 61 & 0,6 & \ldots & \ldots & 2,1 & 0,8 & \ldots & \ldots & 2,1 \\ 68 & 0,5 & 0,5 & \ldots & \ldots & 0,7 & 0,8 & 0,7 & 0,9\end{array}$

Esses valores apresentam variacóes da $r$ s, de 0,5 a $5,5 \mathrm{s.cm}^{-1}$, condizentes com outros trabalhos, como os de BERGAMASCHI (1984) e SANTOS (1985), En Piracicaba, SP, en similares intensidades de estresse hidrico. As medicốes no periodo da manhä eram sempre menores do que as obtidas à tarde, quando en geral ocorriam as maiores demandas de água para a atmosfera. O tratamento de irrigagáo freqiiente ( $100 \% A D)$ sempre apresentou valores baixos de rs $\left(0,5\right.$ a $0,85 .\left(m^{-1}\right)$, exceto aos $53 \mathrm{DAG}$, quando atingiu 1,3 s. $\mathrm{cm}^{-1}$, imediatamente antes da irrigacăo (Figura 7 ). 
o valor da ra mais elevado $\left(5,55 . \mathrm{cm}^{-1}\right)$ foi medido no tratamento DHI, aos 55 DAG, após quinae dias da ultima precipitacăo ocorpida na parcela. Nesse tratamento, a irrigacáo somente no final de 62 DAG certamente permitiu o desenvolvimento do estresse hidrico até essa data, como se pode observar pelos dados de ris medidos no periodo da manhá e da tarde. Os valores da tarde, coincidentemente, diminuiram de 55 para 56 e para 61 DAG, provavelmente pelo efeito das condicóes ambientais de temperatura, radiacăo e déficit de saturacáo do ar. Medicốs feitas seis dias após a irrigacáo no DHI (68 DAG) revelaram recuperacáo na abertura estomatica das folhas do feijoeiro. A Tabela 4 mostra tamberm que, no tratamento $M 50 \%$, os valores for am um pouco mais acentuados que no $M 75 \%$. Este, por outro lado, mostra indices próximos da ras comparados ao tratamento de irrigaçóo frequiente nos dias em que as irrigacóes eram coincidentes.

\subsection{Balanco hidrico}

- balango hidrico em condicöes de campo foi efetuado em todos os tratamentos a intervalos de quatro dias, desde os doze dias após a germinacâo até o.final do ciclo da cultura.

- controle dos fluxos de entrada, saida e variacăo de água no 5010 foi a camada de $0-40 \mathrm{~cm}$ de profundidade, onde se encontram mais de $90 \%$ das raizes do feijoEirO (INFORZATO \& MIYASAKA, 1963).

Nas Tabelas - 5 a 12 acham-se os valores dos termos do balanco hidrico, respectivamente, dos tratamen$\operatorname{tos} 100,75,50$ e $25 \% A D ; D H I ; M 50$ E $M 75 \%, E$ DHN. 
Tabela 5 - Valores dos componentes do balanço hídrico de campo - precipitação, irrigação, variação no armazenamento da água no solo $(\Delta A)$, drenagem profunda e evapotranspiração real (ETr) na cultura do feijoeiro para o tratamento 100\%AD, em 1986, em Campinas, SP.

\begin{tabular}{|c|c|c|c|c|c|}
\hline Período & Precipit. & Irrig. & $\triangle A$ & Dren. prof. & ETr \\
\hline mês dia & $\therefore-$ & - & $-m n n-$ & - & --_-- \\
\hline Ag. $\quad 1-5$ & 0,0 & 0,0 & $-11,5$ & 5,4 & 6,1 \\
\hline $6-9$ & 0,0 & 0,0 & $-9,0$ & 1,4 & 7,6 \\
\hline $10-13$ & 4,2 & 30,0 & 22,0 & 7,3 & 4,8 \\
\hline $14-17$ & 38,1 & 0,0 & 18,5 & 13,2 & 6,4 \\
\hline $18-21$ & 21,9 & 0,0 & $-3,0$ & 16,9 & 8,0 \\
\hline $22-25$ & 38,0 & 0,0 & 7,5 & 19,0 & 11,5 \\
\hline $26-29$ & 0,0 & 0,0 & $-23,0$ & 11,3 & 11,7 \\
\hline Set. 30-2 & 0,0 & 45,0 & 23,5 & 8,8 & 12,7 \\
\hline $3-6$ & 0,0 & 25,0 & $-1,0$ & 13,1 & 12,9 \\
\hline $7-10$ & 0,0 & 30,0 & 6,5 & 9,3 & 14,2 \\
\hline $11-14$ & 0,0 & 0,0 & $-24,0$ & 10,6 & 13,4 \\
\hline $15-18$ & 0,0 & 60,0 & 28,0 & 17,3 & 14,7 \\
\hline $19-22$ & 0,0 & 0,0 & $-31,0$ & 17,2 & 13,8 \\
\hline $23-26$ & 6,0 & 25,0 & 4,5 & 12,9 & 13,6 \\
\hline $27-30$ & 30,6 & 30,0 & 26,0 & $26,7 \ldots$ & $7,9 \div$ \\
\hline Out. 1-4 & 0,0 & 0,0 & $-33,0$ & 20,2 & 12,8 \\
\hline $5-8$ & 0,0 & 0,0 & $-20,0$ & 5,8 & 14,2 \\
\hline $9-12$ & 24,0 & 25,0 & 25,5 & 10,5 & 13,0 \\
\hline $13-16$ & 0,0 & 0,0 & $-20,0$ & 6,0 & 14,0 \\
\hline Total & 162,8 & 270,0 & $-14,5$ & 232,9 & 213,3 \\
\hline
\end{tabular}


Tabela 6 - Valores dos componentes do balanço hídrico de campo - precipitação, irrigação, variação no amazenamento da água no solo $(\triangle A)$, drenagem profunda e evapotranspiração real (ETr) na cultura do feijoeiro para o tratamento 75AD, em 1986, em Campinas, SP.

\begin{tabular}{|c|c|c|c|c|c|c|}
\hline \multicolumn{2}{|c|}{ Período } & \multirow[t]{2}{*}{ Precipit. } & \multirow[t]{2}{*}{ Irrig. } & \multirow[t]{2}{*}{$\Delta A$} & Dren. prof. & \multirow[t]{2}{*}{ ETr } \\
\hline mês & dia & & & & - & \\
\hline \multirow[t]{7}{*}{$\mathrm{Ag}$} & $1-5$ & 0,0 & 0,0 & $-10,1$ & 3,9 & 6,2 \\
\hline & $6-9$ & 0,0 & 0,0 & $-9,0$ & 2,9 & 6,1 \\
\hline & $10-13$ & 4,2 & 30,0 & 22,0 & 7,6 & 4,6 \\
\hline & $14-17$ & 38,1 & 0,0 & 15,0 & 16,7 & 6,4 \\
\hline & $18-21$ & 21,9 & 0,0 & 0,5 & 15,9 & 5,5 \\
\hline & $22-25$ & 38,0 & 0,0 & 11,0 & 18,1 & 8,9 \\
\hline & $26-29$ & 0,0 & 0,0 & $-23,5$ & 13,8 & 9,7 \\
\hline \multicolumn{2}{|c|}{ Set. 30-2 } & 0,0 & 40,0 & 18,0 & 9,7 & 12,3 \\
\hline & $3-6$ & 0,0 & 0,0 & $-19,0$ & 6,1 & 12,9 \\
\hline & $7-10$ & 0,0 & 30,0 & 6,5 & 12,5 & 11,0 \\
\hline & $11-14$ & 0,0 & $0 ; 0$ & $-16,0$ & 4,3 & 11,7 \\
\hline & $15-18$ & 0,0 & 40,0 & 21,0 & 9,7 & 9,3 \\
\hline & $19-22$ & 0,0 & 0,0 & $-14,0$ & 5,1 & 8,9 \\
\hline & $23-26$ & 0,0 & 30,0 & 17,0 & 3,4 & 9,6 \\
\hline & $27-30$ & 30,6 & 0,0 & 11,5 & 11,3 & 7,8 \\
\hline \multirow[t]{4}{*}{ out. } & $1-4$ & 0,0 & 0,0 & $-22 ; 0$ & 9,1 & 12,9 \\
\hline & $5-8$ & 0,0 & 0,0 & $-15,5$ & 3,9 & 11,6 \\
\hline & $9-12$ & 24,0 & 0,0 & 11,5 & 2,3 & 10,2 \\
\hline & $13-16$ & 0,0 & 0,0 & $-12,0$ & 3,8 & 8,2 \\
\hline \multicolumn{2}{|c|}{ Total } & 156,8 & 170,0 & $-7,1$ & 160,1 & 173,8 \\
\hline
\end{tabular}


Tabela 7 - Valores dos componentes do balanço hídrico de campo - precipitação, írrigação, variação no armazenamento da água no solo $(\Delta A)$, drenagem profunda e evapötranspiração real (ETr)- na cultura do feijoeiro para o tratamento 50\%AD, em 1986, em Campinas, SP

\begin{tabular}{|c|c|c|c|c|c|}
\hline Período & Precipit. & Irrig. & $\triangle \mathrm{A}$ & Dren. prof. & ETr \\
\hline \multicolumn{6}{|l|}{ mês dia } \\
\hline Ag. $\quad 1-5$ & $0 ; 0$ & 0,0 & $-8,4$ & 2,5 & 5,9 \\
\hline $6-9$ & 0,0 & 0,0 & $-7,4$ & 1,4 & 6,0 \\
\hline $10-13$ & 4,2 & 30,0 & 22,5 & 6,9 & 4,8 \\
\hline $14-17$ & 38,1 & 0,0 & 16,5 & 13,8 & 7,8 \\
\hline $18-21$ & 0,0 & 0,0 & $-14,0$ & 8,4 & 5,6 \\
\hline $22-25$ & 38,0 & 0,0 & 16,0 & 13,7 & 8,3 \\
\hline$\therefore \quad 26-29$ & 0,0 & 0,0 & $-19,5$ & 9,3 & 10,2 \\
\hline Set. 30-2 & 0,0 & 30,0 & 10,5 & 7,0 & 12,5 \\
\hline $3-6$ & 0,0 & 0,0 & $-17,5$ & 5,2 & 12,3 \\
\hline $7-10$ & 0,0 & 20,0 & 1,0 & 8,0 & 11,0 \\
\hline $11-14$ & 0,0 & 0,0 & $-11,0$ & 2,2 & 8,8 \\
\hline $15-18$ & 0,0 & 40,0 & 20,5 & 10,3 & 9,2 \\
\hline $19-22$ & 0,0 & 0,0 & $-14,0$ & 4,9 & 9,1 \\
\hline $23-26$ & 0,0 & 0,0 & $-10,0$ & 2,3 & 7,7 \\
\hline $27-30$ & $30 ; 6$ & 0,0 & 16,0 & 7,2 & 7,4 \\
\hline Out. 1-4 & 0,0 & 0,0 & $-11,0$ & 4,3 & 6,7 \\
\hline $5-8$ & 0,0 & 0,0 & $-7,5$ & 0,5 & 7,0 \\
\hline $9-12$ & 24,0 & 0,0 & 13,0 & 3,1 & 7,9 \\
\hline $13-16$ & 0,0 & 0,0 & $-10,5$ & 1,9 & 8,6 \\
\hline Total & 134,9 & 120,0 & $-14,8$ & 112,9 & 156,8 \\
\hline
\end{tabular}


Tabela 8 - Valores dos componentes do balanço hídrico de campo - precipitação, irriǵação, variação no armazenamento da água no solo $(\triangle A)$, drenagem profunda e evapotranspiração real (ETr) na cultura do feijoeiro para o tratamento 25\%AD, em 1986, em Campinas, SP.

\begin{tabular}{|c|c|c|c|c|c|}
\hline Período & Precipitação & Irrig. & $\triangle A$ & Dren. prof. & ETr \\
\hline mês dia & - & $\cdots$ & $\mathrm{mm}--$ & -------- & - \\
\hline Ag. $1-5$ & 0,0 & 0,0 & $-11,5$ & 5,7 & 5,8 \\
\hline $6-9$ & 0,0 & 0,0 & $-8,0$ & 2,7 & 5,3 \\
\hline $10-13$ & 4,2 & 30,0 & 21,5 & 7,8 & 4,9 \\
\hline $14-17$ & 38,1 & 0,0 & 16,0 & 16,1 & 6,0 \\
\hline $18-21$ & 21,9 & 0,0 & 2,0 & 13,2 & 6,7 \\
\hline $22-25$ & 38,0 & 0,0 & 10,0 & 20,0 & 8,0 \\
\hline $26-29$ & 0,0 & 0,0 & $-20,5$ & 11,3 & 9,2 \\
\hline Set. $30-2$ & 0,0 & 0,0 & $-16,0$ & 7,3 & 8,7 \\
\hline $3-6$ & 0,0 & 40,0 & 26,0 & 6,5 & 7,5 \\
\hline $7-10$ & 0,0 & 0,0 & $-15,0$ & 9,3 & 5,7 \\
\hline $11-14$ & 0,0 & 0,0 & $-13,0$ & 4,3 & 8,7 \\
\hline $15-18$ & 0,0 . & 30,0 & 15,0 & 7,3 & 7,7 \\
\hline $19-22$ & 0,0 & 0,0 & $-13,0$ & 6,4 & 6,6 \\
\hline $23-26$ & 0,0 & 0,0 & $-11,0$ & 2,8 & 8,2 \\
\hline $27-30$ & 30,6 & 0,0 & 14,5 & 8,2 & 7,9 \\
\hline Out. 1-4 & 0,0 & 0,0 & $-10,0$ & 3,3 & 6,7 \\
\hline $5-8$ & 0,0 & 0,0 & $-7,5$ & 1,3 & 6,2 \\
\hline $9-12$ & 24,0 & 0,0 & 14,5 & 2,2 & 7,3 \\
\hline $13-16$ & 0,0 & 0,0 & $-9,5$ & 2,4 & 7,1 \\
\hline Total & 156,8 & 100,0 & $-15,5$ & 138,1 & 134,8 \\
\hline
\end{tabular}


Tabela 9 - Valores dos componentes do balanço hídrico de carmpo - precipitação, irrigação, variação no armazenamento de água no solo $(\triangle A)$, drenagem profunda e evapotranspiração real (ETr) na cultura do feijoeiro para o tratamento DHI, em 1986, Campinas, SP.

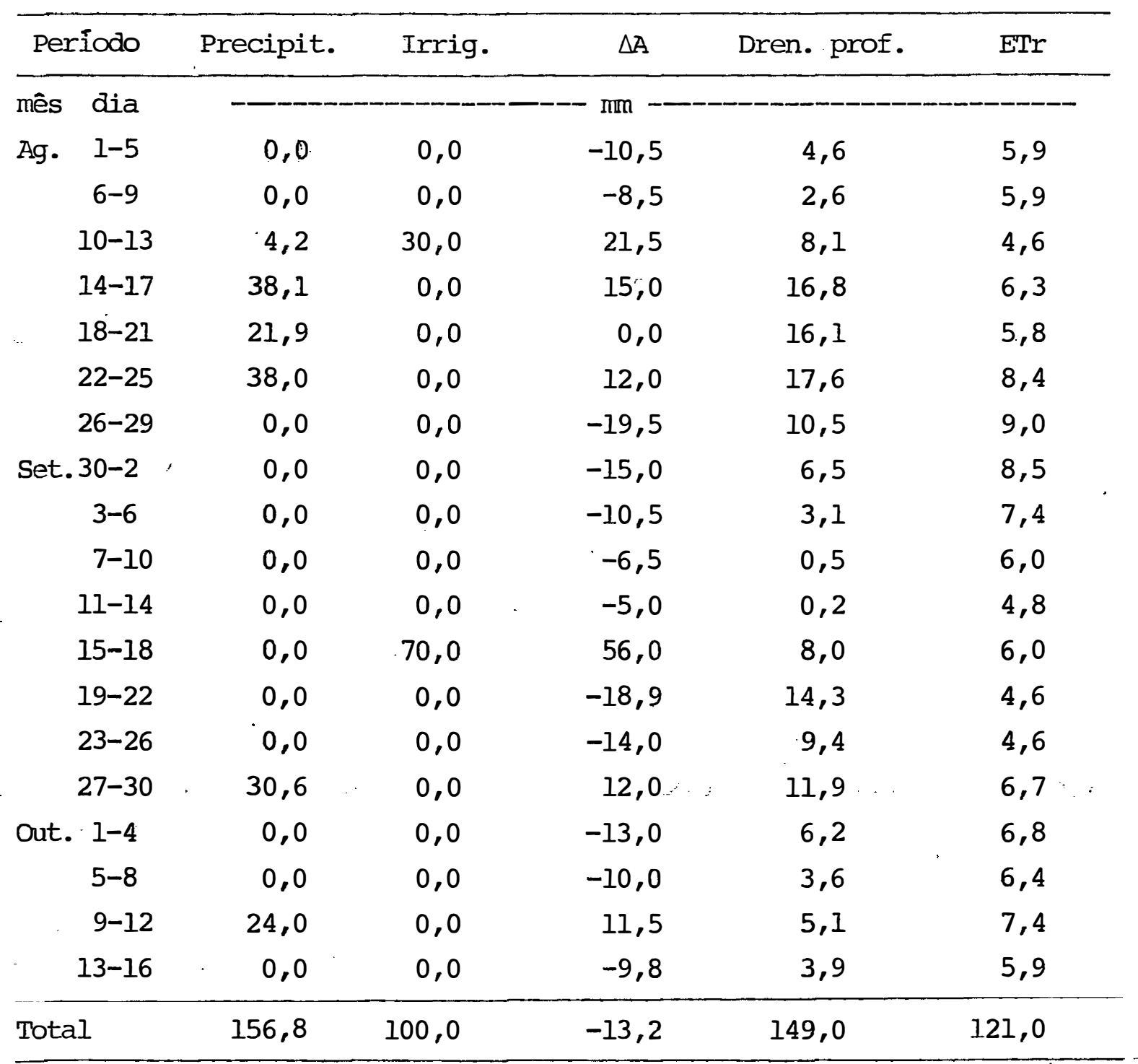


Tabela 10 - Valores dos componentes do balanço hídrico de campo - precipitação, irrigação, variação no armazenamento de água no solo $(\Delta A)$, drenagem profunda e evapotranspiração real (ETr) na cultura do feijoeiro para o tratamento M75\%, em 1986, Cam nas, SP.

\begin{tabular}{|c|c|c|c|c|c|}
\hline Período & Precipit. & Irrig. & $\triangle A$ & Dren. prof. & ETr \\
\hline \multicolumn{6}{|l|}{ mês dia } \\
\hline Ag. $\quad 1-5$ & 0,0 & 0,0 & $-9,7$ & 3,2 & 6,5 \\
\hline $6-9$ & 0,0 & 0,0 & $-8,4$ & 3,0 & 5,4 \\
\hline $10-13$ & 4,2 & 30,0 & 22,5 & 6,8 & 4,9 \\
\hline $14-17$ & 38,1 & 0,0 & 14,5 & 17,6 & 6,0 \\
\hline $18-21$ & 21,9 & 0,0 & $-3,5$ & 18,5 & 6,9 \\
\hline $22-25$ & 77,4 & 0,0 & 21,0 & 45,1 & 11,3 \\
\hline $26-29$ & 9,2 & 0,0 & $-28,0$ & 27,5 & 9,7 \\
\hline Set. 30-2 & 0,0 & 40,0 & 12,0 & 16,4 & 11,6 \\
\hline $3-6$ & 0,0 & 0,0 & $-19,3$ & 7,3 & 12,0 \\
\hline $7-10$ & 0,0 & 30,0 & 7,0 & 8,9 & 14,1 \\
\hline $11-14$ & 0,0 & 30,0 & 9,0 & 9,2 & 11,8 \\
\hline $15-18$ & 0,0 & 25,0 & 8,0 & 6,2 & 10,8 \\
\hline $.19-22$ & 0,0 & 0,0 & $-19,0$ & 5,8 & 13,2 \\
\hline $23-26$ & 6,0 & 30,0 & 20,0 & 4,9 & 11,1 \\
\hline $27-30$ & 30,6 & 0,0 & 8,5 & 15,7 & 6,4 \\
\hline Out. 1-4 & 0,0 & 0,0 & $-23,5$ & 10,9 & 12,6 \\
\hline $5-8$ & 0,0 & 0,0 & $-16,0$ & 3,2 & 12,8 \\
\hline $9-12$ & 24,0 & 0,0 & 11,5 & 3,9 & 8,6 \\
\hline $13-16$ & 0,0 & 0,0 & $-14,0$ & 2,7 & 11,3 \\
\hline Total & 211,4 & 185,0 & $-7,4$ & 216,8 & 187,0 \\
\hline
\end{tabular}


Tabela 11 - Valores dos componentes do balanço hỉdrico de campo - precipitação, irrigação, variação no anmazenamento de água no solo $(\triangle A)$, drenagem profunda e evapotranspiração real (ETr) na cultura do feijoeiro para o tratamento M50\%, em 1986, Cam pinas, SP.

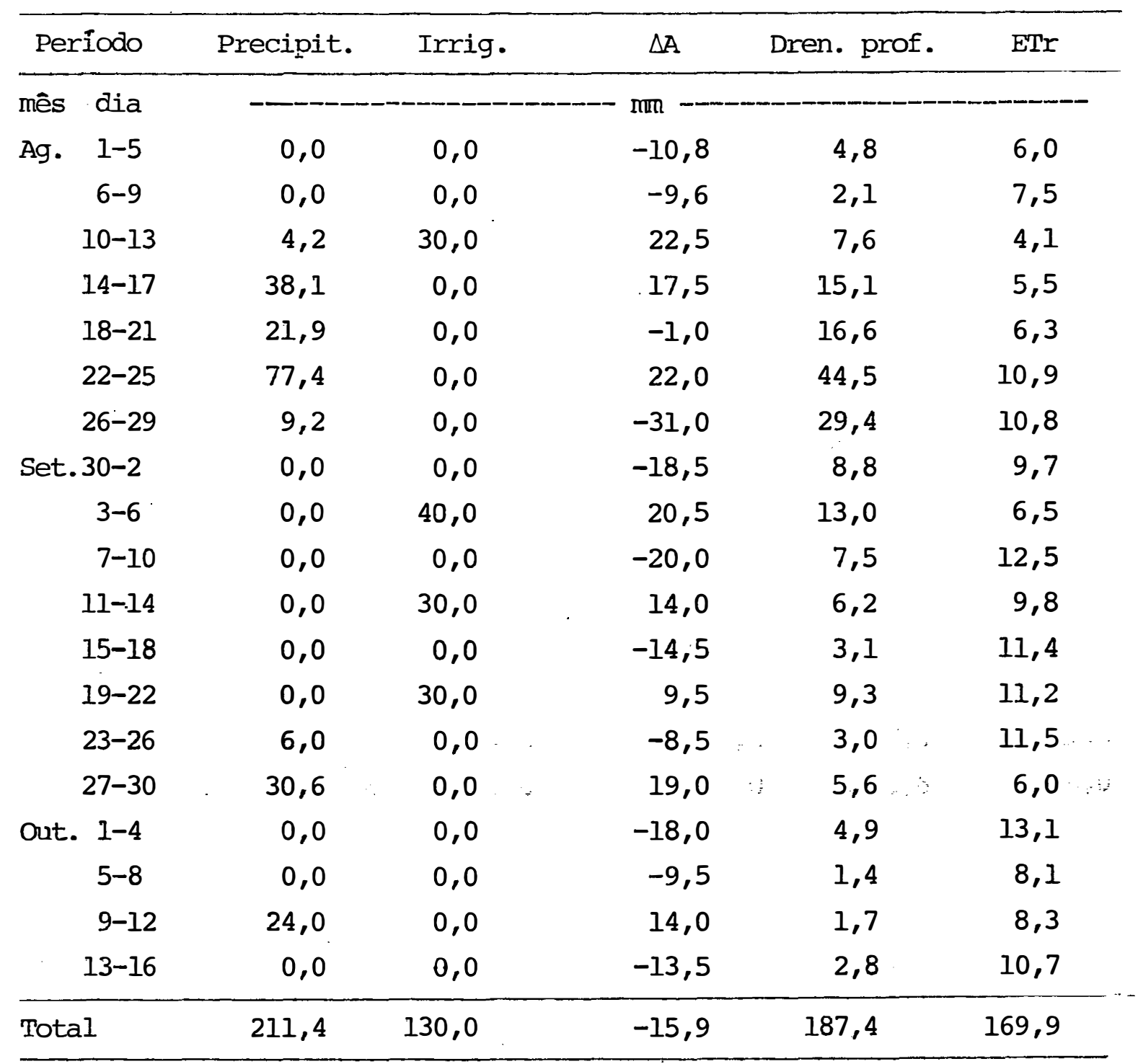


Tabela 12 - Valores dos componentes do balanço hïdrico de campo - precipitação, irrigação, variação no armazenamento de água no solo: $(\triangle A)$, drenag̈em profunda e evapotranspiração real (ETr) na cultura do feijoeiro para o tratamento DHN, em 1986, Campinas, SP.

\begin{tabular}{rrrrrr}
\hline Periodo & Precipit. & Irrig. & \multicolumn{1}{c}{$\Delta$ A } & Dren. prof. & ETr \\
\hline mês dia & - & 0,0 & $-10,9$ & 4,3 & 6,6 \\
Ag. 1 1-5 & 0,0 & 0,0 & $-8,0$ & 2,3 & 5,7 \\
$6-9$ & 0,0 & 0,0 & 23,0 & 6,9 & 4,3 \\
$10-13$ & 4,2 & 30,0 & 15,0 & 17,2 & 5,9 \\
$14-17$ & 38,1 & 0,0 & 0,0 & 15,1 & 6,8 \\
$18-21$ & 21,9 & 0,0 & 22,0 & 44,4 & 11,0 \\
$22-25$ & 77,4 & 0,0 & $-30,5$ & 30,3 & 9,4 \\
$26-29$ & 9,2 & 0,0 & 16,0 & 14,8 & 9,2 \\
Set. 30-2 & 0,0 & 40,0 & $-16,5$ & 10,4 & 6,1 \\
$3-6$ & 0,0 & 0,0 & $-12,5$ & 6,0 & 6,5 \\
$7-10$ & 0,0 & 0,0 & 15,0 & 4,8 & 10,2 \\
$11-14$ & 0,0 & 30,0 & $-12,0$ & 2,2 & 9,8 \\
$15-18$ & 0,0 & 0,0 & 10,0 & 4,9 & 10,1 \\
$19-22$ & 0,0 & 25,0 & $-5,0$ & 2,8 & 8,2 \\
$23-26$ & 6,0 & 0,0 & 15,0 & 9,5 & 6,1 \\
$27-30$ & 30,6 & 0,0 & $-14,8$ & 6,3 & 8,5 \\
Out. 1-4 & 0,0 & 0,0 & $-9,5$ & 2,4 & 7,1 \\
$5-8$ & 0,0 & 0,0 & 10,0 & 5,9 & 8,1 \\
$9-12$ & 24,0 & 0,0 & $-9,8$ & 2,7 & 7,1 \\
$13-16$ & 0,0 & 0,0 & $-3,5$ & 193,2 & 146,7 \\
\hline Total & 211,4 & 125,0 & & &
\end{tabular}




\subsubsection{Adicăo de água no sistema}

A contribuigấo de água no ensaio, conforme item 4.1, deu-se pela precipitacâo natural e irrigacăo dos tratamentos. As quantidades totais de água aplicada en t:ermos relativos ao DHI ou $25 \% A D$ foram de até $170 \%$ para o 100\%AD. No entanto, a diferenciacăo principal na quantidade de água aplicada refere-se à fase reprodutiva da cultura, en vista da precipitacăo freqiente no inicio do ciclo. As diferencas nos valores de precipitacóes, apresentadas nas. Tabelas 5 a 12, foram devidas à cobertura $p l a ́ s-$ tica nos tratamentos DHI $e$ de $100 \%$ a $25 \% A D$.

4.3.2. Variacăo no armazenamento de água no 5010

Calculou-se a variacăo da água no solo a partir da água total armazenada medida no inicio e no fim de cada periodo do balanco hidrico. Conforme se pode ver nas Tabelas 5 a 12, trata-se da componente do balanco hidrico de menor variacáo. Isso também foi observado por costa (1986) E REICHARDT (1987). Essa componente, porém, possivelmente seja a que mais afete o comportamento fisiológico da cultura, por estar diretamente ligada ao teor de umidade e tensăo de água no 5010.

\subsubsection{Drenagem profunda}

As perdas de água por drenagem, abai»o do sistema radicular efetivo da cultura $(40 \mathrm{~cm})$, foram altas durante o ensaio. En geral, seus valores variaram de 49 a $58 \%$ do total de ágla adicionada ao sistema (P + I). As precipitacótes frequentes concentradas no periodo compreendido logo após a primeira irrigacăo geral (25 DAG) até 40 
DAG (Figura 7) contribuíram, em muito, para a magnitude observada. Uma avaliacâo da cobertura plástica, no tratamento 50\%AD, evitou uma precipitacáo de $21,9 \mathrm{~mm}$ aos $35 \mathrm{DAG}$. Eim consegijência, a perda por drenagem profunda nesse tratamento reduaiu-se para $44 \%$.

Houve correlacấo positiva entre os valores acumulados da drenagem profunda (D) e a precipitacấo mais irrigacão $(P+I)$, para todos os tratamentos analisados conjuntamente $\left(R^{2}=0,91^{*} *\right.$ para oito observacóes $)$ :

$D=0.6(P+I)-22,4$

Assim, contribuicöes acima de $37 \mathrm{~mm}$ representam, em perdas por drenagem, $0.6 \mathrm{~mm} / \mathrm{mm}$. Coincidentementer - valor de $37 \mathrm{~mm}$ se aproxima daqueles típicos de uma irriga६ล๊o.

A maior perda en valores absolutos ocorreu no tratamento de irrigacâo freqiente. Nos com cobertura plástica, o aumento de freqijencia de irrigacão elevou a quantidade de água drenada, com excecâo do $50 \% A D$, $P \in 10$ mot ivo acima exposto. Os tratamentos sem cobertura plástica apresentaram valores de perda próximos entresi, porém o que recebeu mais água - M75\% - foi superior.

Nos periodos considerados no balanco hidrico Tabelas 5 a 12 - em que nấo houve chuvas ou irrigafóes, a maior taxa de drenagem foi de $5,1 \mathrm{~mm}$ dia-1 (de 19 a 4/9) $4,3 \mathrm{~mm}$.dia-1 (19 a 22/8) no tratamento 100\%AD, seguido por $3.6 \mathrm{~mm}$.dia-1 (26 a 29/8) no DHI. A umidade do solo e a irrigacâo mais a precipitacão, ocorridas imediatamente antes desses periodos, afetaram a magnitude de tais taxas.

Alguns erros podem ser admitidos na técnica do balanco hidrico de campo, sobretudo na deterninacéo da drenagem profunda através da equacâo de Darcy. Cónseqiientemente, os valores da evapotranspiracáo podem ser superest imados $p \in l a$ subest inativa da drenagem na faixa de alta umidade do solo (REICHARDT et alii, 1974). 
Para BLACK et ali i (1981), o período para cálculo da drenagem profunda deveria ser menor que um dia em época chuvosa. No presente estudo, nâo se diferenciaram os períodos secos e lumidos para a determinacấo do teor de umidade do solo, sendo utilizados os valores médios de cada periodo. Outra fonte de erro é que as variacóes no gradiente de potencial hidráulico foram despresadase, conse-qijentemente, a contribuicäo pela ascensäo capilar. BRUNINI (1981) usando procedimento similar ao presente trabalho mostrou que, para esse tipo de solo, os valores obtidos de ETr eram coerentes, e que outros erros, como na estima$t$ iva de Ko, muito maiores do que $\partial \Psi / \partial z$. Aparentemente, houve uma compensagäo nos erros envolvidos nas est imativas de $\partial \Psi / \partial z \in K(\theta)$, em face dos resultados obtidos.

A drenagem profunda representou entre 40 e $60 \%$ do total de água que entrou a sistema, semelhante a $57.8 \%$ obtido por PAULA SOUZA et ali is (1979), embora esses autores tenham considerado a profundidade efetiva de $120 \mathrm{~cm}$.

\subsubsection{Evapotranspirąâo}

Os dados de evapotranspiracäo real (ETr) acumulada durante a estacấo nos tratamentos do feijoeiro va$r$ iaram de 121 a $213,3 \mathrm{~mm}$, mostrando que houve acentuado efeito dos tratamentos - Tabelas 5 a 12. Tais dados, em termos de valores médios diários, foram de: 2,76; 2,24; 2,$06 ; 1,70 ; 1,50 ; 2,40 ; 2,21 \in 1,87 \mathrm{mmadia}^{-1}$ para os tratamentos $100,75,50$ e $25 \% A D ;$ DHI, M75 $M 50 \%$ e DHN resPeCtivamente. Todos eles sảo consistentes com o obtido por SILUEIRA \& STONE (1979) no periodo seco, $2,8 \mathrm{mmadia}$, menores do que os de GIRALT (1979), 3,3 a $3,5 \mathrm{~mm}^{\mathrm{d}} \mathrm{i} \mathrm{a}^{-1} \mathrm{E}$ de SANTOS (1985), 4.0 mmadia-1 no verăo. 0s résultados dos tratamentos $M 75$ e M50\% foram próximos aos de 75 e $50 \% A D$ respectivamente. A ETr naqueles tratamentos foi cerca de $8 \%$ maior do que nos cobertos. 
A ETr diminuiu linearmente com a reducấo na lâmina de irrigacấo dos tratámentos, en reląấo ao $100 \% A D$, de $0,39 \mathrm{~mm}$ para a reducấo de cada milimetro de irrigacáo até o nivel de 50\%AD. A partir desse ponto, o decréscimo em ETr foi cada vez mais acentuado, de acordo com a seve ridade do tratamento. Quando a ETr acumulada é analisada entre os tratamentos 25 a $100 \% A D$, observa-se a seguinte relacấo:

ETr $(\mathrm{mm})=106,6+1,01 \mathrm{AD} \%\left(\mathrm{R}^{2}=0,97 \div \mathrm{n}=4\right)$.

A evolucấo da ETr ocorrida nos tratamentos é mostrada na Figura 8 , juntamente com a evapotranspiracáo de referência (ETo), calculada a partir da evaporacáo do tanque classe $A$. O tratamento que recebeu irrigacấo freqiiente - 100\%AD - apresentou uma taxa de ETr menor do que ETo até aproximadamente o florescimento ( 40 DAG), provavelmente devido estar a área foliar ainda en desenvolvimento. No estádio reprodutivo e final, as taxas mantiveram-se aprowimadamente constantes, observando-se que a colheita do $100 \%$ AD se processou quando as folhas ainda estavam verdes e possivelmente at lvas.

A imposicấo dos tratamentos de irrigacấo iniciou-se aos 42 DAG, porém já aos 36 DAG comeqou a supressấo das chuvas, con o uso de cobertura plástica nos tratamentos. Assim, na Figura 8, há indicacấo de diferencas na ETr entre os tratamentos aos 40 DAG, acentuando-se ao longo do ciclo da cultura. A acentuada reducấo na ETr dos tratamentos 25\%AD E DHI, en relacấo aos outros, deu-se nấo àpenas pela açấo estomática do estresse hidrico (Tabela 4). mas também pelo efeito da água na área foliar. Segundo HSIAO (1973) E HSIAO \& ACEUEDO (1974), entre outrós, a Extensáo celular e o crescimento de folhas sáo os processos inicialmente afetados pelo déficit hidrico na planta, antes mesmo da abertura estomática. Observacôes visuais no 
campo indicaram que, no florescimento, os tratamentos de menor dotaçóio de rega diminuiram o crescimento, com plantas de menor estatura e folhas pequenas. A cobertura ve-getal do solo se completou primeiramente no tratamento de irrigacáo mais freqiiente, seguido do 75 e $50 \% A D$. Abaixo da aigua disponivel deste iltimo, a cobertura vegetal do solo manteve-se incompleta até o final do ciclo. Resultados semelhantes foram encontrados por RESENDE et aliis (1981) na califórnia.

- maior valor médio de ETr foi de $3,7 \mathrm{~mm}$ adi a no tratamento $100 \% A D(60-63$ DAG), quando ETo at ingiu o seu

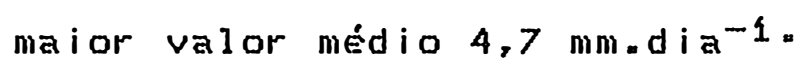

A evapotranspiracáo resulta de uma açáo do ambiente, sendo controlada pela planta, como se pode analisar Pelo comportamento do tratamento DHI: Figura 9. Logo após um periodo de pleno suprimento de água (até 36 DAG), a ETr era muito próxima de ETo. A diferenca observada de 36 a 40 DAG era devida principalmente a cobertura vegetal incompleta, visto que as diferencas na resisténcia estomática pouco se alteram após a irrigacáo se os dias forem amenos (Tabela 4). O aumento de ETo em 40-48 DAG náo cor... respondeu em aumento proporcional na ETr, possivelmente por alguma restricăo hidrica no solo. Essa restricáo se foi agravando sistematicamente até a aplicacáo de água aos-.. 62 DAG: houve uma reducáo de $0,075 \mathrm{~mm}$ na ETr para cada dia desse período, independente da demanda evaporativa. Os $70 \mathrm{~mm}$ de irrigacáo bastaram para a reposifáo da umidade do solo até à capacidade de campo. Mesmo assim, nấo houve recuperacáio completa na taxa evaporativa das plantas do tratamento DHI até os 68 DAG. Pelos resultados do balanco hidrico, essa recuperacáo foi gradativa, apesar de as medicöes de ras, realizadas na tarde de 68 DAG, indicarem a plena abertura dos estômatos $\left(0,95 . \mathrm{cm}^{-1}\right.$ para DHI $E 0,7$ S. $\mathrm{cm}^{-1}$ para $100 \% A D$ - Tabela 4). As medicốes complementares de rge temperatura, realizadas com o porômetro, indi- 
cavam un aquecimento dos foliolos no tratamento DHI de $0,8^{\circ} \mathrm{C}$ em relacấo à temperatura do ar, ao passo que, nos tratamentos irrigados, os foliolos se apresentavam com temperatura 1 a $1,7^{\circ} \mathrm{C}$ abaixo da do ar. Houve, possivelmente, aumento em outras resistências ao fluxo d'água no sis... tema solo-planta-atmosfera, além de modificacóes na exposicấo dos foliolos à radiacấo diretar associado ao visivel amarelecimento geral do tratamento e senescência das folhas velhas. 


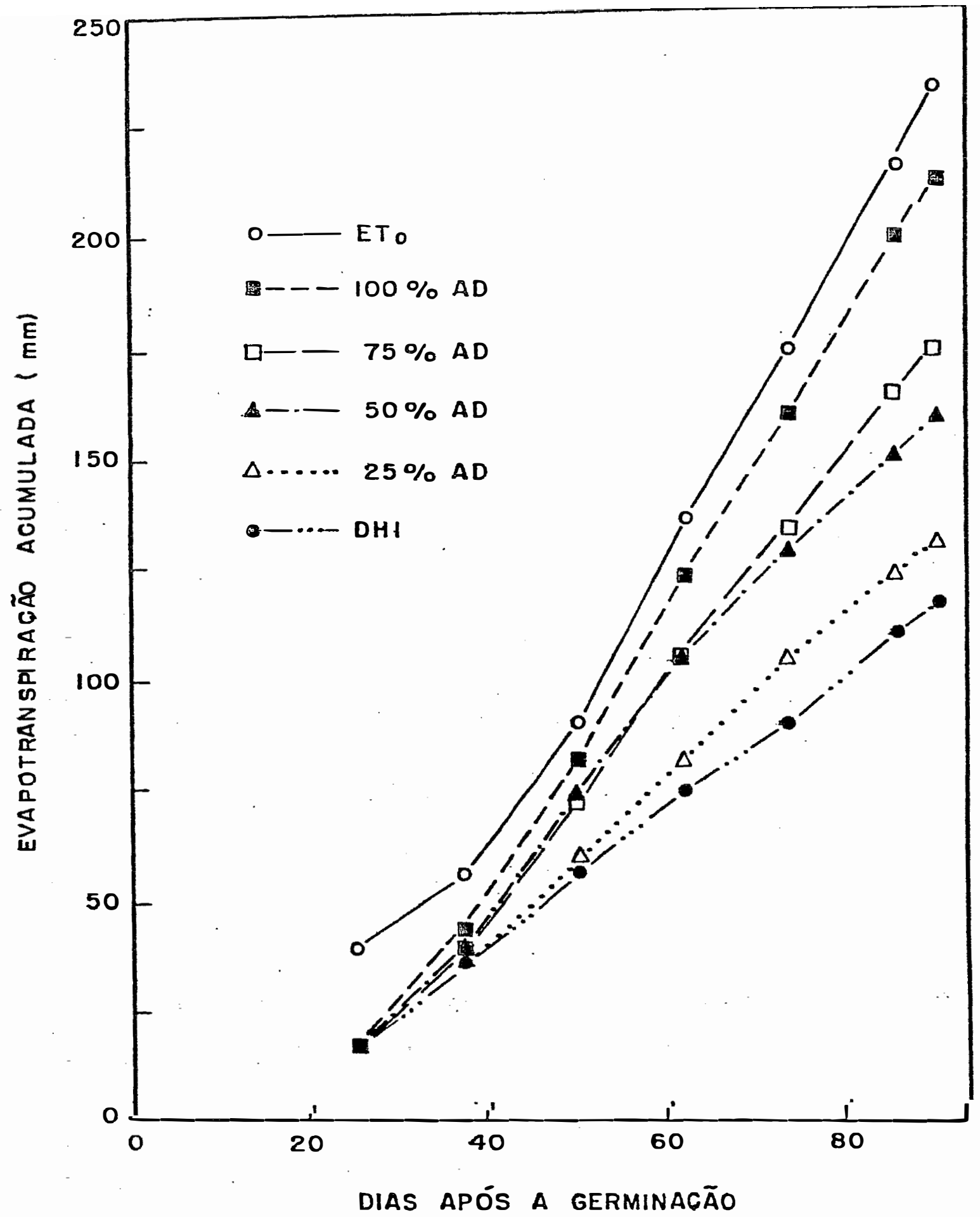

Figura 8 - Evapotranspiração de referência (ETo) e evapotrànspiração real (ETr) acumulada para diferentes níveis de aplicação de água na cultura do feijoeiro, determinadas no inverno de 1986, em Campinas, SP. 


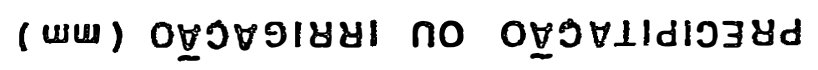

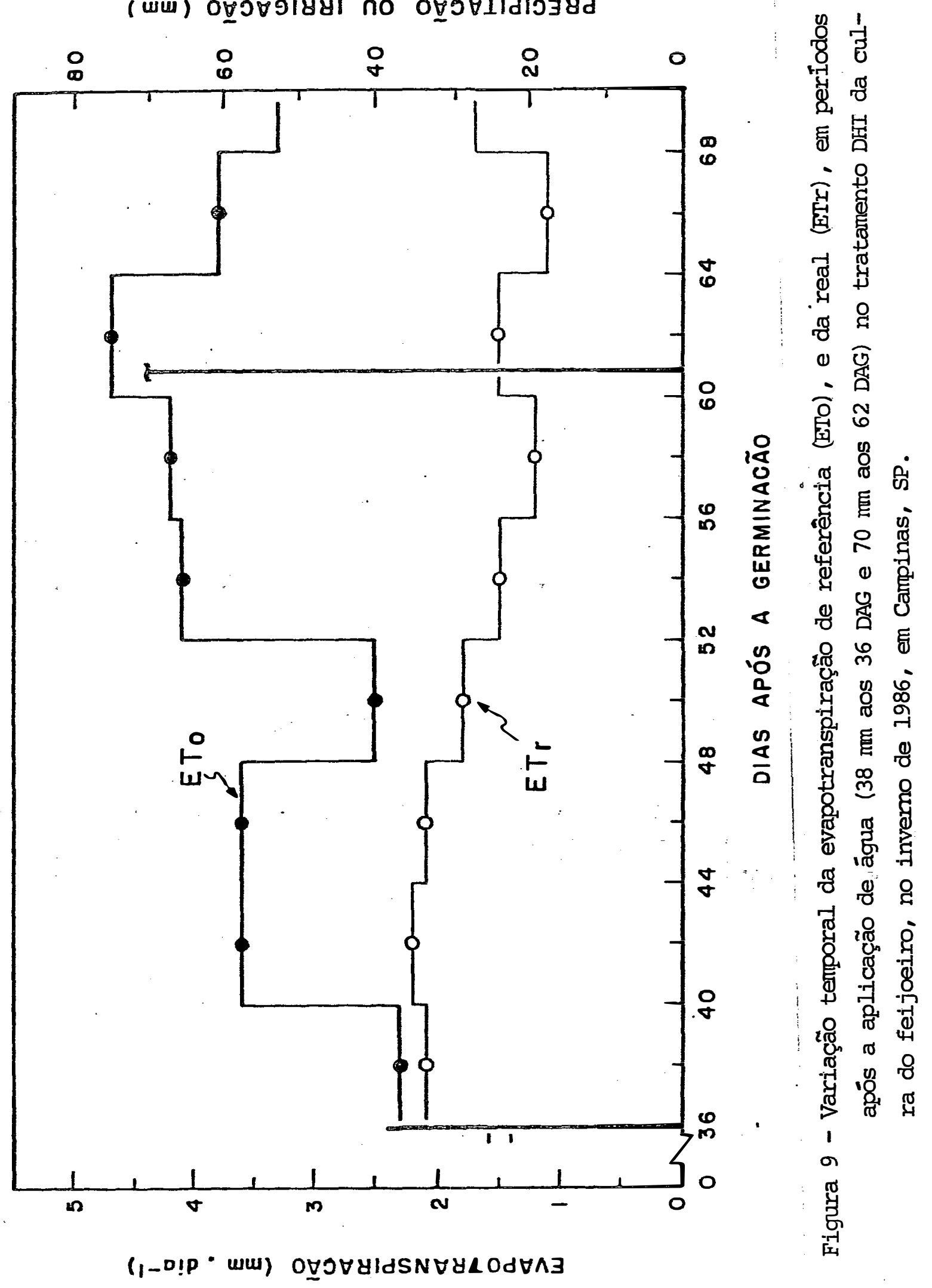




\subsection{Balanco de energia}

Ao longo do ciclo da cultura e após o inicio das diferenciacốes da irrigacăo, efetuaram-se observacóes micrometeorológicas em cinco períodos com duracáo de trếs a quatro dias cada $4 m$, nos tratamentos $100 \% A D$ e M75\%. Em cada periodo, estabeleceu-se um dia tipico para efeito de célculo do balanco de energia.

O critério adotado para a selegấo foi em funGăo do nivel de umidade do solo, da sequiência sistemática das observacóes ao longo do dia $e$ do bom funcionamento dos instrumentos nos tratamentos, principalmente dos psicrómetros, e do sistema de aquisicăo de dados. Assim, os dias considerados para estudo em questáo foram: 28.8 , quando a cultura apresentava 42 DAG; 11.9 (56 DAG); 16.9 (61 DAG); 3.3.9 (68 DAG), e 10.10 .86 (76 DAG), correspondentes à fase de florescimento ao inicio da maturacáo.

Os resultados referentes à temperatura do ar (seco:T, ímido:TU), do gradiente psicrométrico ( $\Delta T / \Delta T U$ ), radiaçóo liquida (RN), fluxo de calor no solo (-G) e demais componentes do balaneo de energia, obtidos nos tratamentos de irrigacấo e calculados através das eq. (15) a (18), sấo apresentados no Apêndice 1 e discutidos a seguir.

\subsubsection{Dia 28-8-86 (42 DAG)}

Esse dia se caracterizou por uma evapotranspiracăo potencial de $4,2 \mathrm{~mm}$.dia ${ }^{-1}$, estimada pelo tanque classe $A$ e de $5.8 \mathrm{mmadia}^{-1}$, por penman, insolacáo de 1.0, Ghoras, sem ocorrência de nuvens, velocidade média de $5,0 \mathrm{~m}^{-1}$ e temperatura maxima em torno de $28,50 \mathrm{C}$. 
A variacăo dos componentes do balango de ener-gia encontra-se nas Figuras 10 e 11, para os tratamentos 100\%AD e M75\% respectivamente. As diferencas no indice da evapotranspiracăo (-LE) dependen, sobretudo, do regime de umidade do solo e das condicôes micrometeorológicas.

- tratamento $100 \% A D$ teve como suprimento de água anterior ao dia $28 / 8$ uma precipitaçón de $38 \mathrm{~mm}$, a 36 DAG. Esse foi o periodo de maior deficiência hidrica nesse tratamento de alta freqiencia de irrigaça: longo o suficiente para afetar a particăo da energia disponivel no sistema, resultando numa redugăo no fluxo de vapor (-LE) $E$ no aumento da componente do calor sensivel (-H) en relacăo ao $175 \%$.

As precipitacóes ocorridas até dois dias antes de 42 DAG possibilitaram que a maior parte de RN fosse utilizada no processo evaporativo (-LE). Nessa situacăo, a razão de Bowen ( $\beta$ ) apresentou valores mito próximos da nulidade (Apêndice 1.1.b), caso típico da boa disponibilidade de água para a cultura, de acordo com SLATYER (1967). Por outro lado, os valores de $\beta$ no tratamento $100 \%$ AD mostraram-se mais elevados e sempre positivos (Apêndice 1.1. a).

- fluxo de calor no solo (-G) nấo foi elevado em ambos os tratamentos porque o solo, como mencionado, apresentava-se com bom suprimento hidricoe, a superficie, quase totalmente vegetada. 


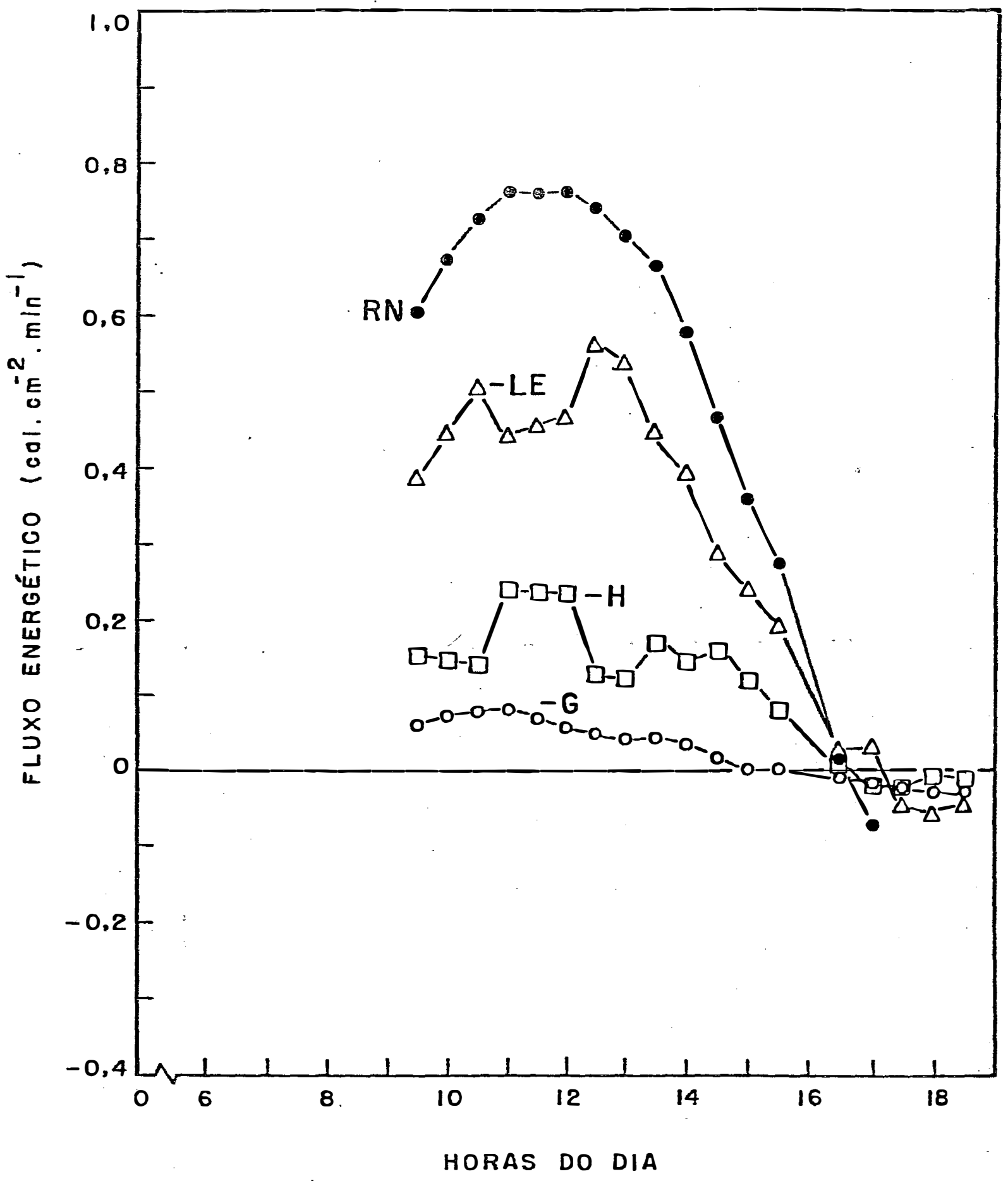

F.igura 10 - Variação horária da radiação líquida (RN), do fluxixo de calor no solo $(-G)$, do fluxo de calor sensivel $(-H)$ e latente $(-I E)$ em cultura de feijão, no dia 28.8.86, no tratamento $100 \%$ D. 


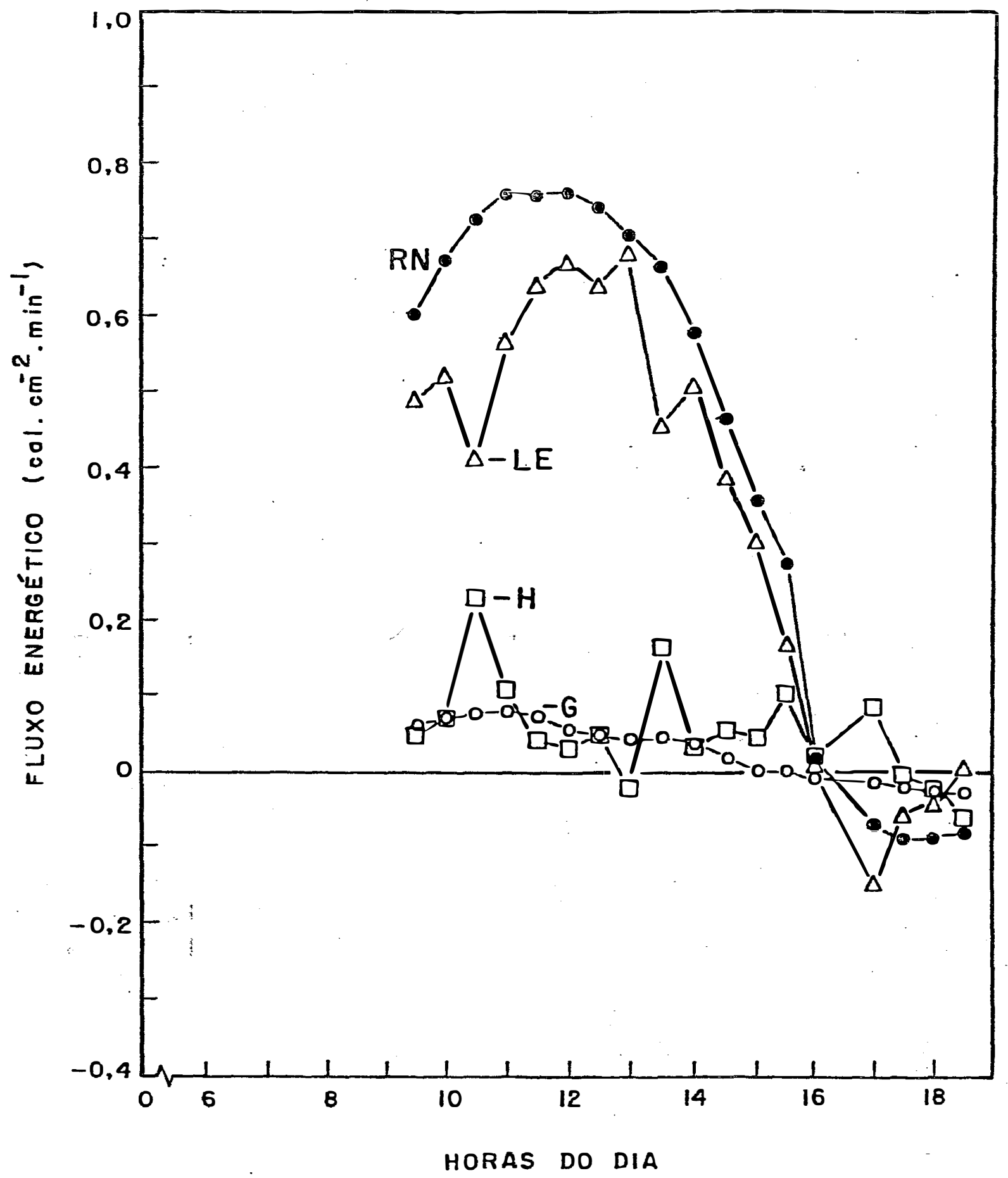

Figura 11 - Varịação horâria da radiação líquida (RN), do fluxo de calor no solo $(-G)$, do fluxo de calor sensível $(-H)$ e latente (-LE) em cultura de feijão, no dia 28.8.86, no tratamento M75\%. 


\subsubsection{Dia 11.9 .86 (56 DAG)}

Nesse dia, houve uma evapotranspiracăo potencial de 3,4 mmodia $a^{-1}$ pelo tanque classe $A$ e 4,5 mm.dia-1, c. alculado por Penman, insolacấo de 10,5 horas, com o céu totalmente aberto, velocidade média do vento de $2,3 \mathrm{~m} . \mathrm{s}^{-1}$ e temperatura máxima de $29,00 \mathrm{C}$.

As Figuras 12 e 13 apresentam a variacáo dos componentes do balanco de energia para os tratamentos $100 \%$ AD e M75\% respectivamente. A condicấo pouco mais amena do dia 11.9, quando comparada à do 28.8 , resultou em particấo da radiaçáo liquida (RN) dos tratamentos 100\%AD $E$ M75\% similar ao daquele dia. Apesar de que em 11.9 a dis... ponibilidade de água no solo era un pouco menor e de forma invertida para os tratamentos $100 \%$ AD $E$ M75\%, visto que havian decorridos cinco e dois dias desde o litimo suprimento de água respectivanente.. No presente caso, o supri -.. mento de água no $100 \% A D$ ocorreu na manhä de 55 DAG e no M75\% quatro dias antes. Medicốs de resistência estomáti-ca, às 14h, mostraram una diferenca de $0,35 . \mathrm{cm}^{-1}$ apenas entre os tratamentos $100 \% A D \in M 75 \%$ (Tabela 4). De fato, a perda por evapotranspiracấo (-LE) ocorrida nessa hora era um Pouco maior para o 100\%AD. Entretanto, as medicóes de $r$ tomadas na tarde desse dia, aparentemente, nấo expressaram a situacáo de maior déficit hidrico na planta, visto que a depressấo de (-LE) ocorreu entre 11 e 12h : Figuras $1.2 \in 1.3$.

A maior disponibilidade de água no tratamento 100\%AD propiciou una taxa evaporimétrica maior do que no M75\% E una recuperacăo mais rápida à depressấo da evapo-transpiracấo no meio do dia. Os valores mais elevados da relacâo de Bowen (Apêndice 1.2.a) evidenciam o nivel menor de armazenamento de água no 5010 do M75\%. É interessante notar o efeito advectivo à tarde no 100\%AD. Isso se repetiu algunas vezes durante a estacăo, porém nem sempre evi-.. 
dente nos resultados do presente trabalho. LUCHIARI JR. (1988) relata a ocorrência regular de adveçáo vespertina na cultura do trigo irrigado na regiâo de Goiânia.

\subsubsection{Dia 16.9.86 (61 DAG)}

Em 16.9, embora correspondente ainda ̀̀ fase de enchimento dos grấos, algumas plantas se apresentavam com flores: a temperatura maxima era de $31,8^{\circ} \mathrm{C}$; velocidade média do vento $1,7 \mathrm{~m} . \mathrm{s}^{-1}$, e evapotranspiraçáo potencial (tanque classe A), 4,8 $\mathrm{mm}_{\mathrm{d}} \mathrm{di} \mathrm{a}^{-1} \in \mathrm{de} 4,9 \mathrm{~mm}_{\mathrm{d}} \mathrm{di} \mathrm{a}^{-1}$ (Penman) com insolacấo de 9,4 horás.

Ambos os tratamentos revelavam bom suprimento de água, pela proximidade das irrigacőes realizadas na manhấ da véspera para o 100\%AD, e de dois dias no M75\% - Figuras 14 e 15. Apesar dessa alta disponibilidade de água no solo, houve reducöes na taxa evaporativa no meio do dia no $M 75 \%$, em vista da alta demanda da atmosfera. A recuperaçóo do sistema, aparentemente, processou-se rapidamente, visto que -LE E RN, como no 100\%AD, se aproximaram muito durante toda a tarde. A transferencia da energia do ar para a superficie evaporante também pode ser observada em ambos, Embora en intensidades e horários diferentes, com valores da razấo de Bowen negativos. Essa contribuigáo do fluxo do calor sensivel (-H) para o latente (-LE), ocorreu desde as $10 h$ até o final da tarde no $100 \% A D$, e a partir das 12h, no M75\%. Nessas condicöes, a relacä́o -LE/RN aproximolu-se de $1,0(0,92$ no $100 \%$ AD e 0.82 no M75\%). Embora a advectấo tenha contribuido com adicáo de energia ao sistema, nấo refletiu no fluxo de calor no solo (-G), comparativamente aos outros dias. 


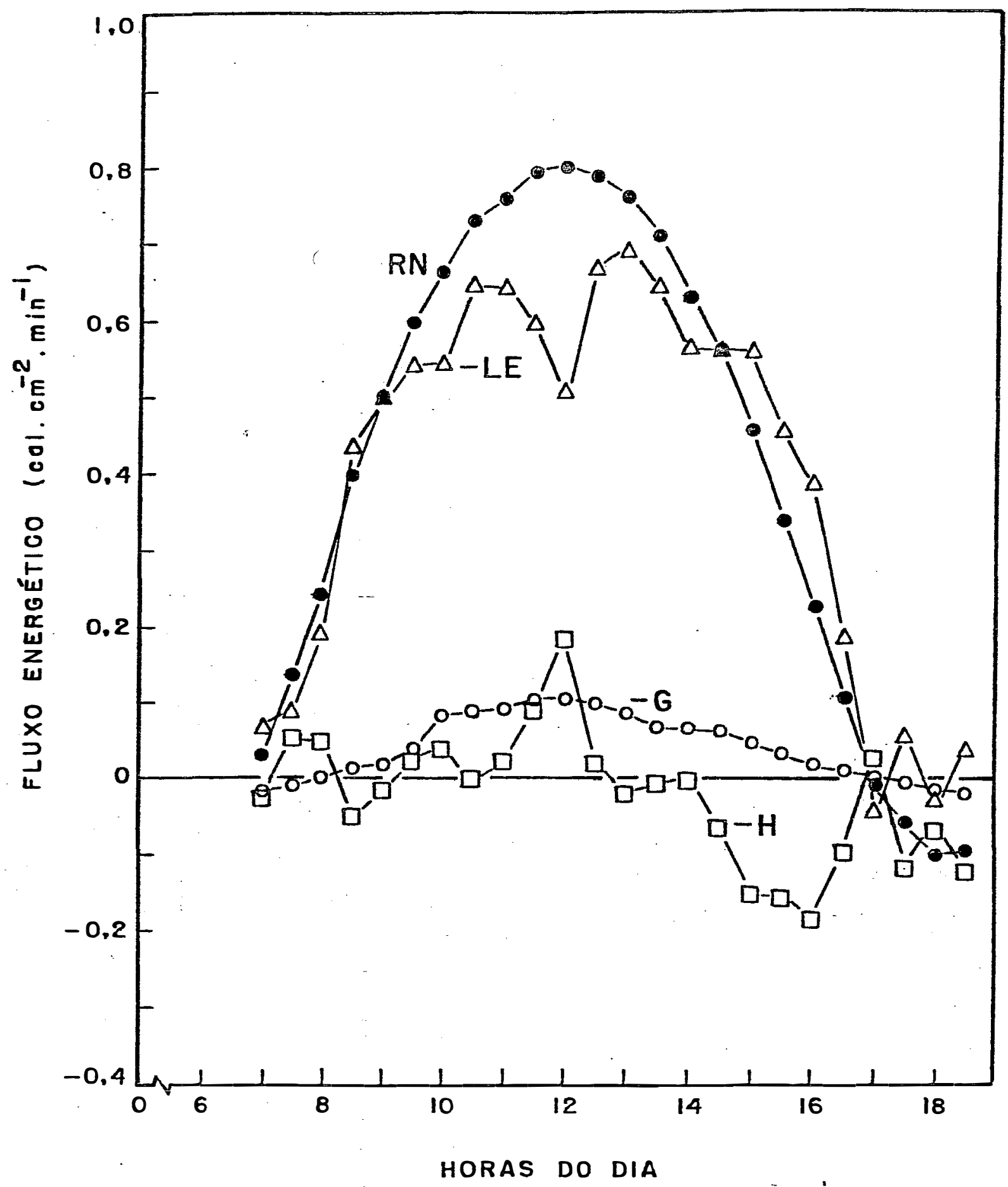

Figura 12 - Variação horāria da radiação líquida (RN), do fluxo de calor no solo $(-G)$, do fluxo de calor sensível $(-H)$ e latente (-LE) em cultura de feijão, no dia 11.9.86, no tratamento 100\%AD. 


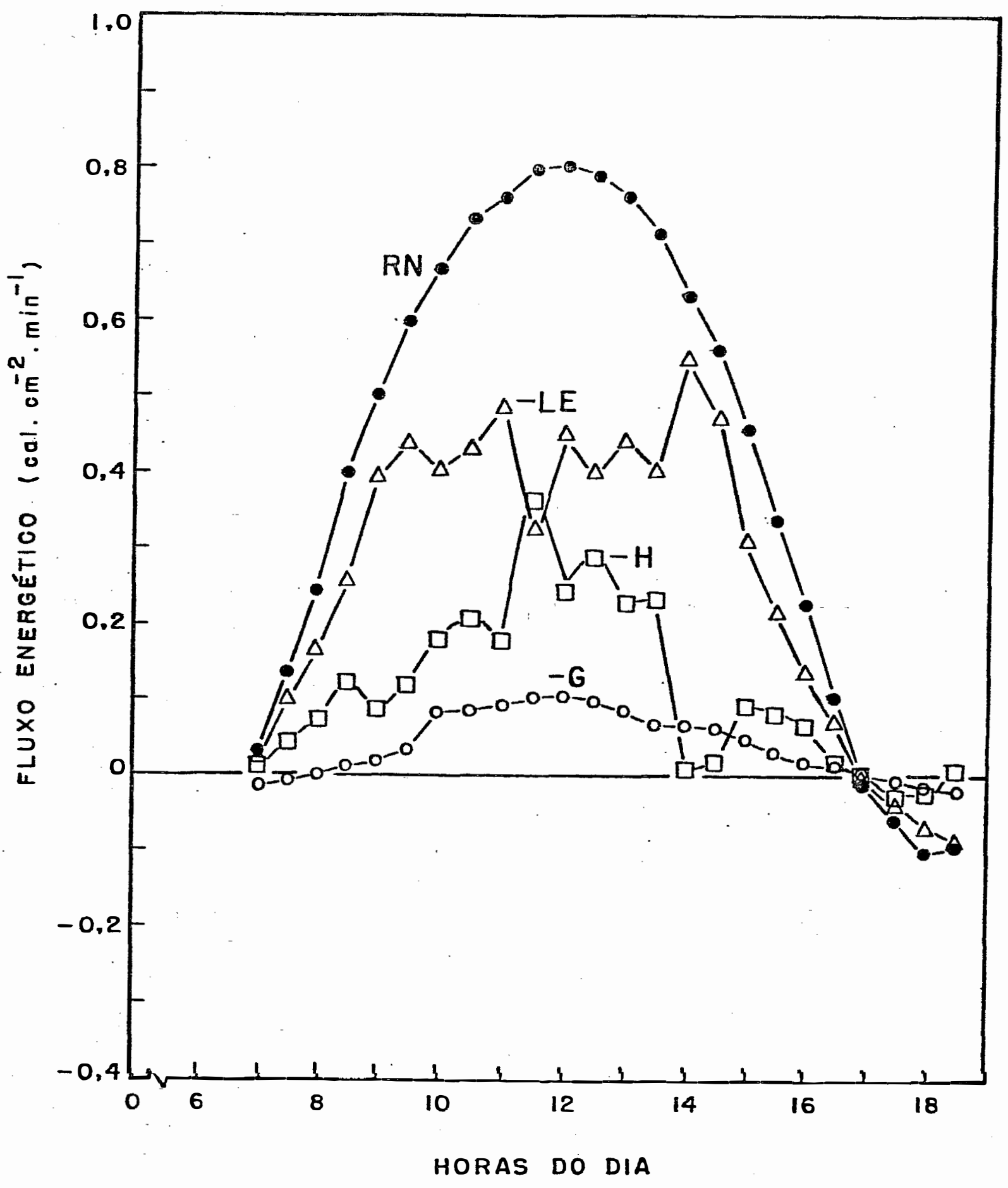

Figura 13 - Variação horârìa da radiação líquida (RN), do fluxo de calor no solo $(-G)$, do fluxo de calor sensível $(-H)$ e latente (-LE) em cultura de feijão, no dia 11.9.86, no tratamento M75\%. 


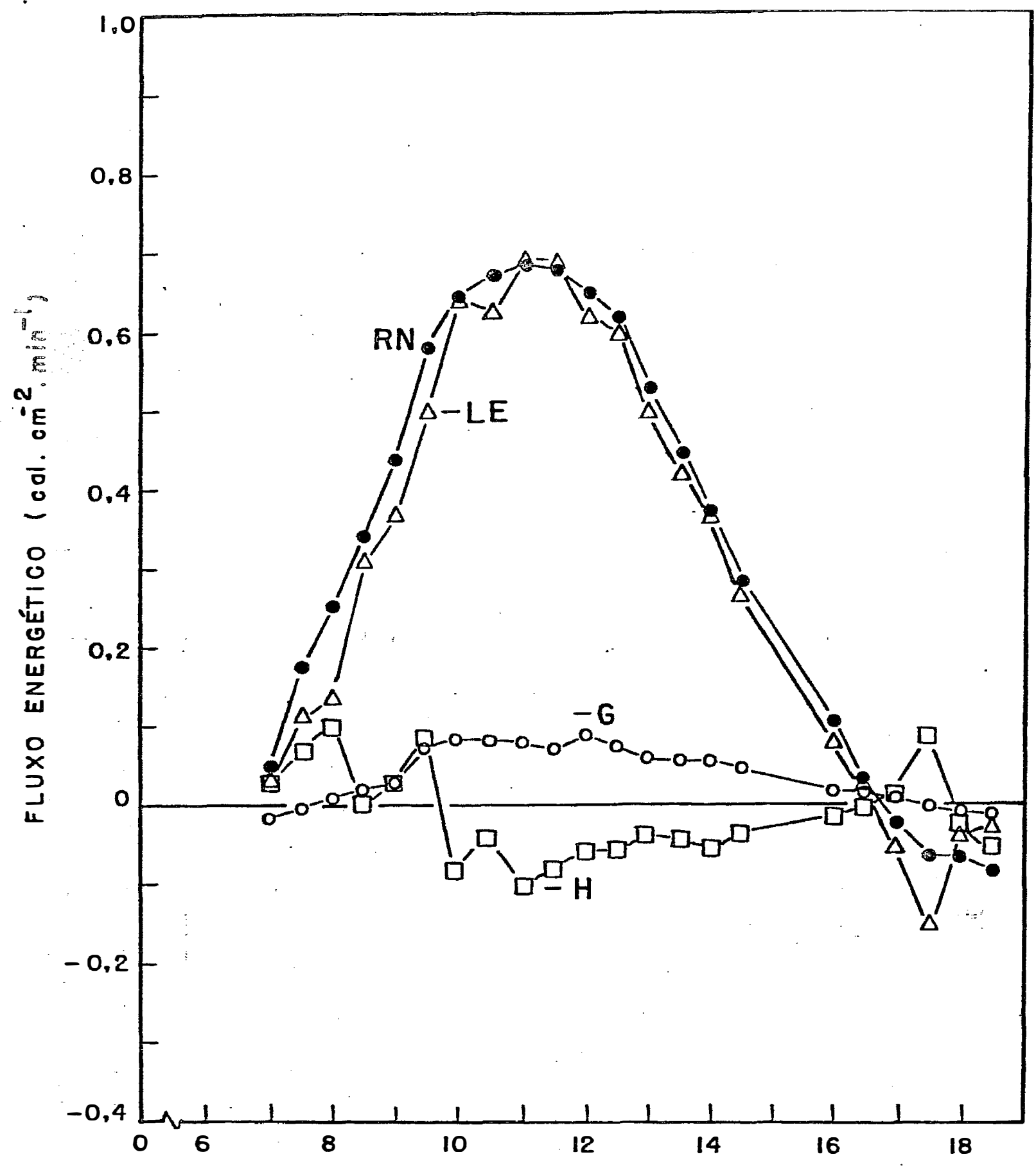

HORAS DO DIA

Figura 14 - Variação horäria da radiação líquida (RN), do fluxo de calor no solo $(-G)$, do fluxo de calor sensîvel $(-H)$ e latente (-LE) em cultura de feijão, no dia 16.9.86, no tratamento 100 aํ. 


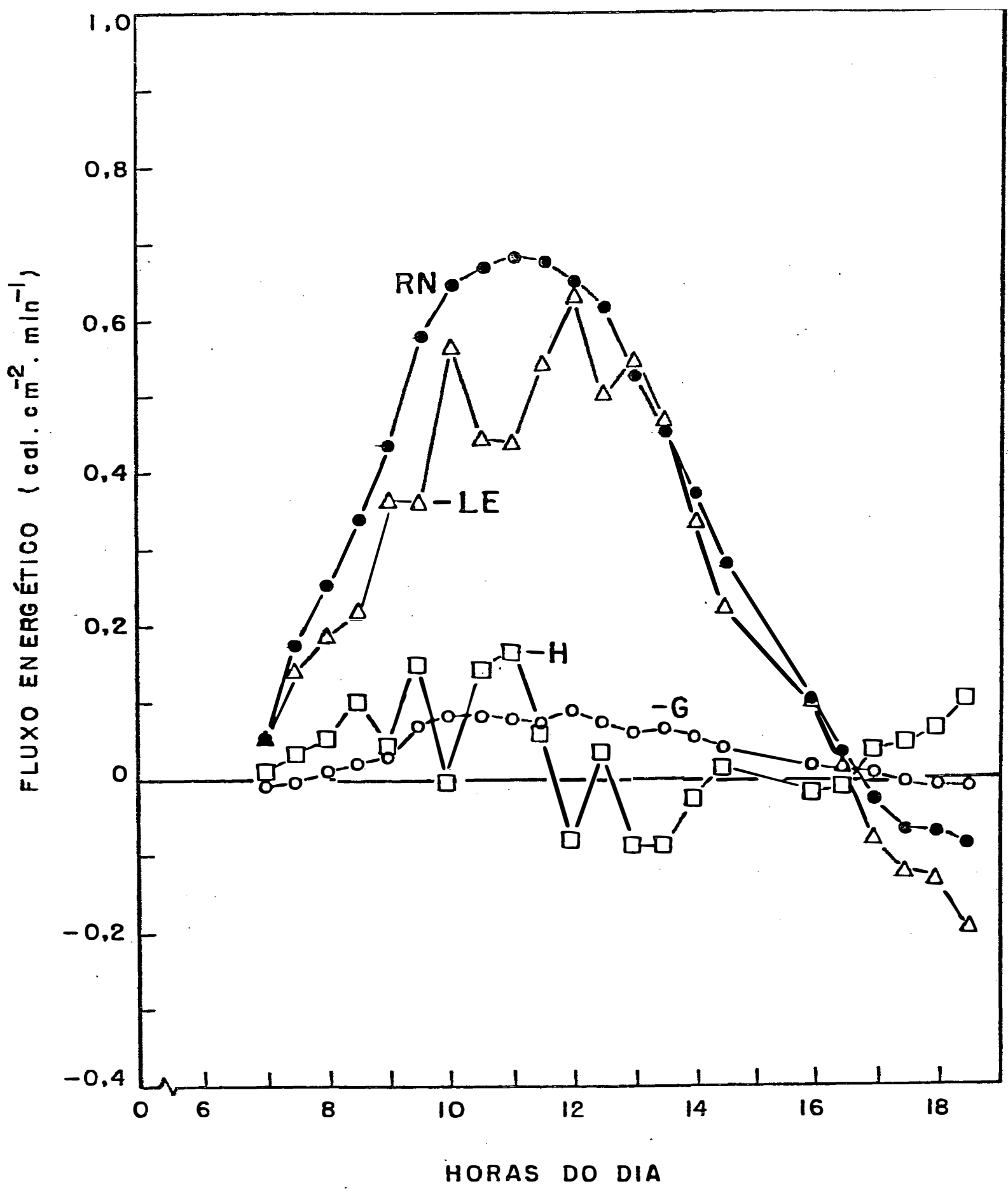

Figura 15 - Varịação horāria da radiação líquịda (RN), do fluxo de calor no solo $(-G)$, do fluxo de calor sensivel $(-H)$ e latente (-LE) en cultura de feijão, no dia 16.9.86, no tratamento M75\%. 


\subsubsection{Dia 23.9.86 (68 DAG)}

O dia 23.9 caracterizou-se por apresentar pe$r$ íodos nublados (7,1 horas de insolacão), diminuindo a radiacăo en torno do meio-dia. A evapotranspiracáo potencial estimada pelo tanque classe A foi de $4,5 \mathrm{mmadia}^{-1} \mathrm{ey}_{\text {y }}$ por penman, de $5,0 \mathrm{mmadia-1}$, com a temperatura máxima em torno de $30^{\circ} \mathrm{C}$.

A ditima irrigafáo recebida pelos tratamentos 100\%AD E M75\%, coincidentemente, ocorreu a 63 DAG. As Va$r$ iacóes dos componentes do balanco de energia ao longo do dia 23.9 (Figuras $16 \in$ (17) mostraram-se muito próximas en-

tre os dois tratamentos, indicando que, provavelmente, o déficit hidrico desenvolvido nas plantas de ambos tenha afetado -LE de forma similar. Essas figuras também mostram periodos de nebulosidade que caracterizaram os horarios da tarde, quando todos os componentes do balanco de energia diminuiram de forma irregular, com uma pequena defasagem no fluxo do calor no solo, como era de esperar.

os valores elevados de $\beta$ no inicio da manhä, nos tratamentos, indicam una imprecisắo na estimativa da evapotranspiracăo nesse intervalo (Apêndice 1.4). Posteriormente, $\beta$ estabilizou-se, com quase a totalidade de energia disponivel sendo utilizada no fluxo de vapor (evaporacăo). Houve tambén una contribuicáo do fluxo de calor sensivel ( $-H$ ) por volta das 13 às $16 h$ para o incremento de -..LE.

As medicôes de resistência estomática também não diferiram entre os dois tratamentos, tanto no periodo da manhã quanto no da tarde, na hora próxima da maior demanda evaporativa (Tabela 4).

A similaridade dos resultados de -LE $\dot{e}$ gr para ambos os tratamentos, indica a pouca influência do his-tórico de irrigacão na ETr, quando da realizacão de uma irrigacão geral. Isso talvez seja real apenas para os 
tratamentos de irrigacấo próximos, como o 100 e 0 75\%AD. Além disso, a imposicấo dos tratamentos somente no meio da estacấo talvez nấo tenha modificado significativamente a arquitetura da planta, o movimento de folhas, a área foliar e outros atributos que interferem no seu consumo de água.

As tawas de LE de 23.9 foram maiores do que as do tratamento $100 \% A D$, em 28.8, para um mesmo intervalo de c: inco dias desde a ultima precipitacäo, provavelmente como resultado de un armazenamento menor de água no solo naquela data, visto que, apesar da nebulosidade do dia 23 , as condicốes meteorológicas gerais de ambos os dias são próximas.

\subsubsection{Dia 19.10 .86 (76 DAG)}

A cultura do feijoeiro, aos 76 DAG, iniciavase no estádio de maturacấo fisiológica. Os tratamentos de irrigacấo mais freqientes apresentavam completa cobertura vegetal do solo. A evapotranspiracấo potencial, nesse dia, de $5,1 \mathrm{~mm} d \mathrm{da}^{-1}$ (tanque classe A) $E 5,3 \mathrm{~mm}_{\mathrm{dia}} \mathrm{di}^{-1}$ (Penman); a temperatura máxima, de $28,3^{\circ} \mathrm{C}$; insolacăo, de 9,9 horas e períodos com nebulosidade variável à tarde. A evapotranspiracăo real representou 89,2 e $93,8 \%$ da energia radiante, respectivamente, para os tratamentos 100\%AD $E$ M75\%, Embora nesse cômputo tenha ocorrido contribuicấo esporádica do ar por advectấo. Assim, os fluxos de calor no solo e sensivel para a atmosfera representaram pequena fracto da radiąốo liquida (Apêndice 1.5 e Figuras 18 (19). 


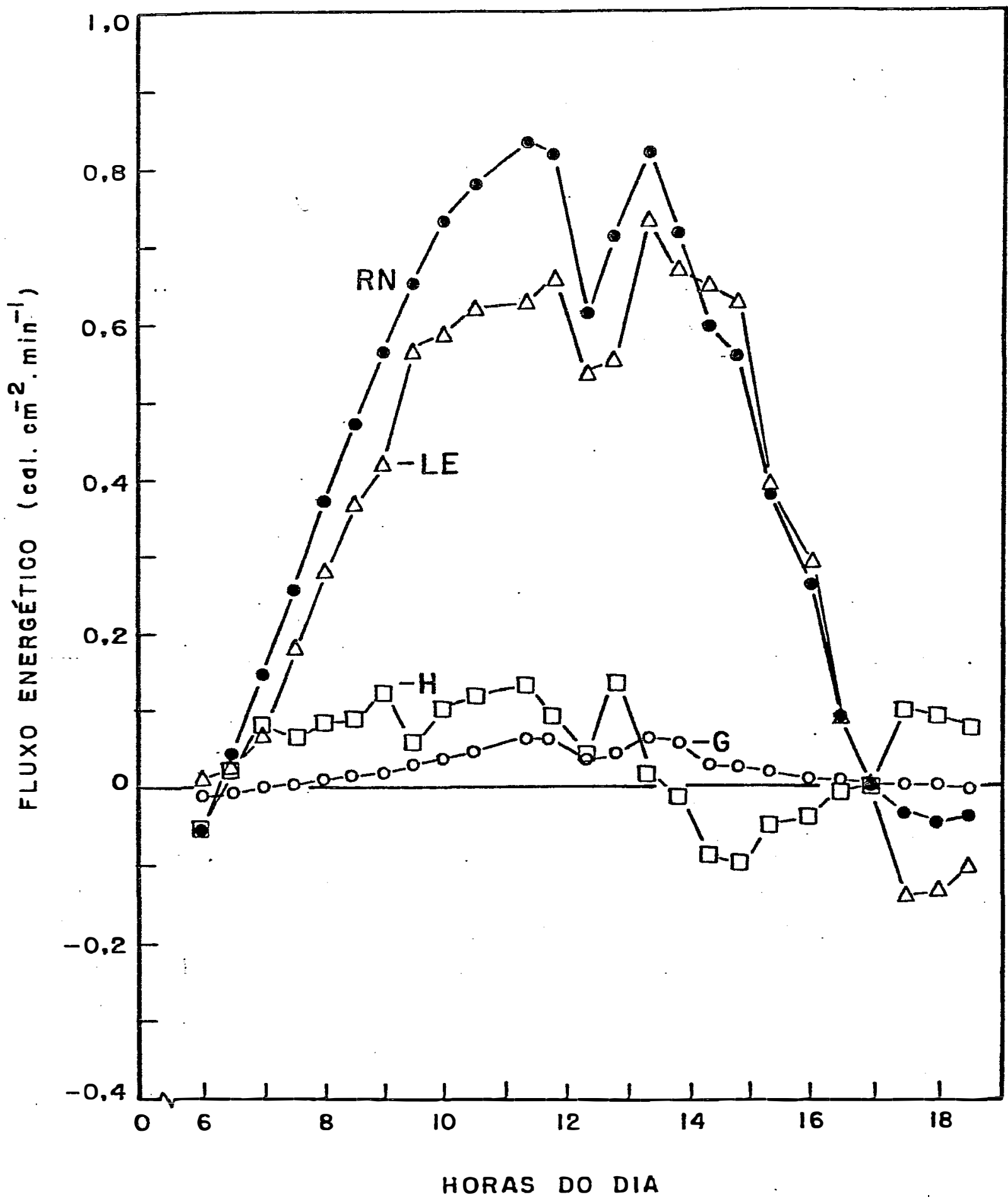

Figura 16 - Variação horária da radiação líquida (RN), do fluxo de calor no solo $(-G)$, do fluxo de calor sensível $(-H)$ e latente (-LE) em cultura de feijão, no dia 23.9.86, no tratamento 100\%AD. 


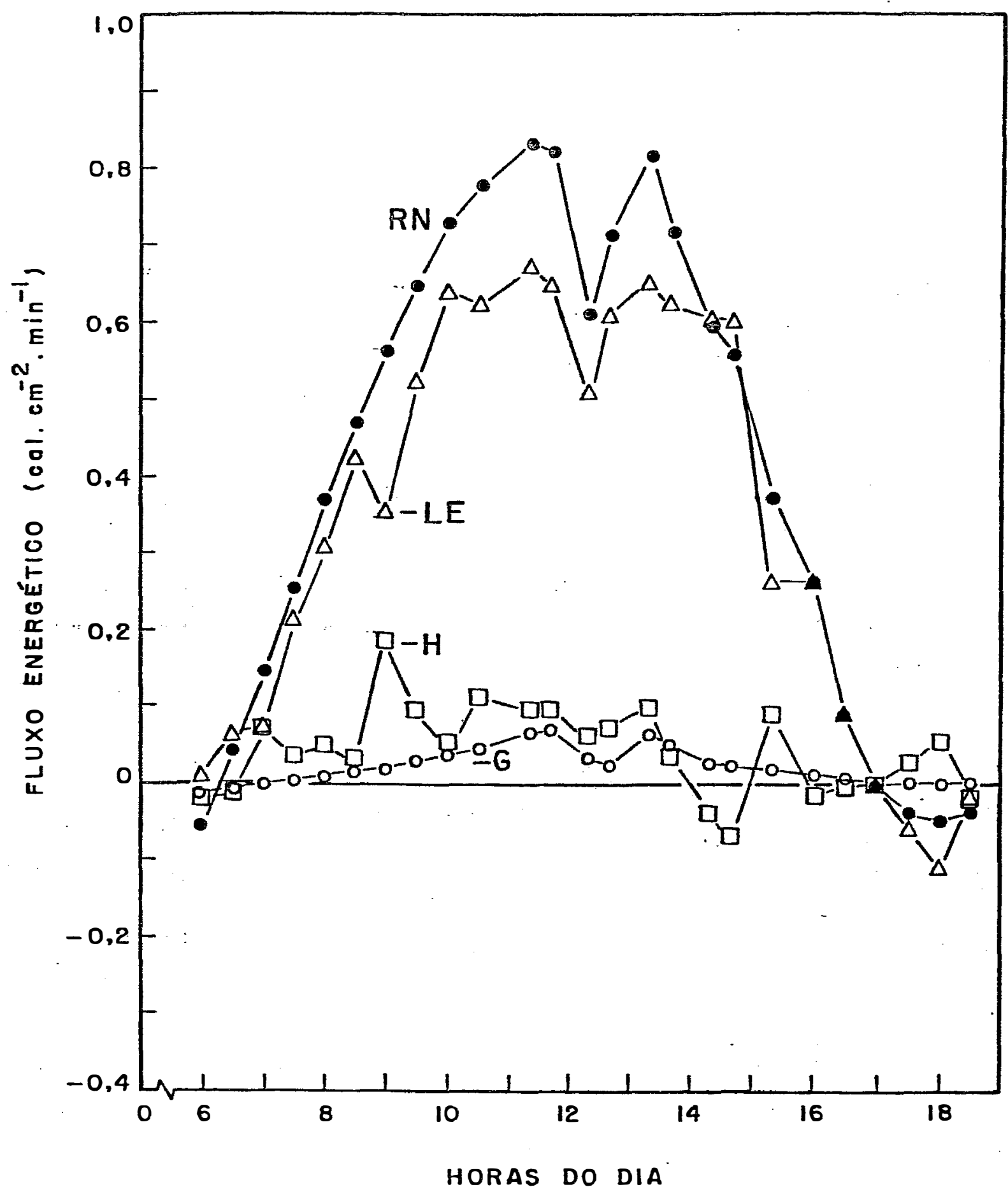

Figura 17 - Variação horária da radiação líquida (RN), do fluxo de calor no solo $(-G)$, do fluxo de calor sensivel $(-H)$ e latente (-LE) en cultura de feijão, no dia 23.9.86, no tratamento M75\%. 


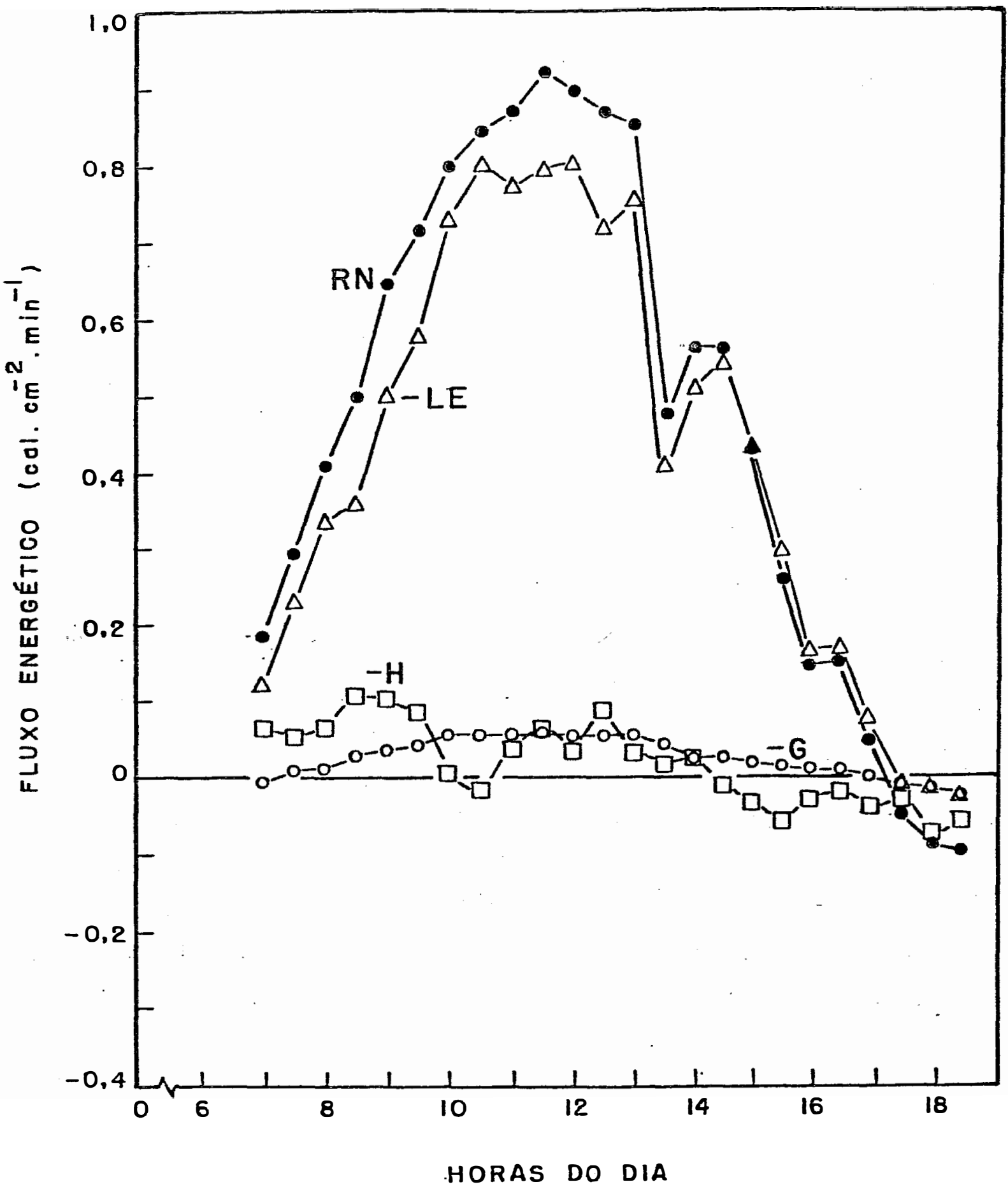

Figura 18 - Variação horária da radiação líquida (RN), do fluxo de calor no solo $(-G)$, do fluxo de calor sensivel $(-H)$ e latente (-LE) en cultura de feijão, no dia 10.10.86, no tratamento 100\%AD. 


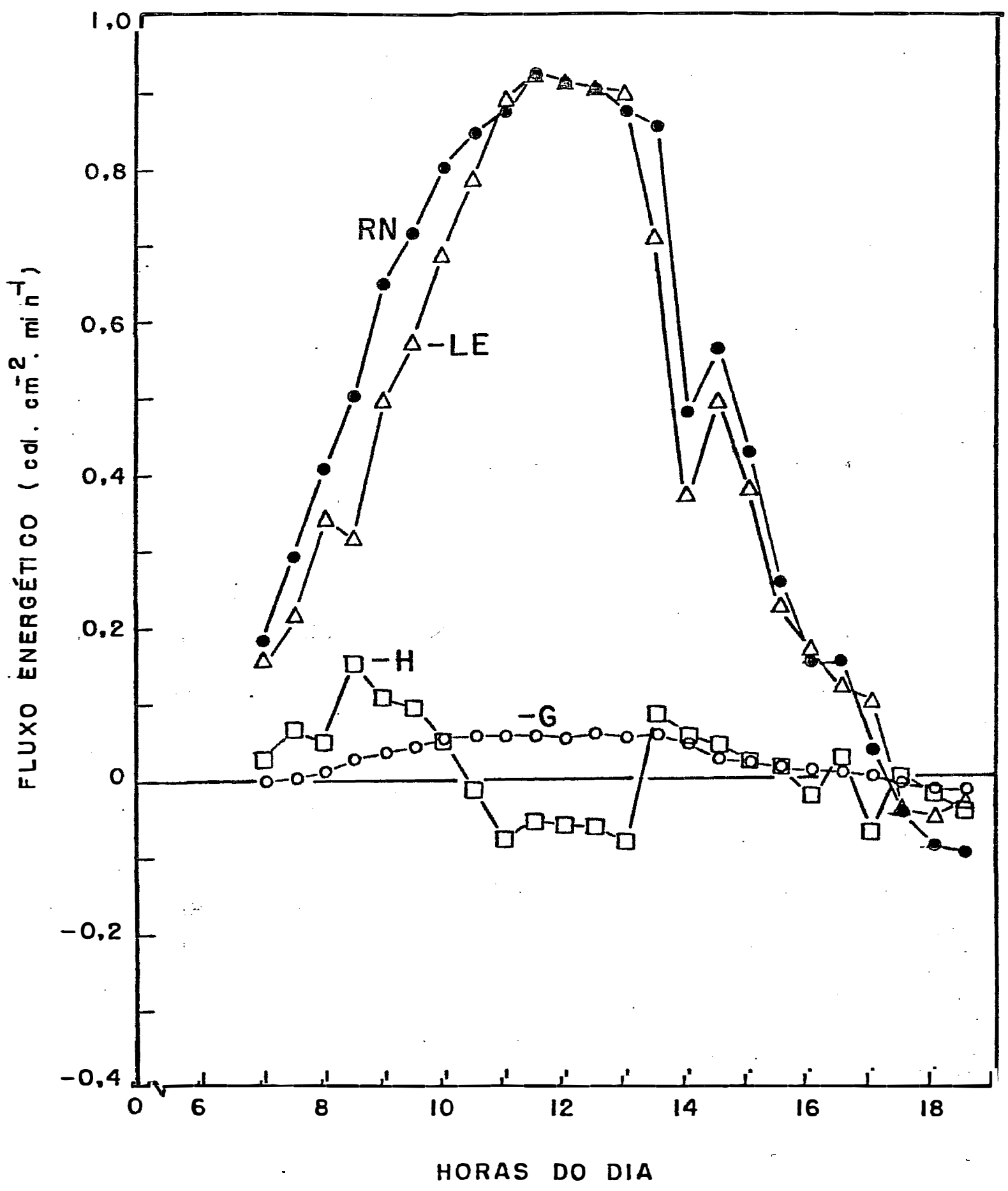

Figura 19 - Variação horária da radiação líquida (RN), do fluxo de calor no solo $(-G)$, do fluxo de calor sensivel $(-H)$ e latente (-LE) em cultura de feijão, no dia 18.10.86, no tratamento M75\%. 
4.5. Coeficiente de cultura

Os coeficientes de cultura (KC), obtidos ao longo do ciclo do feijoeiro, encontram-se na Tabela 13 . Seus valores estacionais variaram de 0,52 a 0,85 , en funGáo dos tratamentos de unidade. De fato, existe una es-.. treita correlaçáo entre os valores gerais de Kc com a porc:entagen de água disponivel $\left\langle R 2=0,88^{*}\right.$, para oito observacóes). Nesse caso, obteve-se a equacáo abaixo, bastante insensivel para analisar a contribuigáo de una única irrigacáo típica no valor do Kc estacional"

$$
K c=0,41+0,0017 . I
$$

Apesar de, no presente trabalho, náo se ter tido um tratamento sem irrigafáo, porém, essa equacáo estima um Kc médio igual a 0,41 , obtido apenas às custas da precipitacáo natural.

Os valores estacionais de Kc médio (Tabela 13) concordam com os obtidos por LUCHIARI JR. (1978) E SANTOS (1985), en Piracicaba: 0,88 e 0,73 respectivamente. No entanto, no tratamento $100 \% A D$, foi menor do que o indice 0.99, de ENCARNAC\%O (1980), obtido en evapotranspirômetro de nivel constante, também em Piracicaba, porém maior do que $0 \quad 0,7-0,8$ recomendado pela FAO (DOORENBOS \& KASSAM, 1979).

No inicio do ciclo da cultura, as freqijentes precipitacóes afetaram, certamente, a estimativa de ETr (item 4.3.4). Conseqiientemente, Kc também foi afetado, como se pode notar pelos dados acima de 1,0 , num período de pouca probabilidade de ocorrência de advecaóes. Percebense, en todos os casos, elevados valores de Kc, se comparados com os de DOORENBOS KASSAM (1979). A cultura ainda apresentava pouca área foliar e as precipitacóes pluviais contribuiram para que as perdas por evaporacáo direta da superficie do solo fossem mais significativas. Esse perío... 
do inicial de cinco semanas representou apenas $30 \%$ do to tal da ETr ocorrida no ciclo da cultura.

A partir da diferenciacăo nos niveis de apli-. cacăo da água (Figura 7), 40 DAG, os índices de Kc diversificaram-se entre os tratamentos (Tabela 13) : os máximos verificaram-se apenas após 76 DAG, posteriarmente à época em que a área foliar da cultura se estabiliza (BERGAMAS-..CHI, 1984, E SANTOS, 1985).

Entre os valores observados ao longo do ciclo (Tabela 13), os do 100\%AD aproximaram-se dos de SANTOS (1985) E dos recomendados pela FAO (DOORENBOS \& KASSAM, 1979), exceto na fase próxima da colheita. Nesse periodo final, a ocorrência de chuvas de uma irrigaçóo tardia provavelmente tenham contribuido para que os dados obtidos rossem maiores.

A diferenca nos coeficientes culurais entre os tratamentos DHN, 25\%AD E DHI, apesar de o volume de água aplicado ser semelhante, deve-se à amplitude do turno de rega (Figura 7). Assim, o estresse mais drástico eprow longado às plantas do DHI resultou em menor desenvolvimento vegetativo, maiores valores de resistência estomática ( $r_{\text {sis }}$ ) (Tabela 4) e, conseqiientemente, menor Kc.

Os resultados da Tabela 13 servem para a orientacáo da prática da irrigacấo no campo, de acordo com o histórico da cultura, visto que valores de Kc se mostraram dependentes da data das irrigacốs (Figura 7) e do estresse admissivel em cada tratamento ( Tabela 4) pelo seu Efeito na ETr (item 4.3.4. E Figura 9).

o fato de o cálculo do balango hídrico de campo englobar um periodo de quatro dias dificulta a dife-renciacăo do efeito real desses fatores ambientais e de manejo de irrigacáo no Kc. No entanto, uma análise nesse sentido foi feita com os resultados do tratamento DHI, no período de 36 a 70 DAG, e parcialmente discutido no item 4.3.4 E Figura 9, E sumarizado a seguir. 


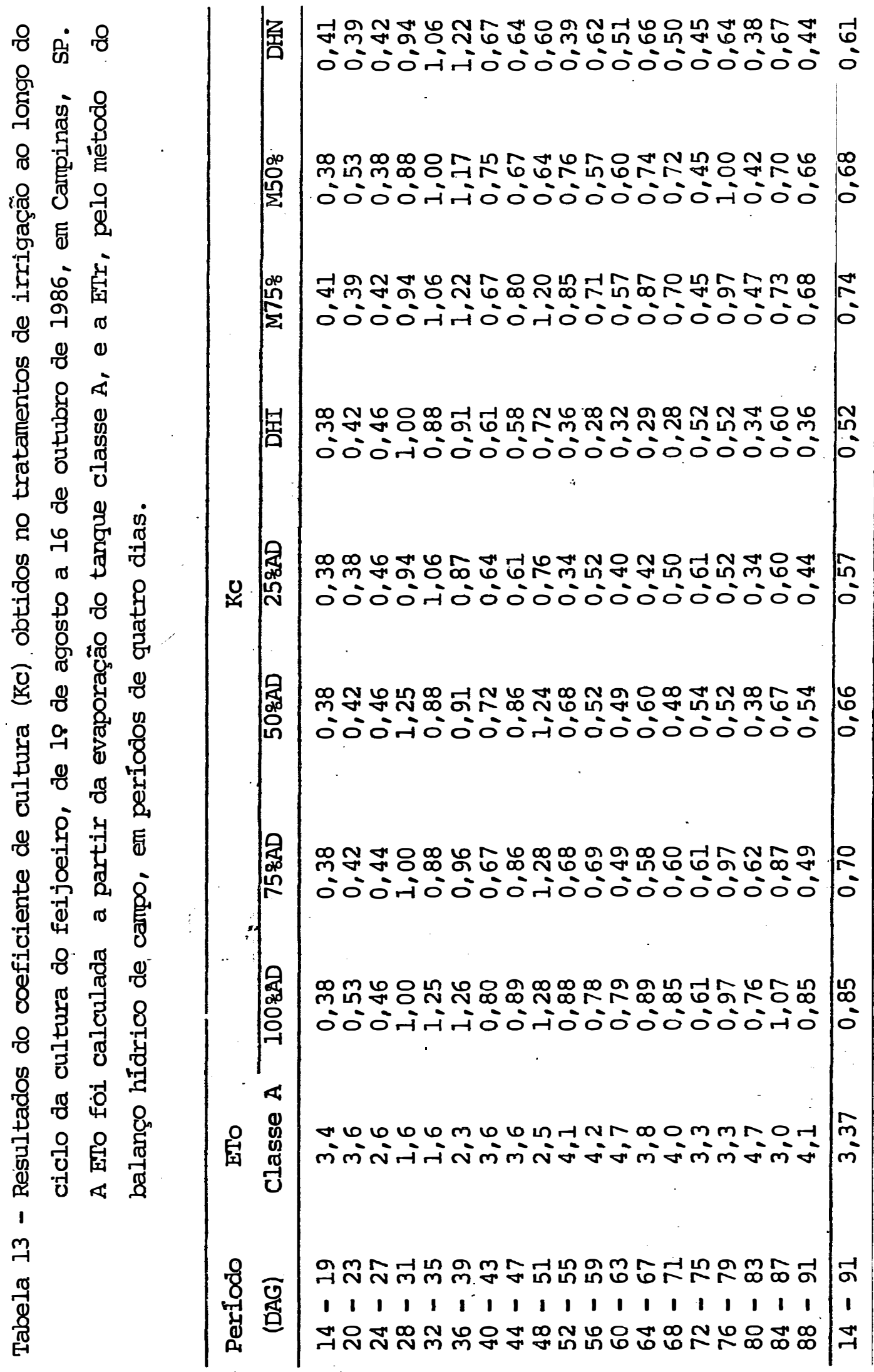


A ETr se aproxima da ETo, para valores elevados do IAF e com alta disponibilidade de água no solo (próximo a 100\%AD). Dependendo da severidade do estresse. näo há pronta recuperacåo na taxa transpiratória da cultura, E o Kc continua baixo logo após a irrigacấo. Com a im-.. posicấo de estresse hidrico prolongado, a ETr aproxima-se de un valor baixo que gradualmente se reduz ao longo do tempo, de forma quase independente do valor da ETo. Nessa situacăo de estresse acentuado. Kc apresenta-se variável fortemente dependente de ETo, visto que ETr pouco varia.

Una comparacáo entre os resultados de Kc foi feita entre os dois métodos utilizados no cálculo da ETr: balango hidrico de campo e balango de energia. A Tabela 1, apresenta essa comparacáo para seis diferentes dias durante o ciclo da cultura do feijoeiro.

Os indices de ETr determinados pelos dois métodos nấo sấo passiveis de comparacấo por se tratar de periodos de ocorrência diferentes, mas, com o cálculo de ETr/Eto, a influência do periodo deveria ser eliminada. Isso, no entainto, parece nâo ocorrer (Tabela 14), pois a correlacão encontrada entre os valores de Kc foi baixa $(0,44)$.

Un exemplo do efeito da duracấo do periodo, associado a outros fatores, pode ser visto na análise do dia 56 (Tabela 14). A determinacấo no 100\%AD ocorreu logo após a irrigacấo combinada a condicốes de adveçấo no periodo da tarde (Figura 12), resultando en Kc maior que 1, 0 . Por outro lado, o balango hidrico de campo considerou - período 56-59 DAG (um a cinco dias após a irrigacấo) suficientemente longo para mostrar diferencas na abertura estomática (Tabela 4) e reducâo na ETr, visto nấo ter ocorrido aplicacấo de água (Figura 7 ). 
Tabela 14. Comparąâo entre coeficientes de cultura (KC) calculados pelo método do balanco hidrico de campo (B.H.), em períodos de quatro dias, $E$ pe-.lo método do balanco de energia ( $\left.B_{0} E_{n}\right)$ ao curso do dia indicado, em seis diferentes épocas e em três tratamentos de irrigacấo do feijoeiro. ETo: Evapotranspiracấo de referência, calculada pelo tanque classe $A-C . A$ (média de quatro dias), E por Penman no dia indicado.

ETO $100 \% \mathrm{AD}$ M75\%

DHT.

DAC
C. A* Penman
B.H.* B.E.
B. H.* B.E.
B.H.* B.E.

$--m m / d i a---$

\begin{tabular}{|c|c|c|c|c|c|c|c|}
\hline 3,6 & 5,8 & 0.80 & 0,62 & 0.67 & $0,50$. & 0,61 & 0.60 \\
\hline 4,1 & 5,5 & 0.88 & 0.76 & 0,85 & 0.62 & 0,36 & \\
\hline 4,2 & 4,5 & 0.78 & 1.07 & 0,71 & 0.73 & 0,28 & \\
\hline 4,7 & 4,9 & 0.79 & 0,76 & 0.57 & 0.67 & 0.32 & \\
\hline 4,0 & 5.0 & 0,85 & 0.96 & 0,70 & 0.94 & 0,28 & \\
\hline 3,3 & 5,3 & 0.97 & 0.98 & 0.97 & 1,00 & 0,52 & $\gamma$ \\
\hline
\end{tabular}

(*) Média de quatro dias consecutivos.

Outro elemento importante na comparacão entre os métodos de determinacấo de Kc refere-se à forma de cál-culo da Evapotranspiracấo de referencia. Os dados de ETo calculados por Penman, usados no balanco de energia, não sấ comparáveis aos valores médios de ETo calculados para quatro dias a partir da evaporacấo do tanque classe $A$. usado no balanco hidrico de campo. Assim, também nấo produziram resultados consistentes os indices diarios de ETo por Penman e pelo tanque nos seis dias de análise $(\theta, 46)$. 
Verificaram-se resultados consistentes de KC quando as condicóes do dia e do período eram similares. Por exemplo, 076 DAG $e$ o periodo 76-79 DAG caracteriza-.. ram-se por ser úmidos e nâo apresentar restricấo de água em todos os tratamentos: nesse periodo, nấo houve recupe-... racấo total da taxa de transpiragáo no tratamento DHI, conforme discutido no item 4.3.4. (Figura 9).

Os dados de ETr e Kc pelo balanco de energia nâo foram apresentados no tratamento DHI para aqueles dias de restricấo hidrica acentuada. Os resultados obtidos nesses casos apresentaram indices elevados da razáo de Bowen : muitas vezes, discrepantes. PEDRO JR. (1977) também nâo obteve sucesso com o balango de energia, em condicóes $5 i-$ milares, na cultura de soja, em Campinas.

\subsection{Producâo final}

\subsubsection{Beneficio da irrigaçóo e uso da água}

Na Tabela 15, encontram-se os resultados de producăo final de gräos obtidos com os tratamentos de ir-rigacăo. A producăo das parcelas variou de $1.287 \mathrm{~kg}^{-h a^{-1} \text {, }}$ para o tratamento que recebeu menos água (DHI), até 2.145 kg.hat, para o mais favorável-(M75\%). A produtividade normal, dependendo das condicốs ambientes e do sistema de

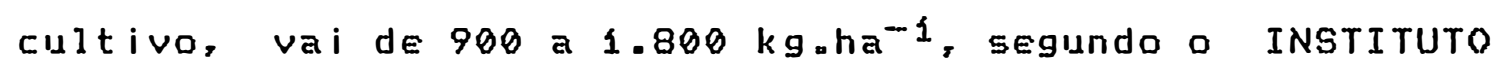
AGRONômICO (1987). Portanto, a produtividade do presente estudo pode ser considerada acima da média e satisfatória em termos de irrigacấo por aspersấ, segundo BULISANI (1.987).

A Tabela 15 indica que houve dois niveis de produtividade no ensaio, como resultado do efeito da cobertura plastica protetora contra a precipitacáo. A comparacấo entre os tratamentos 75 e $50 \% A D$ com $M 75$ e $M 50 \%$ 
indica serem os líltimos cerca de $15 \%$ mais produtivos. Prom vavelmente, a cobertura plástica tenha reduzido a radiacáo fotossinteticamente ativa nas parcelas cobertas durante grande parte do ciclo da cultura.

Considerando que os tratamentos de irrigacáo Ge iniciaram somente a partir do florescimento, vê-se, pela Tabela 15, que praticamente nâo existem diferencas na producăo para intervalos entre irrigacóes menores do que nove dias. Por outro lado, as irrigacóes freqientes aumentaram consideravelmente o consumo de água $<F i g u r a ~ 20$ e Tabelas 5 a $12 \in 15)$, sem aumento proporcional na producáo de gräos, acima de $50 \%$ de disponibilidade de água no 5010.

Tabela 15 - Valores acumulados de irrigacấ, intervalo médio entre irrigacöes, producấo final de grấos E Eficiência no $u s 0$ da água (EUA), em funcấo dos tratamentos de irrigacáo na cultura do feijoeiro, em Campinas, SP.

Tratamento Irrigacão Intervalo Produgão EUA

\begin{tabular}{ccccc} 
& $\mathrm{mm}$ & dia & $\mathrm{kg} / \mathrm{ha}$ & $\mathrm{kg} / \mathrm{mm} / \mathrm{ha}$ \\
$1.00 \% A D$ & 270 & 10 & 1.882 & 6.97 \\
$75 \% A D$ & 170 & 6 & 1.874 & 11.02 \\
$50 \% A D$ & 120 & 9 & 1.781 & 14,84 \\
$25 \% A D$ & 100 & 12 & 1.540 & 15.40 \\
$D H I$ & 100 & 18 & 1.287 & 12.87 \\
$M 75 \%$ & 185 & 5 & 2.145 & 11.59 \\
$M 50 \%$ & 130 & 7 & 2.041 & 15.70 \\
$D H N$ & 125 & 10 & 1.893 & 15.15 \\
\hline
\end{tabular}




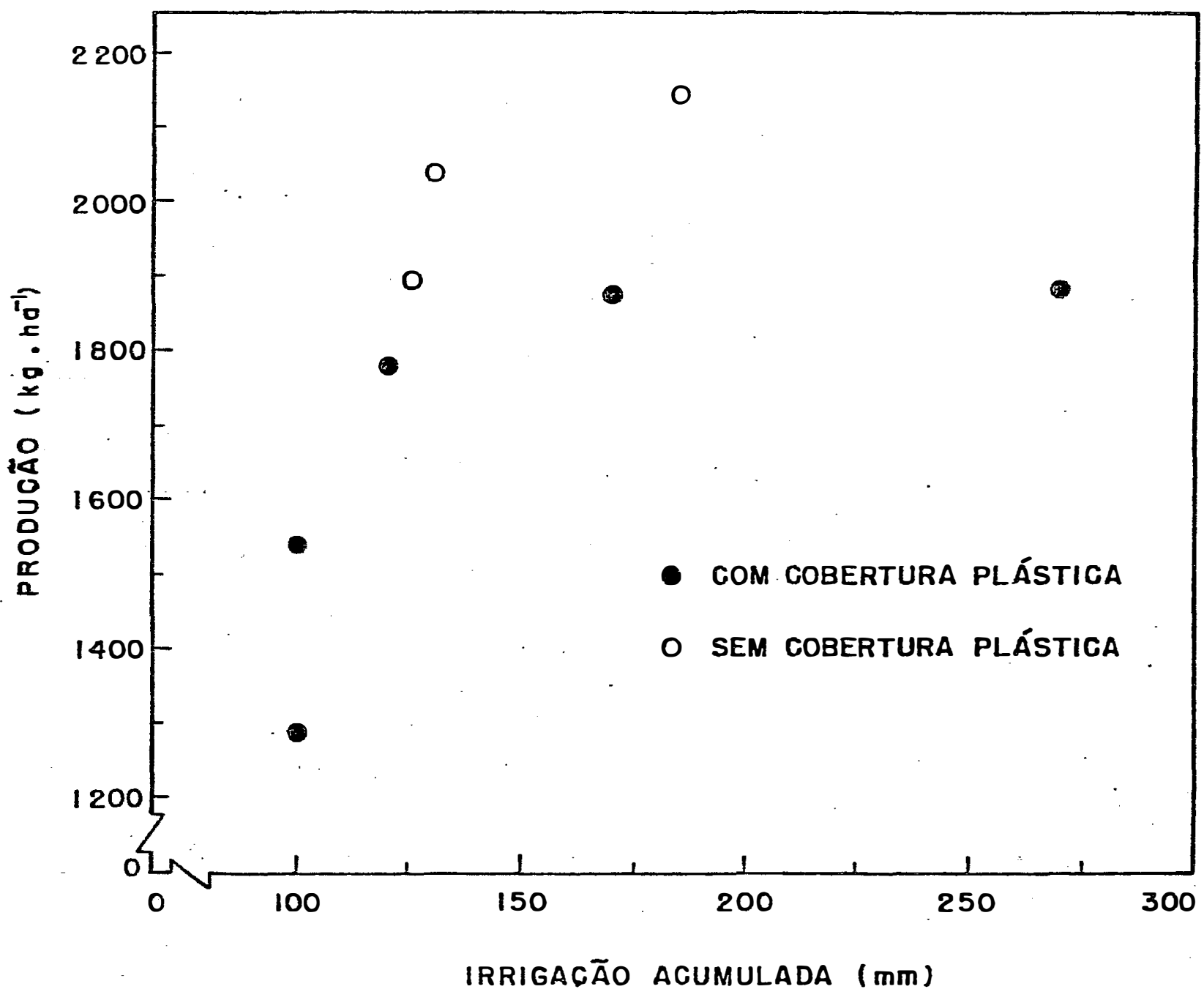

Figura 20 - Produção de grãos do feijoeiro em função da irrigaçãa acumulada nos tratamentos de irrigação. 
HALTERLEIN ( 983 ), revendo a literatura sobre irrigacăo do feijoeiro, encontrou as maiores producóes quando a disponibilidade de źgua no solo foi mantida a $50 \%$ Esse resultado é semelhante ao obtido no presente experimento, visto que as producöes entre os tratamentos 100, 75 e 50\%AD nåo diferiram significativamente. Para manter essa disponibilidade hidrica a $50 \%$, KATTAN \& FLEMING (1956) afirmam que é necessário uma aplicacấ semanal de $25 \mathrm{~mm}$ de água, da germinacấo ao inicio do florescimen-to, ede $38 \mathrm{~mm}$ do florescimento à colheita. Para Kriegbaum (citado por SALTER \& GOODE, 1967), en condicóes de solo com grande armazenamento de água, a irrigacâo aplicada dez dias antes a dez dias após o florescimento resulta em máxima producâo, pelo aumento no mímero de vagens e de sementes por legume.

Nas condicöes deste ensaio, a melhor conversäo no $u s 0$ da água, nos tratamentos cobertos, foi alcancada no $25 \% A D$, seguido do 50\%AD. A cobertura plástica afetou a Eficiência do uso da água, tornando-a um pouco menor quan.. do comparada ao descoberto. A eficiência do uso da água é um critério de selecăo de manejo deve ser adotado na situacấ de limitacấo de recurso hidrico, quando se deseja maximizar a producấo de grâos por unidade de água aplicada (BERNARDO, 1987).

As irrigacốes mais freqijentes do $100 \% A D$ aumentaram a taxa de drenagem. A lixiviacăo ocorrida, porém, parece nấo ter afetado nutricialmente nenhum dos tratamentos, conforme a análise foliar aos 67 DAG $e$ o aspecto das plantas até o final do ciclo. Apenas o tratamento DHI revelou alguma reducấo nos teores de $N, P, K \in$ Mg, provavelmente pelo secamento da camada fértil do solo (BATAGLIA, 1980). 
- longo periodo de déficit hidrico imposto no DHI, dos 36 aos 62 DAG, afetous significativamente sua producâo. Quando esse periodo de estresse foi reduzido ì metade no $25 \% A D$, a producấo aumentou en $20 \%$ sem uso adicional de água; no $25 \% A D$, en vez da lâmina de $70 \mathrm{~mm}$ aos 62 DAG, necessairia para repor a umidade à capacidade de campo no DHI, ela foi subdividida en duas aplicacóes de 40 E $30 \mathrm{~mm}$, respectivamente, aos 50 e $62 \mathrm{DAG}$.

4.6.2. Relacâo entre a producâo e a evapotranspi-racăo

A relacâo entre a producâo de grấos e a evapotranspiracão real acumulada nos tratamentos de irrigacăo do feijoeiro - Figura 21 - revela dois tipos de comportamento en funcâo da cobertura plastica: enquanto os descobertos apresentaram valores de producâo maior e linearmente relacionados com a ETr, os cobertos aproximaram-se de uma funcấo assintótica.

Vários autores encontraram uma relacäo linear entre a fitomassa produzida e a água transpirada CWIT. 1958; ARKLEY, 1963). Quando a producâo de grãos $e$ a evapotranspiracăo real săo proporcionais, respectivamente, à fitomassa e à transpiracăo, esses elementos também se relacionam linearmente entre si (WIT, 1958; DOWNEY, 1972). No presente trabalho, observou-se uma relacăo próxima da linear entre a producắo de grăos e a ETr acumulada para os tratamentos até $75 \%$ de disponibilidade de água, com ousem cobertura plástica. A ETr acima de $174 \mathrm{~mm}$, promovida pelas irrigacóes frequientes após o florescimento, nấo reverteu en acréscimo na producâo de grấos. 


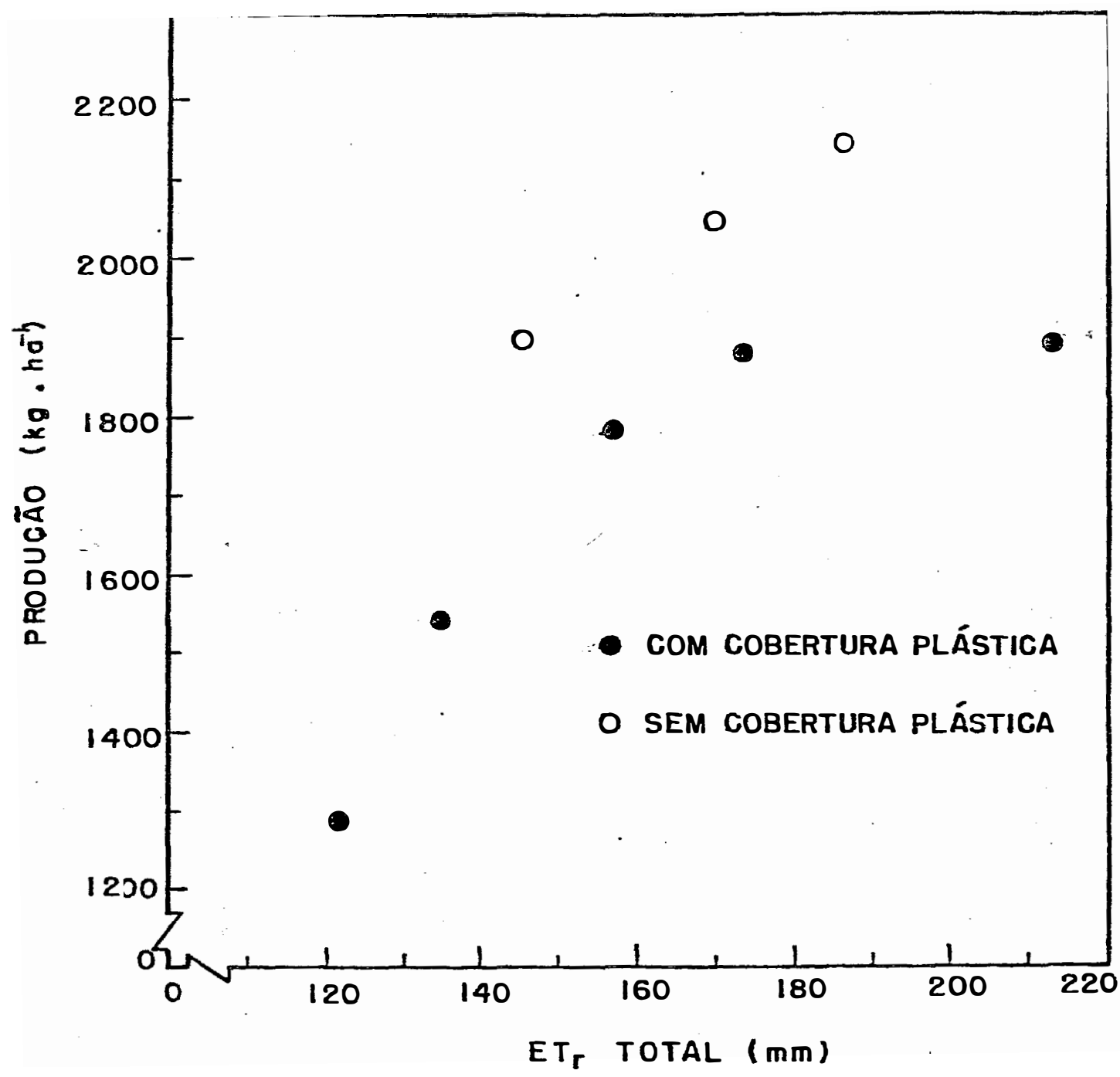

Figura 21 - Produção de grãos do feijoeiro em função da evapoträanspiração (ETr) acumulada nos tratamentos de irrigação: 
As irrigacóes freqientes se deram principalmente quando a cobertura do solo era completa, reduzindo, portanto, a diferenca entre a ETr e a transpiracấo, por minimizar a evaporacấo direta do solo. Assim, a explicaGấo para a perda de linearidade entre a producáo e a ETr nấo parece ser devida ̀̀s diferencas entre transpiracấo $E$ evapotranspiracấ, mas a duas outras possibilidades. A primeira, ao efeito da cobertura plástica no decréscimo da radiacâo fotossinteticamente ativa, promovendo queda na produtividade vegetal. A segunda refere-se a que um aumento na fitomassa total pelo incremento da ETr ino 1.00\%AD) possivelmente nâo tenha correspondido a um proporcional aumento na producấo de grấos. Houve, provavelmente, variacấo no valor do indice de colheita entre os tratamentos, com reducấo para o irrigado freqijentemente. Ou-.tro fator associado k̀ reducấo da producấo de grấos é que o $100 \%$ AD teve o seu ciclo alongado, processando-se a colheita com as plantas ainda verdes.

A imposicấo dos tratamentos pela suspensấo das chuvas após 36 DAG parece ter sido cedo o suficiente para afetar o número de estruturas reprodutivas por planta. Na Figura ae observa-se uma clara limitacáo da producấo em funcấo do número de vagens por planta (e por área), nas parcelas com cobertura plástica. Os tratamentos de disponibilidade de água afetaram visivelmente o porte das plantas, reduzindo-lhes o numero de ramificacốes das hastes onde se desenvolvem as estruturas reprodutivas. o efeito do estresse hidrico antes do florescimento, afetando o numero de flores e vagens do feijoeiro, foi relatado na literatura, entre muitos, por ROBINS \& DOMINGO (1956), MAGAL.HÄES \& MILLAR (1978) E BULISANI (1987). RAGGI et aili (1977), trabalhando com déficit hidrico em diferentes époc:as no ciclo dessa planta, observaram reducăo na producăo em qualquer fase, mesmo que o suprimento de água fosse adequado nos outros periodos. 


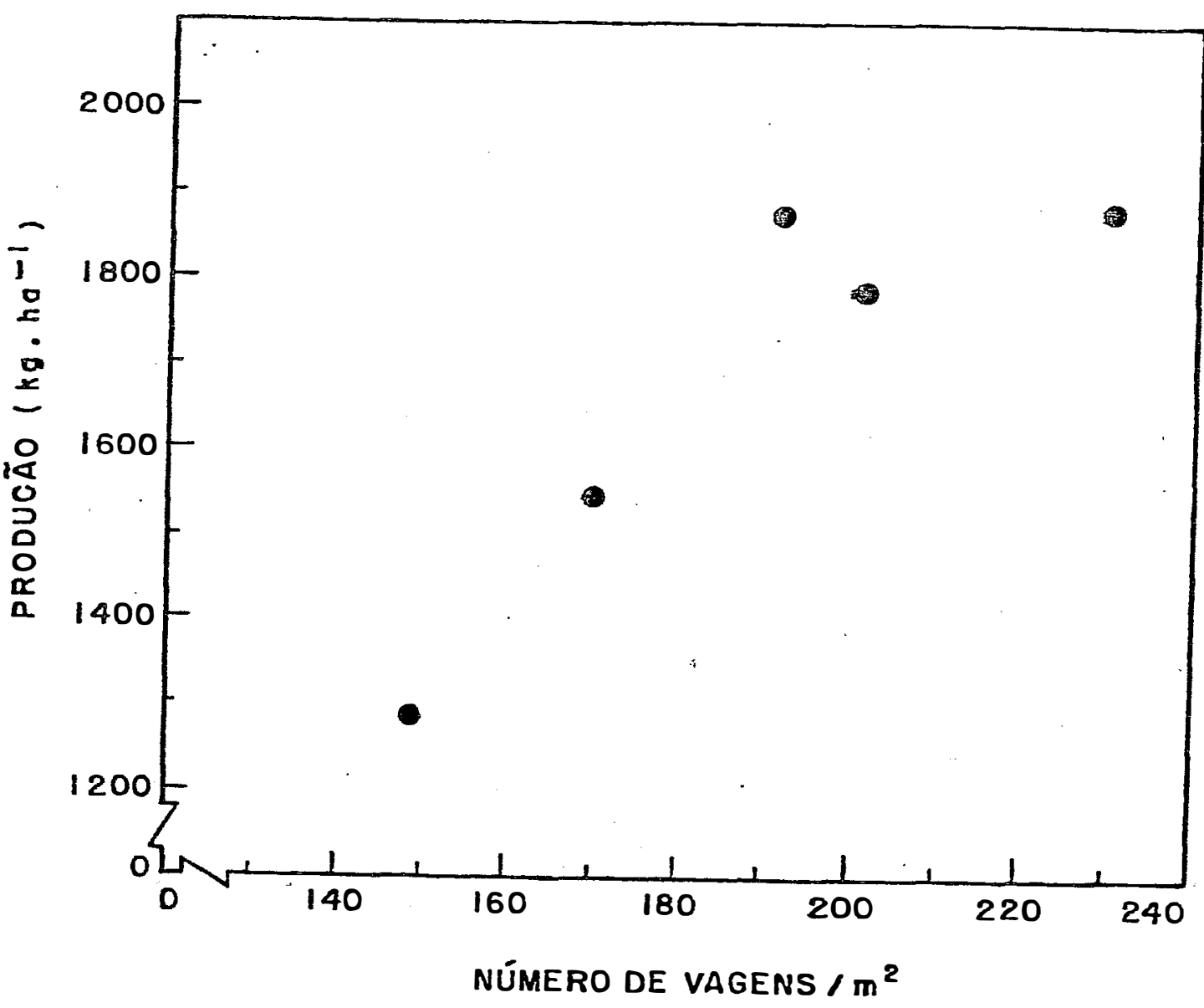

Figura 22 - Relação entre a produção de grãos do feijoeiro e o número de vagens por área obtida nos tratamentos de irrigação - DHI e de 25 a 100\%AD.

Existe similaridade nas relacótes entre a proclucâo de grãos en funcấo da irrigacăo acumulada e da $\mathrm{ETr}$ acumilada - Figura 21. De fato, a ETr e a irrigacáo estáo linearmente relacionadas $\left(R^{2}=0,87 * *\right)$, pois o manejo das irrigacöes visou à reposicăo da água evapotranspirada do solo (ARRUDA, 1987). O déficit hidrico imposto, o uso da cobertura plástica e a ocorrência de precipitacẫo no inicio e no final do ciclo produziram discrepancias entre os resultados das figuras 20 e 21 e a linearidade entre ETr e a aplicacâo de água, especialmente nas baixas producốcs. 


\section{CONCLUSÖES}

A drenagem profunda representou uma fracáo importante no balanco hidrico e deve ser levada en conside-racăo no cálculo do momento de irrigacáo, mesmo para os niveis de secamento mais acentuados"

o feijoeiro mostrou recuperacão total na abertura estomática após estresse hidrico, porém nấo houve pronta recuperacăo na taxa de transpiracăo quando o estresse foi severo:

- consumo total de água pela cultura mostrouse linearmente relacionado à porcentagen de água disponi.-. vel e à lânina total de irrigaçăo.

Em condicốs de alta umidade do solo, o coeficiente de cultura (KC) foi máximo e relacionado ao desenvolvimento da cultura. Sob estresse moderado,o Kc foi afetado pela resistência estomática e pela demanda evaporativa $e$, sob estresse severo, principalmente en funcấo da evapotranspiracấo de referência, visto que a evapotranspiracáo real variou sistematicamente de 2,2 a 1,2 mm.dia-1. independente da demanda evaporativa.

O efeito da adveckấo no aumento da evapotranspiracáo real foi de até $10 \%$, e observado apenas alguns dias durante o ensaio. A razáo entre a evapotranspiragăo e a radiacăo (-LE/RN) variou de 0.67 a 0.93 .

Resultados similares de Kc foram obtidos pelos dois métodos - balanco de energia e hidrico de campo apenas quando foram considerados os seguintes aspectos: 
a) existem diferencas resultantes da duracáo do periodo de cálculo de cada método e fatores a ele associados, como a adveção:

b) as condicốs de disponibilidade hidrica nos períodos deven ser similares"

c) a taxa transpiratória após a aplicacão de água depende do grau de estresse anterior e do desenvolvimento da cul-tura: $e$

d) há diferencas entre as estimativas da evapotranspiracáo de referencia, por diferentes métodos de cálculo.

A conversão da água aplicada em producấo va-

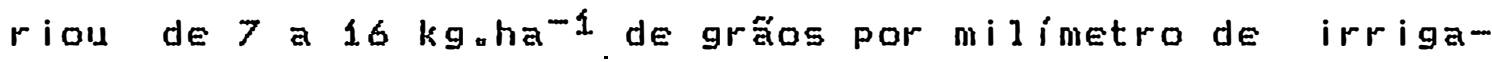
Gão, E para valores estacionais de Kc E ETr, de 0,52 a 0,85 e 121 a $213 \mathrm{~mm}$ respectivamente.

A relacáo entre a producão de grãos e a evapotranspiracão real não foi tipicamente linear, mas assintótica.

A producâo do feijoeiro não aumentou significativamente para intervalos médios de irrigacóes menores do que nove dias, ou para a manutengấo da disponibilidade da água no solo acima de $50 \%$.

As irrigacốs de alta freqiiencia iniciadas a partir do florescimento não aumentaram a producấo da cultura, pela limitacáo no número de vagens por área estabelecido no periodo de pré-florescimento, mas elevaram o consumo de água $P \in l a$ cultura. 
REFERÊNCIAS BIBLIOGRAFICAS

AMORIM NETO, M. da S. \& UILLA NOUA, N.A. Novo sistema de medidas de evaporacăo para o tanque classe "A". Pesq. agropec. bras., Brasilia, 18(7):695-702, 1983.

ARKLEY, R.J. Relationships between plant growth and transpiration. Hilgardia, Berkeley, 34:559-584, 1963.

ARRUDA, F.B. Uso da água na producấo agricola. Ina SIMPósIO SOBRE O MANEJO DE AGUA NA AGRICULTURA, 1., Campi-nas, 1987. Anais, Ed. por G.P. Viégas. Campinas, Funcląấo Cargil1, 1987. P.177-199.

BASCUR, G.; OLIUA, M.A.; LAING, D.R. Termometria infrar-roja en selección de genótipos de frijol (Phaseolus vulgaris L.) resistentes a sequia. II. Crescimiento y productividad. Turrialba, 35(1):49-53, 1985.

BATAGLIA, O.C. Effects of nitrogen-water relations on maize productivity. Davis, 1980. 182P. (Ph.D. - Uni-versity of California)

BEGG, J.E \& TURNER, N.C. Crop water deficits. Advances in Agronomy, New York, 28:161-217, 1976. 
BELCHER, D.j.; CUYKENDALL, T.R; SACK, H.S. The measurenent of soil moisture and density by neutron and gammaray scattering. Washington,DC, Civil Aeronautical Adm. Sech Div. Rept. 127, DC, 1950.

BERGAmaschI, H. Perda de água e desenvolvimento do fei-. joeiro (Phaseolus vulgaris $L_{\text {. }}$ ) sob diferentes condiGôes de disponibilidade hidrica no solo e da atmosfera. Piracicaba, 1984. 204P. (Doutorado - Escola Superior de Agricultura "Luiz de Queiroz"/USP)

BERNARDO, S. Manual de irrigacâo. Vigosa, Imprensa Uni... versitária da Universidade Federal de Vicosa, 1987. $463 p$.

BERNARDO, S.; GALUÃO, J.D.; GUERINI, H.; CARUALHO, J.B. Efeito de niveis de água no solo sobre a producấo do feijoeiro. Seiva, Viqosa, 30:7-13, 1970.

BIDINGER, F.R. Water stress effects on crop environment interactions. In: INTERNATIONAL CROP RESEARCH INSTITUTE FOR SEMI-ARID TROPICS, Hyderabad, India, 1978. Proceedings of the International Workshop on the research needs of semi-arid tropics. Hyderabad, India, 1978. P.147-153.

BLACK, C.A. Crop yield in relation to water supply and soil fertility. In: PIERRE, W.R.; KIRKHAM, D.; PESEK, J.; SHAW, R. Plant environment and efficient water use. 4.ed. Wisconsin, Anerican Society of Agronomy and Soil Science Society of Anerica, 1981. cap 9 , P.177-205. 
BOWEN, I.S. The ratio of heat losses by conduction and by evaporation from any water surface. Phys. Rev. Ithaca, $27: 779-787: 1926:$

BRUNINI, 0. Relacấo entre o potencial da água no solo e nas folhas e a transpiracáo en mudas de cafeeiro. In: CONGRESSO BRASILEIRO DE AGROMETEOROLOGIA, 2., PElotas. Pelotas, Sociedade Brasileira de Agrometeorologia/ UFPEL, 1981. P.125-129.

BULISANI, E.A. Feijão: fatores de producấo e qualidade. Campinas, Fundacấo Cargil1, 1987. 326 P.

BULISANI, E.A. \& ROSTON, A.J. FEijão Carioca 80. Campi-nas, Coordenadoria de Assistência Técnica Integral, 1987. 6P. (Comunicado técnico, 70)

BURMAN, R.D. \& BOLMONT, D.W. Evaluating the growth rate of great Northern beans as influenced by soil moisture level under green house conditions. Agron. J.. Madison, $53: 354-355,1961$.

CAIXETA, T.J.; PURCINO, J.R.C.; SILUA, L. IrrigaGão de algumas culturas. Inf. agropec., $9(100): 65-76,1983$.

CHING CHOY, E.W. \& KANEMASU, E.T. EnErgy balance comparisons of wide and narrow row spacings in sorghum. Agron. J., Madison, 66:98-100, 1974 .

COSTA, A.C.S. Balango hidrico en culturas de feijão e de mitho sob condicóes de campo. Piracicaba, 1986. 166p. (Mestrado - Escola Superior de Agricultura "Luiz de Queiroz"/USP) 
COWAN, InR. \& MILTHORPE, F.L. Plants factors influencing the water status of plant tissues. In: KOZ̈LOWSKI, T.T., ed. Water deficits and plant grown. New York, Acadenic Press, 1968. V.1, P.137-193.

DAKER, A. A água na agricultura. In: Irrigacåo edrenagem. Rio de Janeiro, Livraria Freitas Bastos, 1984. V.3, 43 . .

DANG, JuH. Comparison of field and laboratory determined by hydraulic conductivity values. Soil Sci. Soc. Am. J., Madison, 44:228-231, 1980.

DOORENBOS, J. \& KASSAM, A.H. Yield response to water. Roma, FAO, 1979. 193P. (FAO Irrigation and Drainage paper, 33)

DOORENBOS, J. \& PRUITT, W. 0. Crop water requirements. Roma, FAO, 1977. 180P. (FAO Irrigation and Drainage paper, 24)

DOWNEY, L.A. Water-yield relations for nonforage crops. Journal of the Irrigation and Drainage Division, ASCE, $98: 107-115,1972$.

ENCARNAGÃo, C.R.F. Estudo da demanda de água do feijoeiro (Phaseolus vulgaris L.) var. Goiano precoce. Piracicaba, 1980. G2p. (Mestrado - Escola Superior de Agricultura "Luiz de Queiróz"/USP)

GARDNER, WaR. Dynamic aspects of water availability to plants. Soil Science, Baltimore, 89:63-73, 1960. 
GARDNER, WaR. Water content. In: BLACK, C.A. Methods of soil analysis. Madison, Amer. Soc. Agron.,. 1965. P.87-127. (ASA Monograph series, Agronomy, 9)

GARDNER, W.R. \& NIEMANN, R.H. Lower 1 imit of water availability to plants. Science, Washington, 143:1460-.. 1462,1964 .

GATES, D.M. Biophysical ecology. New York, Springer-Verlag 1980. $611 \mathrm{P}$.

GIRALT, P.E. Regimen de riego del cultivo de frijol negro (Phaseolus vulgaris L.). Ciencia y técnica en la agricultura, Série Riego y Drenage, $2(1): 5-28,1979$.

GUIMARÄES, C.M.; STEINMETZ, S.; PORTES CASTRO, A.T. USO de microlisimetros na determinacâo. da evapotranspiracâo. do feijoeiro da seca. In: REUNIÄO NACIONAL DE PESQUISA DE FEIJđ̛o, 1, Goiânia, 1982. Anais. Goiânia, CNPAF, 1982. P. 133-137.

HAGAN, R.M.; HAISE, H.R.; EDMINSTER, T.W. Irrigation of agricultural lands. Madison, American Society of Agronony, 1967. 1180p. (ASA monograph series, Agronomy, 11)

HALTERLEIN, A.J. Bean. In: TEARE, I.D.; PEET, M.M. Crop water relations. New York, John Wiley \& Sons, 1983. P. $157-186$.

HANKS, R.u.; ALLEN, L.H.; GARDNER, H.R. Advection and evapotranspiration of wide row sorghum in Central Great Plains. Agron. J., Madison, 63:520-527, 1971. 
HILLEL, D. Fundamentals of soil physics. New York, Aca-demic Press, 1980. 413. P.

HILLEL, D. Soil and water. Physical principles and processes. New York, Academic Press, 1971. 288p.

HILLEL, D.; KRENTOS, U.D. STYLIANOU, Y. Procedure and test of an internal drainage method for measuring soil hydraulic conductivity in situ. Soil Sci. Soc. Am. Proc., Madison, 114:395-400, 1972.

HORNER, G.M. \& MOJTEHERI, N. Yield of grain legumes as affected by irrigation and fertilizer regimes. Agron. J. Madison, 62:449-450, 1970 .

HSIAO, T.C. Plant responses to water stress. Ann. ReV. Plant Phisiol., Washington, 24:519-570, 1973.

HSIAO, T.C. \& ACEVEDO, E. Plant responses to water deficits, water use efficiency and drought resistance. Agric. Meteorol.. Amsterdam, 14:59-84, 1974.

HSIAO, T.C.; O'TOOLE, J.C.; TOOMAR, U.S. Water stress as a constraint to crop production in the tropics. Trab. apresentado na conferência: Priorities for alleviating soil-related constraints to food productins in the tropics. Los Baños (Philippines), IRRI, 4 a 8 de junho de 1979.

INFORZATO, R. \& MIYASAKA, S. Sistema radicular do feijoeiro en dois solos do Estado de Sấo Paulo. Bragan$t i a$, Campinas, $22(2): 477-482,1963$. 
INSTITUTO AGRONôMICO. Instrucỗes agrícolas para o Estado de São Paulo. Campinas, 1987. 231p. (Boletin 200)

JARUIS, PaG. Water transfer in plants. In: DE URIES, D.An, ed. Heat and mass transfer in the environment of vegetation. Washington, Seripta, 1975. P.369-394.

JARUIS, P.G. The interpretation of the varieties in leaf water potential and stomatal conductance found in canopies in the field. Phil. Trans. R. Soc. Lon, $273: 593-610,1976$.

JENSEN, C.R. Influence of water and salt stress on water relationships and carbon dioxide exchange of top and roots in beans. New Phytol., Oxford, 87:285-295, 1981.

JONES, H.G. \& HIGGS, K.H. Resistance to water loss from the mesophyll cell surface in plant leaves. J. Exper. Bot., Oxford, 31(121):543-553, 1980.

JONES, J.W.; ZUR, B.; BOOTE, K.J.; HAMMOND, L.C. Plant resistance to water flow in field soybeans. I. Non-limiting soil moisture. Agron. J., Madison, 74:92-105, 1982.

KANEMASU, E.T. \& TANNER,C.B. Stomatal diffusion resistance of snap beans. I. Influence of leaf water potential. Plant Physiol., Washington, 44:1547-1552, 1969.

KATTAN, A.A. \& FLEMING, J.W. Effect of irrigation at specific stages of development on yield, quality, growth and composition of snap beans. Proc. Soc. Hort. Sci., $68: 328-342,1956$, 
KAUFMANN, MaR. Water transport through plants, currents perspectives. In: WARDLAW, I.F. \& PASSIOURA, JaB., Ed. Transport and transfer processes in plants. New York Academic Press, 1976. 484p.

KAUFMANN, M.R. \& HALL, A.E. Plant water balance - its relationships to atmospheric and edaphic conditions. Agric. meteorol., Ansterdam, 14:85-98, 1974.

KRETCHMER, P.Ja; LAING, D.R.; ZULUAGA, S. Uso del termometro infrarrojo para la selección por tolerancia a sequia en Phaseolus vilgaris L. Cali (Colombia), CIAT, 1980. 10p.

LAMBERTH, U.N. Some factors influencing pod set and yield of 1 ima beans. Columbia, University of Missouri, 1950 . 66p. (Research bulletin, 466)

LIBARDI, P.L.; REICHARDT, K.; NIELSEN, D.R.; BIGGAR, J.W. Simple field methods for estimating soil hydraulic conductivity. Soil Sci. Soc. Am. J., Madison, 44:3-7, 1980 .

LOURENCE, F.J.; PRUITT, W.O.; SERUIS, A. I. Energy balance and the crop water requirements of rice grown in California. Davis, 1970. 44p. (Water Science \& Engineering Papers, 9002)

LUCHIARI JUNIOR, A. Determinagăo do coeficiente de cultura (KC) para feijão (Phaseolus vulgaris L. ) pelo método do balanco hidrico. Piracicaba, 1978. 59p. (Mestrado -.Escola Superior de Agricultura "Luiz de Queiroz"/USP) 
LUCHIARI JUNIOR, A. Measurements and prediction of evapo-.transpiration rates from irrigated wheat in the cerrado region of Central Brasil. Ithaca, New York, 1988. 171p. (Ph.D. - Cornell University)

MCMASTER, G.M.; LEBARON, M.S.; COREY, GaLa; HOWTHRORN, LaR.; TOOLE, U.F. The influence of soil moisture on snap bean seed production. Idaho, Agric. Exp. Sta., 1.965. (Bu11., 435)

MAGALHăES, A.A. \& MILLAR, A.A. Efeito do déficit de água no periodo reprodutivo sobre a producão de feijão. Pesq. agropec. bras., Erasília, 13(2) a5s-60, 1978.

MEYER, W.S. \& GREEN, G.C. Water use by wheat and plant indicators of available water. Agron. J., Madison, $72: 253-257$, 1980 .

MILLAR, R.A. \& GARDNER, W.R. Effect of the soil and plant potentials on the dry matter production of snap beans. Agron. J., Madison, 64:559-562, 1972.

MILLAR, R.A.; JENSEN, R.E.; BAUER, A.; NORUM, E.B. Influence of atmospheric and soil environment parameters on the diurnal fluctuations of leaf water status of barley Agr. Meteorol., Madison, 8:92-105, 1971.

MONTEITH, J.L. Principles of environmental physics. London, Edward Arnold, 1975. 241p.

NIELSEN, D.R.; DAUIDSON, J.M.; BIGGAR, J.W.; MILLER, R.J. Water movement through Parroche Clay Loam soil. Hilgardia, Berkeley, 35:491-506, 1962. 
NOBEL, Pas. Introduction to biophysical plant physiology. San Francisco, WaB. Freeman, 1974. 488p.

OGATA, G. \& RICHARDS, L.S. Water content changes following irrigations of bare field soil that is protected from Evaporation. Soil Sci. Soc. Am. Proc., Madison, 21:355-356, 1957 ,

OMETTO, J.C. Bioclinatologia vegetal. Sắ Paulo, Ed. Agrônonica Ceres, 1981. 441p.

PARCEUAUX, S: de. Aspects biophysiques des exchanges entre les fenilles e le milieu environmant. Decologia plantarum, $7(4): 371-401,1972$.

PAULA SOUZA, M.L.; REICHARDT, K,; LIBARDI, P.L. Perdas de água no solo por drenagen profunda. En. Nucl. Agric., Piracicaba, 1:82-93, 1979 .

PEDRo JR., M.J. Balanco de energia en soja (Glicine max (L.) Merry). Piracicaba, 1977. 82p. (Mestrado-Escola Superior de Agricultura "Luiz de Queiroz"/USP)

PERRIER, A.; ITIER, B.; BERTOLINI, J.M.; BLANCO de PLABOS, A. Mesure automatique du bilan d'energia d'une culture. Exemples d'application. Ann. Agron. Paris, 26:19-40, 1975.

RAGGI, L.A., BERNARDO, S.; GALUÃO, J.D. Efeito do turno de rega en três fases do ciclo do feijoeiro. Seiva, vicosa, $32(76): 34-43,1977$. 
REICHARDT, K. Parânetros do solo que influenciam o manejo de água. In: SIMPósIo SOBRE O MANEJO DE GGUA NA AGRICULTURA, 1, Campinas, 1987. ANAIS, Ed, por G.P. Viégas. Campinas, Fundacấo Cargill, 1987. p.3-13.

REICHARDT, K. \& LIBARDI, P.L. A new equation for the estimation of soilwwater diffusivity. In: SYMPOSIUM ON ISOTOPES AND RADIATION TECHNIQUES IN SOIL PHYSICS AND IRRIGATION STUDIES - IAEA, ViEna, 1973. P.45-51.

REICHARDT, K.; LIBARDI, P.L.; NIELSEN, D.R. Unsaturated hydraslic conductivity determination by a scaling technique. Soil Sci., Baltimore, 120(3):165-168, 1975.

REICHARDT, K.; LIBARDI, P.L.; SANTOS, J.M. An analysis of soil-water movement in the field. II. Water balance in snap bean crop. Piracicaba, CENA/ESALQ, 1974. 19p. (Boletim Cientifico, BC-02a)

REICHARDT, K. LIBARDI, P.L.; SAUNDERS, L.C.U.; CADIMAZ, A Dinâmica da água en solo cultivado com milho. R. bras. Ci. Solo, Campina, 3:1-5, 1979.

RESENDE, M.; HENDERSON, D.W.; FERERES, E. Frequînncia de irrigacấ, desenvolvimento e producấo do feijấo kidney. Pesq. agropec. bras., Brasilia, 16(3):363-370, 1981.

RICHARDS, L.A.; GARDNER, W.R.; OGATA, G; Physical processes of determining water loss from soil. Soil sci. Soc. Am. Proc., Madison, 20:310-314, 1956.

RITCHIE, J.T. Influence of soil water status and meteorological conditions on evaporation from a corn canopy. Agron. J., Madison, 65:893-897, 1973. 
RITCHIE, J.T. Atmoepheric and soil water influences on the plant balance. Agric. Meteorol., Amsterdam, 14: $183-198,1974$.

RITCHIE, J.T; BURNETT, Ea; HENDERSON, R.C. Dryland Evaporative flux in a subhumid climate: III. Soil water influence. Agron. J., Madison, 64:168-176, 1972.

ROBINS, J.J. \& DOMINGO, C.E. Moisture deficits in relation to the growth and development of dry beans. Agron. l., Madison, 48:67-70, 1956.

ROSE, C.W. Agricultural physics. Oxford, Pergamon Press. 1966. $230 \mathrm{P}$.

ROSENBERG, N.l. Microclimate: the biological environment. New York, John Wiley \& Sons. 1974. 315p.

ROUIRA, L.A.A. Estudo do sistema radicular do feijoeiro (Phaseolus vilgaris L.) var. Carioca. Piracicaba, 1975. 86p. CDoutorado - Escola Superior de Agricultura "Luia de Queiroz"/USP)

SALTER, P.L. \& GOODE, J.E. Crops responses to water at different stages of growth. Bucks, England, Commonwealth Agricultural Bureaus, 1967. 246P. (REsearch review, 2 )

SANTOS, R. Um estudo das resistências ao transporte de vapor sobre uma cultura de feijấo (Phaseolus vulgaris L.). Piracicaba, 1985. 84p. (Mestrado-Escola Superior de Agricultura "Luiz de Queiroz"/USP) 
SILUEIRA, P.M. da \& STONE, L.F. Balango de água na cultu-$r$ a do feijấo en latossolo vermelho-amarelo. Pesq. agropec. bras., Brasilia, 14(2):111-115, 1979.

SIVAKUMAR, M.V.K. \& SHAW, R.H. Stomatal conductance and leaf-water potential of soybeans under moisture stress. J. Iowa State. Journal of Research, 54(1):17-27, 1979.

SLATYER, R. O. Plant water relationships. New York, Academic Press, 1967. 366p.

STANSELL, J.R. \& SMITTLE, D.A. Effects of irrigation regimes on yield and water use of snap bean (Phaseolus vulgaris L.) J. Amer. Soc. Hort. Sci., 105(6):869-873, 1980.

SUTCLIFFE, J. As plantas e a água. (Trad. H.E.T. MACIEL) São Paulo, EPU/EDUSP, 1980. 126 P. (Temas de Biologia, 26)

TANNER, C.B. Evaporation of water from plants and soil. In: KOLOWSKI, T.T., ed. Water deficits and plants growth. New York, Academic Press, 1968. P.74-106.

THORNTHWAITE, C. W. \& MATHER, J.R. The water balance. New Jersey, 1955. 104p. (Publication in Climatology, V.3, n.1)

TURNER, N.C. \& BEGG, J.E. Stomatal behavior and water status of maize, sorghum and tabacco under field conditions. I. At high soil water potential. Plant Physiol., Washington, 51:31-36, 1973 . 
UILLA NOVA, N.A. Estudos sobre balango de energia em cul..tura de arroz. Piracicaba, 1973. 89p. (Livre-docência - Escola Superior de Agricultura "Luiz de Queiroz"/USP)

UILLA NOUA, N.A.; PEREIRA, A.R.; PEDRO JUNIOR, Mal. Balanco de energia numa cultura de arroz en condicóses de sequeiro. Bragantia, Campinas, 34:171-176, 1975.

WIT, C.T. de. Transpiration and crop yields. Wageningen, Institute of Biological and Chemical Research on Field Crops and Herbage, 1958. 88p.

ZUR, B.; JONES, J.W.; BOOTE, K.J.; HAMMOND, L.C. Total resistance to water flow in field soybeans. II. Lim-iting soil moisture. Agron. J., Madison, 74:99-105, 1982 . 


$$
\text { 1. } 10
$$

APÊNDICE 
Apêndice 1 - Valores médios do gradiente psicrométrico observado $\left({ }^{\circ} \mathrm{C}\right)$ e da distribuição dos componentes do balanço de energia (cal. $\mathrm{cm}^{-2} \cdot$ min $\left.^{-1}\right)$ para cinco dias típicos $(42,56,61,68$ e 76 dias após a germinação do feijoeiro, em Campinas. 
Apēndice 1.1.a - Resultados do dia 28.8.86 (42 DAG), para o tratamento 100\%AD

\begin{tabular}{|c|c|c|c|c|c|c|c|c|c|c|c|c|}
\hline Período & $T_{2}$ & $T_{1}$ & $\mathrm{Tu}_{2}$ & $\mathrm{Tu}_{1}$ & $\Delta \mathrm{Tu} / \Delta \mathrm{T}$ & TuM & $\frac{s+\gamma}{\gamma}$ & RN & G & $\mathrm{H}$ & IE & $B$ \\
\hline $\mathrm{h}$ min & \multicolumn{4}{|c|}{${ }^{\circ} \mathrm{C}=$} & & ${ }^{\circ} \mathrm{C}$ & & \multicolumn{4}{|c|}{ _ cal.cm. ${ }^{-2} \cdot \mathrm{min}^{-1}$} & \\
\hline $\begin{array}{rl}9 & 30 \\
10 & 00\end{array}$ & 21,90 & 23,39 & 17,80 & 19,48 & 1,13 & 18,6 & 3,15 & 0,603 & 0,059 & 0,153 & 0,391 & 0,393 \\
\hline $\begin{array}{ll}10 & 00 \\
10 & 30\end{array}$ & 24,56 & $25, \dot{51}$ & 18,17 & 19,50 & 1,40 & 18,8 & 3,17 & 0,673 & 0,073 & 0,135 & 0,465 & 0,291 \\
\hline $\begin{array}{ll}10 & 30 \\
11 & 00\end{array}$ & 24,76 & 25,79 & 18,56 & 20,04 & 1,44 & 19,3 & 3,23 & 0,726 & 0,076 & 0,140 & 0,510 & 0,275 \\
\hline $\begin{array}{ll}11 & 00 \\
11 & 30\end{array}$ & 25,62 & 27,28 & 19,30 & 20,74 & 0,87 & 20,0 & 3,31 & 0,760 & 0,078 & 0,237 & 0,445 & 0,533 \\
\hline $\begin{array}{ll}11 & 30 \\
12 & 00\end{array}$ & $25 ; 97$ & 27,50 & 19,50 & 20,87 & 0,88 & 20,2 & 3,34 & 0,757 & 0,071 & 0,233 & 0,453 & 0,516 \\
\hline $\begin{array}{l}1200 \\
1230\end{array}$ & 26,29 & 27,72 & 19,68 & 20,97 & 0,90 & 20,3 & 3,35 & 0,760 & 0,055 & 0,233 & 0,472 & 0,494 \\
\hline $\begin{array}{ll}12 & 30 \\
13 & 00\end{array}$ & 27,72 & 28,63 & 19,45 & 20,93 & 1,63 & 20,2 & 3,34 & 0,742 & 0,048 & 0,128 & 0,566 & 0,226 \\
\hline $\begin{array}{ll}13 & 00 \\
13 & 30\end{array}$ & 27,79 & 28,74 & 20,27 & 20,86 & 1,61 & 20,6 & 3,38 & 0,704 & 0,040 & 0,122 & 0,542 & 0,225 \\
\hline $\begin{array}{l}1330 \\
1400\end{array}$ & 27,59 & 27,96 & 19,30 & 19,72 & 1,14 & 19,5 & 3,25 & 0,664 & 0,043 & 0,168 & 0,453 & 0,372 \\
\hline $\begin{array}{ll}14 & 00 \\
14 & 30\end{array}$ & 28,06 & $2753^{\circ}$ & 21,90 & 21,33 & 1,08 & 21,6 & 3,52 & 0,576 & 0,035 & 0,143 & 0,398 & 0,359 \\
\hline $\begin{array}{ll}14 & 30 \\
15 & 00\end{array}$ & 27,37 & 28,37 & 20,00 & 20,85 & 0,85 & 20,4 & 3,37 & 0,466 & 0,016 & 0,157 & 0,293 & 0,537 \\
\hline $\begin{array}{ll}15 & 00 \\
15 & 30\end{array}$ & 27,81 & 27,58 & 19,80 & 19,54 & 1,13 & 19,7 & 3,27 & 0,355 & 0,000 & 0,096 & 0,259 & 0,371 \\
\hline $\begin{array}{ll}15 & 30 \\
16 & 00\end{array}$ & 27,88 & 27,41 & 21,00 & 20,51 & 1,04 & 20,8 & 3,41 & 0,272 & $-0,001$ & 0,077 & 0,196 & 0,392 \\
\hline $\begin{array}{l}1630> \\
1700\end{array}$ & 25,38 & 25,04 . & 22,50 & 19,72 & 8,18 & 21,1 & 3,45 & 0,016 & $-0,010$ & 0,001 & $0 ; 025$ & 0,037 \\
\hline $\begin{array}{ll}17 & 00 \\
17 & 30\end{array}$ & 23,85 & 23,62 & 18,60 & 18,40 & 0,87 & 18,5 & 3,13 & $-0,072$ & $-0,015$ & $-0,021$ & $-0,036$ & 0,581 \\
\hline $\begin{array}{l}1730 \\
1800^{2}\end{array}$ & 22,15 & 21,18 & 18,40 & 17,48 & 0,95 & 17,9 & 3,06 & $-0,087$ & $-0,023$ & $-0,022$ & $-0,042$ & 0,524 \\
\hline $\begin{array}{ll}18 & 00 \\
18 & 30^{\circ}\end{array}$ & 21,12 & 20,39 & 18,10 & $15,7 \dot{6}$ & 3,21 & 16,9 & 2,95 & $-0,088$ & $-0,026$ & $-0,007$ & $-0,055$ & 0,118 \\
\hline $\begin{array}{l}1830 \\
1900^{\prime}\end{array}$ & 20,87 & 19,58 & 17,54 & 15,39 & $1 ; 67$ & 16,5 & 2,90 & $-0,083$ & $-0,029$ & $-0,011$ & $-0,043$ & $\begin{array}{l}0,261 \\
\end{array}$ \\
\hline
\end{tabular}


Apêndice 1.1.b - Resultados do dia 28.8.86 (42 DAG), para o tratamento M75\%.

\begin{tabular}{|c|c|c|c|c|c|c|c|c|c|c|c|c|}
\hline Período & $\mathrm{T}_{2}$ & $\mathrm{~T}_{1}$ & $\mathrm{Tu}_{2}$ & $\mathrm{Tu}_{1}$ & $\Delta \mathrm{Tu} / \Delta \mathrm{T}$ & TuM & $\frac{s+\gamma}{\gamma}$ & $\mathrm{RN}$ & G & $\mathrm{H}$ & LE & $B$ \\
\hline $\mathrm{h}$ min & $\cdots$ & $\ldots$ & ${ }^{\circ} \mathrm{C}-$ & $-\infty$ & & ${ }^{\circ} \mathrm{C}$ & & $\ldots$ & - cal.ca & $n^{-2} \cdot \min ^{-1}$ & $1 \ldots$ & \\
\hline $\begin{array}{rl}9 & 30 \\
10 & 00\end{array}$ & 21,84 & 22,20 & 17,63 & 18,94 & 3,64 & 18,3 & 3,10 & 0,603 & 0,059 & 0,048 & 0,496 & $0 ; 097$ \\
\hline $\begin{array}{ll}10 & 00 \\
10 & 30\end{array}$ & 23,36 & 23,88 & 17,64 & 19,03 & $.2,67$ & 18,3 & 3,11 & 0,673 & 0,073 & 0,072 & 0,528 & 0,137 \\
\hline $\begin{array}{ll}10 & 30 \\
11 & 00\end{array}$ & 23,72 & 25,13 & 17,91 & 19,18 & 0,90 & 18,5 & 3,13 & 0,726 & 0,076 & 0,230 & 0,420 & 0,548 \\
\hline $\begin{array}{ll}11 & 00 \\
11 & 30\end{array}$ & 25,86 & 26,34 & 18,96 & 19,89 & 1,94 & 19,4 & 3,24 & 0,760 & 0,078 & 0,109 & 0,573 & 0,189 \\
\hline $\begin{array}{l}1130 \\
1200^{>}\end{array}$ & 26,78 & 27,20 & 18,54 & 20,76 & 5,29 & 19,7 & 3,27 & 0,757 & 0,074 & 0,040 & $0,6 \dot{43}$ & 0,061 \\
\hline $\begin{array}{ll}12 & 00 \\
12 & 30\end{array}$ & 27,63 & $27 ; 84$ & 18,93 & 20,40 & 7,00 & 19,7 & 3,27 & 0,760 & 0,055 & 0,031 & 0,674 & 0,046 \\
\hline $\begin{array}{l}1230 \\
13.00\end{array}$ & 27,35 & 27,77 & 19,02 & 20,81 & 4,26 & 19,9 & 3,30 & 0,742 & 0,048 & 0,049 & 0,645 & 0,077 \\
\hline $\begin{array}{ll}13 & 00 \\
13 & 30\end{array}$ & 28,30 & 28,09 & 18,99 & 20,80 & $-8,62$ & 19,9 & 3,30 & 0,704 & 0,040 & $-0,023$ & 0,687 & $-0,034$ \\
\hline $\begin{array}{l}1330 \\
1400^{>}\end{array}$ & 28,55 & 29,66 & 19,16 & 20,46 & $1 ; 17$ & 19,8 & 3,29 & 0,664 & 0,043 & 0,161 & 0,460 & 0,351 \\
\hline $\begin{array}{ll}14 & 00 \\
14 & 30\end{array}$ & 28,24 & 28,40 & 18,49 & 19,49 & 6,25 & 29,0 & 3,19 & 0,576 & 0,035 & 0,027 & 0,514 & 0,053 \\
\hline $\begin{array}{ll}14 & 30 \\
15 & 00\end{array}$ & 27,93 & 28,20 & 18,13 & 18,84 & 2,63 & 18,5 & 3,13 & 0,466 & 0,016 & 0,055 & 0,395 & 0,138 \\
\hline $\begin{array}{l}1500 \\
1530\end{array}$ & 27,30 & 27,53 & 17,32 & 17,94 & 2,70 & 17,6 & 3,03 & 0,355 & 0,000 & 0,043 & 0,312 & 0,140 \\
\hline $\begin{array}{l}1530 \\
1600^{>}\end{array}$ & 25,90 & 26,91 & 18,03 & 18,90 & 0,86 & 18,5 & 3,13 & 0,272 & $-0,000$ & 0,101 & 0,172 & 0,591 \\
\hline $\begin{array}{ll}16 & 30 \\
17 & 00\end{array}$ & 25,80 & 25,47 & $18,01$. & 17,85 & 0,48 & 17,9 & 3,06 & 0,016 & $-0,010$ & 0,018 & 0,008 & 2,060 \\
\hline $1730^{\circ}$ & 23,58 & 22,77 & 16,69 & 16,87 & $-0,22$ & 16,8 & 2,94 & $-0,072$ & $-0,015$ & 0,087 & $-0,144$ & $-0,605$ \\
\hline $\begin{array}{l}1730 \\
1800\end{array}$ & 22,16 & 21,88 & 15,69 & 14,76 & 3,32 & 15,2 & 2,77 & $-0,087$ & $-0,023$ & $-0,007$ & $-0,057$ & 0,122 \\
\hline $\begin{array}{lll}18 & 00 \\
18 & 30\end{array}$ & 21,15 & 20,20 & 15,42 & 24,50 & 0,97 & 15,0 & 2,75 & $-0,088$ & $-0,026$ & $-0,023$ & $-0,039$ & 0,602 \\
\hline $\begin{array}{ll}18 & 30 \\
19 & 00\end{array}$ & 21,20 & 20,59 & 14,82 & 14,63 & 0,31 & 14,7 & 2,72 & $-0,083$ & $-0,029$ & $-0,064$ & 0,010 & $-6,604$ \\
\hline
\end{tabular}


Apêndice 1.2.a - Resultados do dia 11.9.86 (56 DAG), para o tratamento 1008AD

\begin{tabular}{|c|c|c|c|c|c|c|c|c|c|c|c|c|}
\hline Período & $T_{2}$ & $T_{1}$ & $\mathrm{Tu}_{2}$ & $T u_{1}$ & $\Delta T w / \Delta T$ & TuM & $\frac{\frac{s+\gamma}{\gamma}}{x}$ & RN & G & H & LE & $B$ \\
\hline h. min & $\therefore$ & $\ldots{ }^{\circ} \mathrm{C}$ & . & - & & ${ }^{\circ} \mathrm{C}$ & & - & -.. cal.c & $m^{-2} \cdot \min$ & 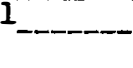 & \\
\hline $\begin{array}{ll}7 & 00 \\
7 & 30\end{array}$ & 16,87 & 16,54 & 14,93 & 15,17 & $-0,73$ & $15,0^{\circ}$ & 2,75 & 0,032 & $-0,014$ & $-0,023$ & 0,069 & $-0,332$ \\
\hline $\begin{array}{ll}7 & 30 \\
8 & 00\end{array}$ & 17,38 & 17,85 & 14,84 & 15,28 & 0,94 & 15,1 & 2,76 & 0,139 & $-0,009$ & 0,057 & 0,091 & 0,632 \\
\hline $\begin{array}{ll}8 & 00 \\
8 & 30\end{array}$ & 18,19 & 18,86 & 15,38 & 16,48 & 1,64 & 15,9 & 2,84 & 0,244 & 0,001 & 0,052 & 0,191 & 0,273 \\
\hline $\begin{array}{ll}8 & 30 \\
9 & 00\end{array}$ & 19,01 & 17,98 & 15,31 & 17,86 & $-2,46$ & 16,6 & 2,91 & 0,398 & 0,011 & $-0,054$ & 0,441 & $-0,122$ \\
\hline $\begin{array}{ll}9 & 00 \\
9 & 30\end{array}$ & 21,71 & 21,50 & 16,28 & 18,30 & $-9,62$ & 17,3 & 2,99 & 0,501 & 0,016 & $-0,017$ & 0,502 & $-0,034$ \\
\hline $\begin{array}{r}9.30 \\
10.00>\end{array}$ & 22,81 & 23,17 & 16,13 & 19,22 & 8,58 & 27,7 & 3,03 & 0,597 & 0,032 & 0,022 & 0,543 & 0,040 \\
\hline $\begin{array}{ll}10 & 00 \\
10 & 30\end{array}$ & 24,15 & 24,82 & 17,06 & 20,24 & 4,72 & 18,6 & 3,15 & 0,666 & 0,081 & 0,039 & 0,546 & 0,072 \\
\hline $\begin{array}{l}10^{\prime} 30 \\
1100^{>}\end{array}$ & 25,02 & 24,96 & 16,72 & 20,25 & $-58,83$ & 18,5 & 3,13 & 0,730 & 0,085 & $-0,004$ & 0,649 & $-0,005$ \\
\hline $\begin{array}{l}\text { II } 00 \text {; } \\
\text { II } 30\end{array}$ & 26,07 & 26,42 & 17,03 & 20,50 & 9,91 & 18,8 & 3,16 & 0,759 & 0,091 & 0,021 & 0,647 & 0,033 \\
\hline $\begin{array}{ll}11 & 30 \\
12 & 00\end{array}$ & 25,40 & 26,88 & 18,23 & 21,65 & 2,31 & 19,9 & 3,30 & 0,793 & 0,101 & 0,091 & 0,601 & 0,151 \\
\hline $\begin{array}{ll}12 & 00 \\
12 & 30\end{array}$ & 22,90 & 26,54 & 17,35 & 21,63 & 1,18 & 19,5 & 3,25 & 0,798 & 0,104 & 0,182 & 0,512 & 0,355 \\
\hline $\begin{array}{ll}12 & 30 \\
13 & 00\end{array}$ & 26,54 & 26,89 & 17,68 & 21,57 & 11,11 & 19,6 & 3,26 & 0,788 & 0,098 & $0,019^{\circ}$ & 0,671 & 0,028 \\
\hline $\begin{array}{ll}13 & 00 \\
13 & 30\end{array}$ & 27,32 & 26,94 & 17,56 & 21,29 & $-9,82$ & 19,4 & 3,24 & 0,760 & 0,085 & $-0,021$ & 0,696 & $-0,030$ \\
\hline $\begin{array}{l}1330 \\
1400\end{array}$ & 26,73 & 26,64 & 17,15 & 19,91 & $-30,67$ & 18,5 & 3,13 & 0,711 & 0,068 & $-0,007$ & 0,650 & $-0,010$ \\
\hline $\begin{array}{ll}14 & 00 \\
14 & 30\end{array}$ & 28,19 & 28,17 & 18,12 & 20,24 & $-106,02$ & 19,2 & 3,21 & 0,630 & 0,066 & $-0,002$ & 0,566 & $-0,003$ \\
\hline $\begin{array}{ll}14 & 30 \\
15 & 00\end{array}$ & 27,86 & 26,39 & 17,59 & 21,02 & $-2,33$ & 19,3 & 3,23 & 0,561 & 0,063 & $-0,066$ & 0,564 & $-0,117$ \\
\hline $\begin{array}{ll}15 & 00 \\
15 & 30\end{array}$ & 27,73 & $24 ; 54$ & 17,82 & 20,45 & $-0,82$ & 19,1 & 3,21 & 0,456 & 0,047 & $-0,155$ & 0,564 & $-0,275$ \\
\hline $\begin{array}{ll}15 & 30 \\
16 & 00\end{array}$ & 27,77 & 24,41 & 18,09 & 20,10 & $-0,60$ & 19,1 & 3,20 & 0,335 & 0,033 & $-0,158$ & 0,460 & $-0,343$ \\
\hline $\begin{array}{ll}16 & 00 \\
16 & 30\end{array}$ & 26,66 & 23,32 & 17,97 & 19,16 & $-0,36$ & 18,6 & 14 & 0,225 & 0,017 & $-0,186$ & 0,394 & $-0,472$ \\
\hline $\begin{array}{ll}16 & 30 \\
17 & 00^{>}\end{array}$ & 26,25 & 22,58 & 17,54 & 18,69 & $-0,31$ & 18,1 &, 08 & 0,104 & 0,009 & $-0,098$ & 0,193 & $-0,508$ \\
\hline $\begin{array}{ll}17 & 00 \\
17 & 30\end{array}$ & 24,46 & 20,54 & 17,02 & 17,69 & $-0,17$ & 17,4 & 3,00 & $-0,010$ & 0,003 & 0,025 & $-0,038$ & $-0,661$ \\
\hline $\begin{array}{ll}17 & 30 \\
18 & 00\end{array}$ & 22,75 & 19,15 & 17,07 & 16,52 & 0,15 & 16,8 & 2,94 & $-0,058$ & $-0,004$ & $-0,120$ & 0,066 & $-1,814$ \\
\hline $\begin{array}{ll}18 & 00> \\
18 & 30\end{array}$ & 19,09 & 16,78 & 15,78 & 14,68 & 0,48 & 25,2 & 2,77 & $-0,101$ & $-0,013$ & $-0,067$ & 0,021 & 3,114 \\
\hline $\begin{array}{ll}18 & 30> \\
19 & 00\end{array}$ & 19,18 & 16,80 & 14,74 & 14,18 & 0,24 & 14,5 & 2,70 & $-0,097$ & $-0,019$ & $-0,123$ & .045 & $-2,739$ \\
\hline
\end{tabular}


Aqêndice 1.2.b - Resultados do dia 11.9 .86 (56 DAG), para o tratamento M758

\begin{tabular}{|c|c|c|c|c|c|c|c|c|c|c|c|c|}
\hline Període & $\mathrm{T}_{2}$ & $\mathrm{~T}_{1}$ & $\mathrm{Tu}_{2}$ & $\pi u_{1}$ & $U / \Delta T$ & TuM & $\frac{s+\gamma}{\gamma}$ & $\mathrm{RN}$ & G & $\mathrm{H}$ & IE & $B$ \\
\hline$h \min$ & $\ldots$ & $\ldots{ }^{\circ}$ & 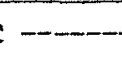 & & & ${ }^{\circ} \mathrm{C}$ & & $\ldots$ & - cal.cm & $n^{-2} \cdot \min ^{-1}$ & & \\
\hline $\begin{array}{ll}7 & 00 \\
7 & 30\end{array}$ & 16,06 & 16,46 & 14,44 & 14,94 & 1,25 & 14,7 & 2,72 & 0,032 & $-0,014$ & 0,014 & 0,032 & 0,416 \\
\hline $\begin{array}{ll}7 & 30 \\
8 & 00^{2}\end{array}$ & 16,79 & 17,36 & 14,66 & 15,36 & 1,23 & 15,0 & 2,75 & 0,139 & $-0,009$ & 0,044 & 0,104 & 0,420 \\
\hline $\begin{array}{ll}8 & 00 \\
8 & 30\end{array}$ & 17,02 & 17,70 & 15,58 & 16,35 & $1 ; 13$ & 16,0 & 2,85 & 0,244 & 0,001 & 0,075 & 0,168 & $\dot{0}, 450$ \\
\hline $\begin{array}{ll}8 & 30 \\
9 & 00^{\prime}\end{array}$ & 17,26 & 18,05 & 16,50 & 17,34 & 1,06 & 16,9 & 2,95 & 0,398 & 0,011 & 0,123 & 0,264 & 0,468 \\
\hline $\begin{array}{ll}9 & 00 \\
9 & 30\end{array}$ & 19,94 & 20,68 & 14,56 & 16,06 & 2,03 & 15,3 & 2,78 & 0,501 & 0,016 & 0,086 & 0,399 & 0,216 \\
\hline $\begin{array}{rl}9 & 30 \\
10 & 00\end{array}$ & 22,62 & 23,05 & 14,74 & 15,47 & 1,70 & 15,1 & 2,76 & 0,597 & 0,032 & 0,120 & 0,445 & 0,271 \\
\hline $\begin{array}{ll}10 & 00 \\
10 & 30\end{array}$ & 23,53 & 24,11 & 15,65 & 16,31 & 1,14 & 16,0 & 2,85 & 0,666 & 0,081 & 0,180 & 0,405 & 0,446 \\
\hline $\begin{array}{ll}10 & 30 \\
11 & 00^{>}\end{array}$ & 24,50 & 25,48 & 16,89 & 17,90 & 1,03 & 17,4 & 3,00 & 0,730 & 0,085 & 0,208 & 0,437 & 0,477 \\
\hline $\begin{array}{ll}11 & 00 \\
11 & 30\end{array}$ & 25,65 & 25,95 & 27,83 & 18,20 & 1,23 & 18,0 & 3,07 & 0,759 & 0,091 & 0,176 & 0,492 & 0,358 \\
\hline $\begin{array}{ll}11 & 30 \\
12 & 00^{>}\end{array}$ & 24,80 & 27,57 & 17,61 & 19,30 & 0,61 & 18,5 & 3,12 & 0,793 & 0,101 & 0,363 & 0,329 & 1,104 \\
\hline $\begin{array}{ll}12 & 00 \\
12 & 30\end{array}$ & 25,88 & 27,42 & 17,99 & 19,40 & 0,92 & 18,7 & 3,15 & 0,798 & 0,104 & 0,240 & 0,454 & 0,530 \\
\hline $\begin{array}{ll}12 & 30 \\
13 & 00\end{array}$ & 25,78 & 27,25 & 18,39 & 19,50 & 0,76 & 18,9 & 3,18 & 0,788 & 0,098 & 0,287 & 0,403 & 0,713 \\
\hline $\begin{array}{l}1300 \\
1330^{>}\end{array}$ & 26,82 & 28,33 & 18,50 & 19,90 & 0,93 & 19,2 & 3,21 & 0,760 & 0,085 & 0,227 & 0,448 & 505 \\
\hline $\begin{array}{l}1330 \\
1400^{7}\end{array}$ & 25,58 & 27,39 & 17,70 & 19,30 & 0,88 & 18,5 & 3,13 & 0,711 & 0,068 & 0,232 & 0,411 & 0,566 \\
\hline $\begin{array}{l}14.00 \\
1430^{>}\end{array}$ & 26,15 & 26,21 & 17,28 & 18,66 & 23,00 & 18,0 & 07 & 0,630 & 0,066 & 0,008 & 0,556 & 0,014 \\
\hline $\begin{array}{l}1430 \\
1500^{>}\end{array}$ & 28,59 & 28,81 & 17,72 & 19,60 & 8,55 & 18,7 & 3,15 & 0,561 & 0,063 & $0,01,9$ & 0,479 & 0,039 \\
\hline $\begin{array}{ll}15 & 00 \\
15 & 30\end{array}$ & 28,26 & 29,21 & 18,91 & 20,19 & 1,35 & 19,6 & 3,26 & 0,456 & 0,047 & 0,093 & 0,316 & 0,295 \\
\hline $\begin{array}{ll}15 & 30 \\
16 & 00\end{array}$ & 27,51 & 28,77 & 18,43 & 19,90 & 1,17 & 19,2 & 3,21 & 0,335 & 0,033 & 0,081 & 0,221 & 0,364 \\
\hline $\begin{array}{ll}16 & 00 \\
16 & 30\end{array}$ & 27,12 & 28,42 & 18,40 & 19,70 & 1,00 & 19,1 & 3,19 & 0,225 & 0,017 & 0,065 & 0,143 & 0,456 \\
\hline $\begin{array}{ll}16 & 30 \\
17 & 00\end{array}$ & 26,64 & 27,02 & 18,30 & 19,00 &, 84 & 18,7 & 15 & 4 & 0,009 & 0,016 & 0,079 & 0,208 \\
\hline $\begin{array}{ll}17 & 00 \\
17 & 30^{3}\end{array}$ & 25,40 & 25,36 & 18,20 & 18,60 & $-10,00$ & 18,4 & 3,12 & $-0,010$ & 0,003 & 0,000 & $-0,013$ & $-0,031$ \\
\hline $\begin{array}{ll}17 & 30 \\
18 & 00^{>}\end{array}$ & 23,10 & 21,86 & 18,00 & 17,10 & 0,73 & 17,6 &, 02 & $-0,058$ & $-0,004$ & $-0,025$ & $-0,029$ & 0,839 \\
\hline $\begin{array}{ll}18 & 00 \\
18 & 30\end{array}$ & 20,24 & 19,15 & 17,90 & 16,50 & 1,28 & 17,2 & 2,98 & $-0,201$ & $-0,013$ & $-0,023$ & $-0,065$ & 0,353 \\
\hline $\begin{array}{ll}18 & 30 \\
19 & 00^{>}\end{array}$ & 18,09 & 18,30 & 16,67 & 16,03 & $-3,05$ & 16,4 & 89 & $-0,097$ & $-0,019$ & 0,009 & $-0,087$ & $-0,102$ \\
\hline
\end{tabular}


Apêndice 1.3.a - Resultados do dia 16.9.86 (61 DAG), para o tratamento 1008AD

\begin{tabular}{|c|c|c|c|c|c|c|c|c|c|c|c|c|}
\hline Período & $T_{2}$ & $\mathrm{~T}_{1}$ & $\mathrm{Tu}_{2}$ & $T u_{1}$ & $\Delta \mathrm{T} w / \Delta \mathrm{T}$ & TuM & $\frac{s+\gamma}{\gamma}$ & $\mathrm{RN}$ & G & H & IE & $B$ \\
\hline$h \min$ & $\longrightarrow$ & $\ldots$ & $\therefore$ & $\ldots$ & & ${ }^{\circ} \mathrm{C}$ & & - & - cal. & ${ }^{-2} \cdot \min$ & -1 & \\
\hline $\begin{array}{ll}7 & 00 \\
7 & 30\end{array}$ & 17,02 & 17,92 & 15,08 & 15,80 & 0,80 & 15,4 & 2,79 & 0,052 & $-0,012$ & 0,029 & 0,035 & 0,812 \\
\hline $\begin{array}{ll}7 & 30 \\
8 & 00\end{array}$ & 18,45 & 18,98 & 16,10 & 16,60 & 0,94 & 16,4 & 2,89 & 0,180 & $-0,006$ & 0,068 & 0,118 & 0,5982 \\
\hline $\begin{array}{ll}8 & 00 \\
8 & 30\end{array}$ & 19,52 & 19,90 & 17,09 & 17,39 & 0,79 & 17,2 & 2,99 & 0,250 & 0,008 & 0,102 & 0,140 & 0,734 \\
\hline $\begin{array}{ll}8 & 30 \\
9 & 00^{>}\end{array}$ & 21,62 & 21,68 & 17,58 & 18,95 & 22,83 & 18,3 & 3,10 & 0,340 & 0,019 & 0,005 & 0,316 & $.0,014$ \\
\hline $\begin{array}{ll}9 & 00 \\
9 & 30\end{array}$ & 23,51 & 24,05 & 17,39 & 19,62 & 4,13 & 18,5 & 3,13 & 0,435 & 0,027 & 0,032 & 0,376 & 0,084 \\
\hline $\begin{array}{l}930 \\
10.00\end{array}$ & 25,49 & 26,37 & 18,54 & 20,18 & 1,86 & 19,4 & 3,23 & 0,579 & 0,069 & 0,085 & 0,425 & 0,200 \\
\hline $\begin{array}{ll}10 & 00 \\
10 & 30\end{array}$ & 27,47 & 26,50 & 18,72 & 20,77 & $-2,11$ & 19,7 & 3,28 & 0,646 & 0,081 & $-0,081$ & 0,646 & $-0,126$ \\
\hline $\begin{array}{l}10 \cdot 30 \\
1100\end{array}$ & 28,32 & 27,64 & 18,35 & 21,11 & $-4,06$ & 19,7 & 3,28 & 0,672 & 0,082 & $-0,044$ & 0,634 & $-0,070$ \\
\hline $\begin{array}{ll}11 & 00 \\
11 & 30\end{array}$ & 28,84 & 27,29 & 18,81 & 21,52 & $-1,75$ & 20,2 & 3,34 & 0,683 & 0,078 & $-0,103$ & 0,708 & $-0,146$ \\
\hline $\begin{array}{l}1130 \\
1200^{3}\end{array}$ & 29,86 & 28,44 & 19,05 & 22,20 & $-2,22$ & 20,6 & 3,38 & 0,679 & 0,073 & $-0,081$ & 0,687 & $-0,118$ \\
\hline $\begin{array}{l}1200 \\
1230\end{array}$ & 30,01 & 28,96 & 19,45 & 22,29 & $-2,70$ & 20,9 & 3,41 & 0,652 & 0,090 & $-0,061$ & 0,623 & $-0,098$ \\
\hline $\begin{array}{l}1230 \\
1300\end{array}$ & 30,88 & 29,78 & 19,48 & 22,30 & $-2,56$ & 20,9 & 3,41 & 0,618 & 0,074 & $-0,062$ & 0,606 & $-0,103$ \\
\hline $\begin{array}{l}1300 \\
1330^{>}\end{array}$ & 31,51 & 30,60 & 19,30 & 22,65 & $-3,68$ & 21,0 & 3,42 & ,527 & 0,059 & $-0,037$ & 0,505 & $-0,074$ \\
\hline $1430>$ & 32,05 & 30,97 & 19,37 & 22,37 & $-2,78$ & 20,9 & 3,41 & 0,452 & 0,066 & $-0,040$ & 0,426 & $-0,095$ \\
\hline $\begin{array}{l}1400 \\
14.30\end{array}$ & $-31,58$ & 30,01 & 18,79 & 21,60 & 1,79 & 20,2 & 3,34 & 0,372 & 0,056 . & $-0,053$ & 0,369 & $-0,143$ \\
\hline $\begin{array}{ll}1430 \\
1500\end{array}$ & 32,16 & 29,89 & 19,33 & 21,82 & $-1,96$. & 20,6 & 3,38 & 0,283 & 0,041 & $-0,036$ & $0 ., 278$ & $-0,131$ \\
\hline $\begin{array}{ll}16 & 00 \\
16 & 30\end{array}$ & 29,58 & 29,00 & 18,93 & 20,84 & $-3,29$ & 19,9 & 3,30 & 0,106 & 0,018 & $-0,008$ & 0,096 & $-0,084$ \\
\hline $\begin{array}{ll}16 & 30 \\
17 & 00^{>}\end{array}$ & 28,29 & 27,52 & 19,75 & 22,06 & 0,00 & 20,9 & $\sqrt{140}$ & 0,034 & 0,016 & $-0,002$ & 0,020 & $-0,088$ \\
\hline $\begin{array}{l}1700 \\
1730\end{array}$ & 25,13 & 21,66 & 18,09 & 20,16 & $-0,60$ & 19. & 20 & $-0,023$ & 0,007 & 0,016 & $-0,046$ & $-0,343$ \\
\hline $\begin{array}{l}1730 \\
1800\end{array}$ & 23,23 & 20,06 & 17,52 & 18,28 & $-0,24$ & 17,9 & 3,06 & $-0,063$ & 0,000 & 0,086 & $-0,149$ & $-0,577$ \\
\hline $\begin{array}{l}1800 \\
1830\end{array}$ & 22,07 & 76 & 1 & 3 & 82 & 16,8 & 2,94 & $-0,062$ & $-0,006$ & $-0,023$ & $-0,033$ &, 714 \\
\hline $\begin{array}{ll}1830 \\
19 & 00\end{array}$ & 23,54 & 21,70 & 18,06 & 17,24 & .45 & 17,7 & 3,03 & $-0,082$ & $-0,008$ & $-0,055$ & $-0,019$ & 2,848 \\
\hline
\end{tabular}


Apéndice 1.3.b - Resultados do dia 16.9.86, para o tratamento M75\%

\begin{tabular}{|c|c|c|c|c|c|c|c|c|c|c|c|c|}
\hline Período & $T_{2}$ & $T_{1}$ & $\mathrm{Tu}_{2}$ & $\mathrm{Tu}_{1}$ & $\Delta \mathrm{T} \mathrm{U} / \Delta \mathrm{T}$ & TuM & $\frac{s+\gamma}{\gamma}$ & $R N$ & $G$ & $\mathrm{H}$ & LE & $B$ \\
\hline$h \mathrm{~min}$ & - & __ & - & - & & ${ }^{O} \mathrm{C}$ & & - & - cal.cm & $\mathrm{nin}^{-1}$ & & \\
\hline $\begin{array}{l}700 \\
730^{\circ}\end{array}$ & 14,05 & 14,54 & 12,18 & 13,52 & 2,73 & 12,9 & 2,55 & 0,052 & $-0,012$ & 0,009 & 0,055 & 0,167 \\
\hline $\begin{array}{l}730 \\
800^{\circ}\end{array}$ & 18,20 & 18,59 & 15,44 & 16,12 & 1,84 & 25,8 & 2,83 & 0,180 & $-0,006$ & 0,036 & 0,150 & 0,238 \\
\hline $\begin{array}{l}800 \\
8 \quad 30\end{array}$ & 19,32 & 19,73 & 15,86 & 16,54 & 1,66 & 16,2 & 2,87 & 0,250 & 0,008 & 0,051 & 0,191 & 0,265 \\
\hline $\begin{array}{ll}8 & 30 \\
9 & 00^{>}\end{array}$ & 21,38 & 22,77 & 16,47 & 17,98 & 1,09 & 17,2 & 2,98 & 0,340 & 0,019 & 0,099 & 0,222 & 0,446 \\
\hline $\begin{array}{ll}9 & 00 \\
9 & 30\end{array}$ & 23,88 & 24,13 & 18,24 & 19,06 & 3,28 & 18,7 & 3,15 & 0,435 & 0,027 & 0,040 & 0,368 & 0,107 \\
\hline $\begin{array}{r}930 \\
1000^{\circ}\end{array}$ & 25,89 & 26,88 & 18,59 & 19,66 & 1,08 & 19,1 & 3,20 & 0,579 & 0,069 & 0,147 & 0,363 & 0,406 \\
\hline $\begin{array}{l}1000 \\
1030^{\prime}\end{array}$ & 28,23 & 28,19 & 19,16 & 20,83 & $-41,75$ & 20,0 & 3,31 & 0,646 & 0,081 & $-0,004$ & 0,569 & $-0,007$ \\
\hline $\begin{array}{l}1030 \\
1100^{\prime}\end{array}$ & 28,38 & 28,95 & 19,49 & 20,22 & 1,28 & 19,9 & 3,29 & 0,672 & 0,082 & 0,140 & 0,450 & 0,311 \\
\hline $\begin{array}{l}1100 \\
1130^{\prime}\end{array}$ & 29.35 & 30,11 & 19,71 & 20,55 & 1,11 & 20,1 & 3,33 & 0,683 & 0,078 & 0,164 & 0,441 & 0,373 \\
\hline $\begin{array}{l}1130 \\
1200^{\circ}\end{array}$ & 30,63 & 31,03 & 18,85 & 20,12 & 3,17 & 19,5 & 3,25 & 0,679 & 0,073 & 0,059 & 0,547 & 0,107 \\
\hline $\begin{array}{l}1200 \\
1230\end{array}$ & 30,69 & 29,78 & 18,82 & 20,79 & $-2,16$ & 19,8 & 3,29 & 0,652 & 0,090 & $-0,079$ & 0,641 & $-0,123$ \\
\hline $\begin{array}{l}1230 \\
1300\end{array}$ & 31,18 & 31,32 & 19,75 & 20,38 & 4,50 & 20,1 & 3,32 & 0,618 & 0,074 & 0,036 & 0,508 & 0,072 \\
\hline $\begin{array}{ll}13 & 00 \\
13 & 30\end{array}$ & 30,91 & 30,03 & 18,20 & 19,68 & $-1,68$ & 18,9 & 3,18 & 0,527 & 0,059 & $-0,087$ & 0,555 & $-0,157$ \\
\hline $\begin{array}{l}1330 \\
1400^{\circ}\end{array}$ & 31,36 & 30,41 & 19,01 & 20,30 & $-1,36$ & 19,7 & 3,27 & 0,452 & 0,066 & $-0,087$ & 0,473 & $-0,184$ \\
\hline $\begin{array}{l}14.00 \\
1430\end{array}$ & 32,24 & 31,76 & 18,79 & 20,55 & $-3,67$ & 19,7 & 3,27 & 0,372 & 0,056 & $-0,026$ & 0,342 & $-0,077$ \\
\hline $\begin{array}{l}1430 \\
1500^{\circ}\end{array}$ & 30,26 & 30,68 & 18,73 & 20,86 & 5,07 & 19,8 & 3,29 & 0,283 & 0,041 & 0,015 & 0,227 & 0,064 \\
\hline $\begin{array}{ll}16 & 00 \\
16 & 30\end{array}$ & 29,87 & 27,95 & 18,34 & 21,52 & $-1,66$ & 19,9 & 3,30 & 0,106 & 0,018 & $-0,016$ & 0,104 & $-0,155$ \\
\hline $\begin{array}{l}1630 \\
1700^{2}\end{array}$ & 27,82 & 25,70 & 19,16 & 20,83 & $-0,79$ & 20,0 & 3,31 & 0,034 & 0,016 & $-0,007$ & 0,025 & $-0,277$ \\
\hline $\begin{array}{l}1700 \\
1730\end{array}$ & 26,67 & 23,22 & 19,02 & 19,82 & $-0,23$ & 19,4 & 3,24 & $-0,023$ & 0,007 & 0,040 & $-0,070$ & $-0,571$ \\
\hline $\begin{array}{ll}1730 \\
1800^{\prime}\end{array}$ & 23,63 & 21,18 & 27,76 & 18,74 & $-0,40$ & 18,3 & 3,10 & $-0,063$ & 0,000 & 0,051 & $-0,114$ & $-0,446$ \\
\hline $\begin{array}{ll}18 & 00 \\
18 & 30\end{array}$ & 21,7 & 19,39 & 17,39 & 18,01 & $-0,27$ & 17,4 & 3,00 & $-0,062$ & $-0,006$ & 0,069 & $-0,125$ & $-0,552$ \\
\hline $\begin{array}{l}1830 \\
1900^{\circ}\end{array}$ & 22.41 & 21,30 & 27,21 & 17,46 & $-0,22$ & 17,3 & 2,99 & $-0,082$ & $-0,008$ & 0,110 & $-0,184$ & $-0,598$ \\
\hline
\end{tabular}


Apéndice 1.4.a - Resultados do dia 23.9.86 (68 DAG), para o tratamento 1008AD

\begin{tabular}{|c|c|c|c|c|c|c|c|c|c|c|c|c|}
\hline Período & $T_{2}$ & $T_{1}$ & $T u_{2}$ & $T u_{1}$ & $\Delta \mathrm{T} \mathrm{U} / \Delta \mathrm{T}$ & TuM & $\frac{S+\gamma}{\gamma}$ & $\mathrm{RN}$ & $G$ & $\mathbf{H}$ & LE & $B$ \\
\hline$h \min$ & - & -0 & $\ldots$ & - & & ${ }^{\circ} \mathrm{C}$ & & $\ldots$ & - cal.a & $\mathrm{m}^{-2} \cdot \mathrm{min}$ & -1 & \\
\hline $\begin{array}{l}600 \\
630\end{array}$ & 15,88 & 14,34 & 14,19 & 13,75 & 0,29 & 14,0 & 2,65 & $-0,054$ & $-0,010$ & $-0,058$ & 0,014 & $-4,127$ \\
\hline $\begin{array}{l}630 \\
700\end{array}$ & 17,36 & 16,00 & 15,33 & 14,30 & 0,76 & 14,8 & 2,73 & 0,043 & $-0,006$ & 0,024 & 0,025 & 0,935 \\
\hline $\begin{array}{l}700 \\
730^{\prime}\end{array}$ & 18,75 & 18,36 & 16,13 & 15,88 & 0,64 & 16,0 & 2,85 & 0,146 & $-0,005$ & 0,083 & 0,068 & 1,206 \\
\hline $\begin{array}{l}730 \\
800^{\prime}\end{array}$ & 19,42 & 20,04 & 16,92 & 17,70 & 1,26 & 17,3 & 2,99 & 0,258 & 0,003 & 0,068 & 0,187 & 0,361 \\
\hline $\begin{array}{l}800 \\
830^{\prime}\end{array}$ & 20,66 & 21,14 & 17,79 & 18,49 & 1,46 & 18,1 & 3,09 & 0,370 & 0,007 & 0,081 & 0,282 & 0,285 \\
\hline $\begin{array}{l}830 \\
900^{\circ}\end{array}$ & 21,70 & 22,50 & 18,06 & 19,38 & 1,65 & 18,7 & 3,16 & 0,472 & 0,013 & 0,088 & 0,371 & 0,237 \\
\hline $\begin{array}{ll}9 & 00 \\
9 & 30\end{array}$ & 23,15 & 24,00 & 19,68 & 20,80 & 1,32 & 20,2 & 3,34 & 0,564 & 0,019 & 0,124 & 0,421 & 0,293 \\
\hline $\begin{array}{r}930 \\
1000^{>}\end{array}$ & 24,84 & 25,62 & 19,63 & 22,37 & 3,51 & 21,0 & 3,44 & 0,651 & 0,027 & 0,051 & 0,572 & 0,090 \\
\hline $\begin{array}{l}1000 \\
1030^{\circ}\end{array}$ & 25,40 & 26,93 & 19,64 & 22,65 & 1,97 & 21,1 & 3,45 & 0,730 & 0,036 & 0,102 & 0,592 & 0,172 \\
\hline $\begin{array}{ll}10 & 30 \\
11 & 00^{\circ}\end{array}$ & 26,04 & 27,50 & 19,84 & 22,50 & 1,82 & 21,2 & 3,46 & 0,780 & 0,043 & 0,117 & 0,620 & 0,189 \\
\hline $\begin{array}{ll}11 & 15 \\
11 & 45\end{array}$ & 26,24 & 27,76 & 29,94 & 22,45 & 1,65 & 21,2 & 3,47 & 0,833 & 0,064 & 0,135 & 0,634 & 0,212 \\
\hline $\begin{array}{ll}11 & 45 \\
12 & 15^{2}\end{array}$ & 26,58 & 27,93 & 20,28 & 23,34 & 2,27 & 21,8 & 3,55 & 0,820 & 0,067 & 0,094 & 0,659 & 0,142 \\
\hline $\begin{array}{ll}12 & 15 \\
12 & 45^{\prime}\end{array}$ & 27,03 & 27,71 & 19,93 & 22,49 & 3,76 & 21,2 & 3,47 & 0,612 & 0,032 & 0,044 & 0,536 & 0,083 \\
\hline $\begin{array}{l}1245 \\
1315\end{array}$ & 27,51 & 28,68 & 19,49 & 21,24 & 1,50 & 20,4 & 3,36 & 0,714 & 0,028 & 0,136 & 0,550 & 0,247 \\
\hline $\begin{array}{l}13.15 \\
13.45\end{array}$ & 27,75 & 27,93 & 20,31 & 22,64 & 12,94 & 21,5 & 3,50 & 0,820 & 0,064 & 0,016 & 0,740 & 0,022 \\
\hline $\begin{array}{ll}13 & 45 \\
14 \quad 15\end{array}$ & 28,31 & 28,15 & 12,95 & 22,48 & $-1,5,81$ & $2 l, 2$ & 3,47 & 0,720 & 0,052 & $-0,012$ & 0,680 & $-0,018$ \\
\hline $\begin{array}{ll}14 & 15 \\
14 & 45\end{array}$ & 29,42 & 28,21 & 20,40 & 21,89 & $-1,23$ & 21,1 & 3,42 & 0,595 & 0,027 & $-0,092$ & 0,660 & $-0,192$ \\
\hline $\begin{array}{ll}14 & 45 \\
15 & 15\end{array}$ & 29,26 & 28,27 & 19,77 & 21,28 & $-1,52$ & 20,5 & 3,38 & 0,561 & 0,022 & $-0,105$ & 0,644 & $-0,163$ \\
\hline $\begin{array}{ll}15 & 15 \\
15 & 45\end{array}$ & 28,92 & 28,08 & 19,31 & 21,04 & $-2,06$ & 20,2 & 3,33 & 0,375 & 0,019 & $-0,052$ & 0,408 & $-0,127$ \\
\hline $\begin{array}{l}1600 \\
1630^{\circ}\end{array}$ & 28,65 & 28,04 & 19,27 & 20,38 & $-1,82$ & 19,8 & 3,28 & 0,261 & 0,009 & $-0,042$ & 0,294 & $-0,143$ \\
\hline $\begin{array}{l}1630 \\
1700^{\prime}\end{array}$ & 27,81 & 27,53 & 19,01 & 19,80 & $-2,82$ & 19,4 & 3,24 & 0,091 & 0,006 & $-0,009$ & 0,094 & $-0,099$ \\
\hline $\begin{array}{l}1700 \\
1730^{\circ}\end{array}$ & $26 ; 19$ & 25,92 & 18,70 & 18,85 & $-0,56$ & 18,8 & 3,16 & 0,001 & 0,001 & 0,000 & 0,000 & $-0,361$ \\
\hline $\begin{array}{ll}17 & 30 \\
18 & 00^{\circ}\end{array}$ & 23,88 & 21,19 & 18,39 & 18,70 & $-0,12$ & 18,6 & 3,14 & $-0,036$ & 0,002 & 0,101 & $-0,139$ & $-0,726$ \\
\hline $\begin{array}{ll}18 & 00 \\
18 & 30^{\prime}\end{array}$ & 22,82 & 21,21 & 18,17 & 18,46 & $-0,18$ & 18,3 & 3,10 & $-0,047$ & $-0,001$ & 0,088 & $-0,134$ & $-0,642$ \\
\hline $\begin{array}{ll}18 & 30 \\
19 & 00\end{array}$ & 22,05 & 19,00 & 17,48 & 17,97 & $-0,16$ & 17,7 & 3,04 & $-0,038$ & $-0,004$ & 0,070 & $-0,104$ & $-0,672$ \\
\hline
\end{tabular}


Apêndice 1.4.b - Resultados do dia 23.9.86 (68 DAG), para o tratanento M758

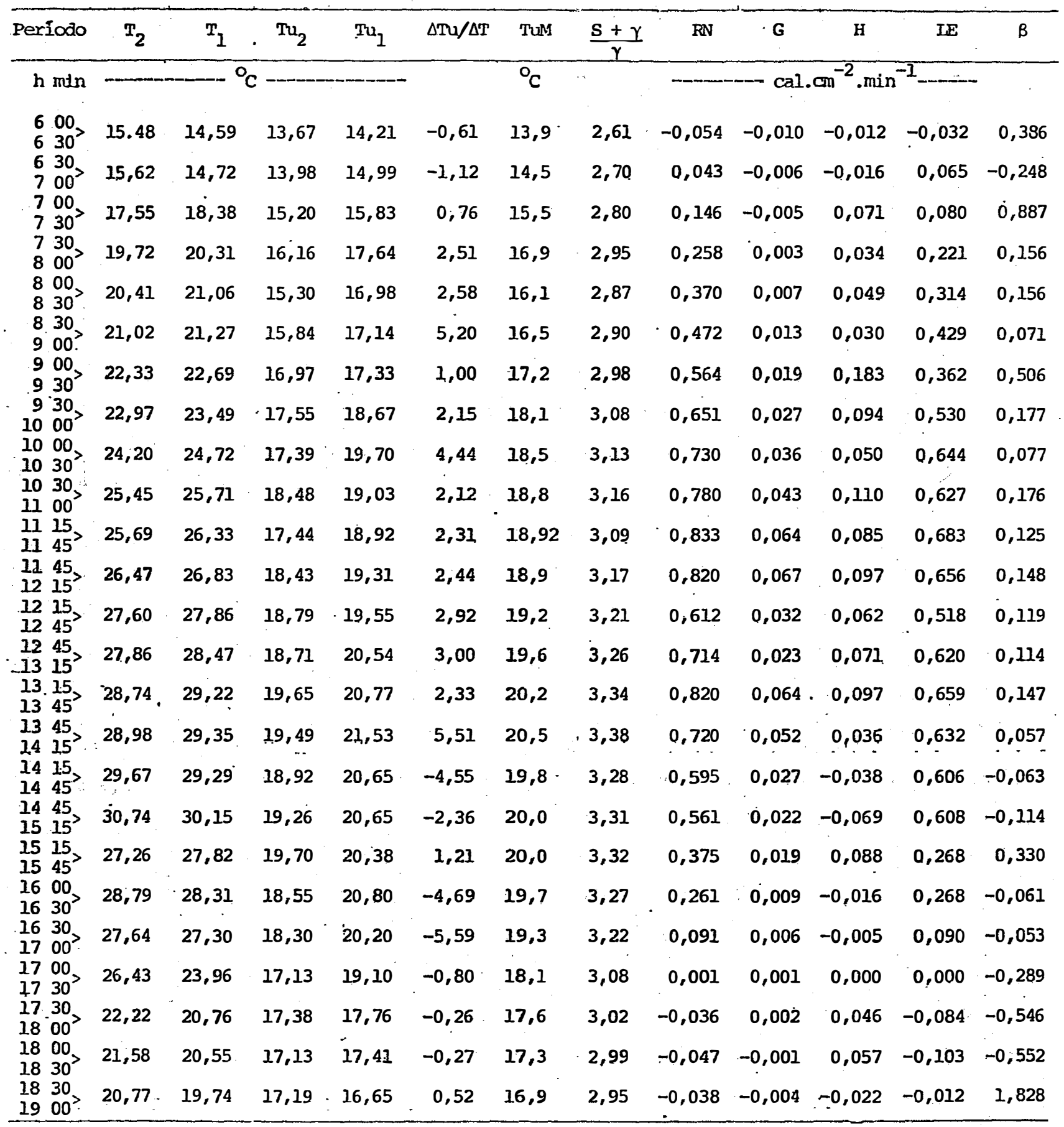


- Apêndice 1.5.a - Resultados do dia 1.10.86, para o tratamento 1008AD

\begin{tabular}{|c|c|c|c|c|c|c|c|c|c|c|c|c|}
\hline Período & $\mathrm{T}_{2}$ & $T_{1}$ & $\mathrm{Tu}_{2}$ & $\mathrm{Tu}_{1}$ & $\Delta T w / \Delta T$ & TuM & $\frac{s+\gamma}{\gamma}$ & $\mathrm{RN}$ & G & H & LE & $B$ \\
\hline$h \min$ & - & $-{ }^{\circ}$ & 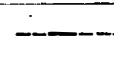 & $\ldots$ & & ${ }^{\circ} \mathrm{C}$ & & $\ldots$ & $-c a$ & $m^{-2}$. & 1 & \\
\hline $\begin{array}{l}7.00 \\
730\end{array}$ & 16,21 & 16,48 & 13,61 & 13,80 & 1,13 & 13,7 & 2,63 & 0,187 & $-0,003$ & 0,065 & 0,125 & 0,514 \\
\hline $\begin{array}{l}730 \\
800\end{array}$ & 17,22 & 17,34 & 14,55 & 14,77 & 1,83 & 14,8 & 2,73 & 0,296 & 0,004 & 0,058 & 0,234 & 0,250 \\
\hline $\begin{array}{ll}8 & 00 \\
8 & 30\end{array}$ & 18,13 & 18,55 & 15,20 & 16,10 & 2,14 & 15,6 & 2,81 & 0,416 & 0,010 & 0,067 & 0,339 & 0,199 \\
\hline $\begin{array}{l}830 \\
900^{\circ}\end{array}$ & 18,90 & 19,59 & $15 ; 53$ & 16,60 & 1,55 & 16,1 & 2,86 & 0,500 & 0,027 & 0,107 & 0,366 & $.0,291$ \\
\hline $\begin{array}{ll}9 & 00 \\
9 & 30\end{array}$ & 20,87 & 22,34 & 16,71 & 19,50 & 1,90 & 18,1 & 3,08 & 0,647 & 0,036 & 0,104 & 0,507 & 0,206 \\
\hline $\begin{array}{rr}9 & 30 \\
10 & 00\end{array}$ & 22,28 & 23,58 & 17,00 & 20,21 & 2,47 & 18,6 & 3,14 & 0,716 & 0,044 & 0,087 & 0,585 & 0,148 \\
\hline $\begin{array}{ll}10 & 00 \\
10 & 30\end{array}$ & 23,70 & 23,81 & 17,40 & 21,56 & 37,82 & 19,5 & 3,25 & 0,799 & 0,056 & 0,006 & 0,737 & 0,008 \\
\hline $\begin{array}{l}10 \cdot 30 \\
1100\end{array}$ & 25,63 & 25,34 & 18,03 & 22,08 & $-13,97$ & 20,1 & 3,32 & 0,844 & 0,057 & $-0,017$ & 0,804 & $-0,021$ \\
\hline $\begin{array}{ll}11 & 00 \\
11 & 30\end{array}$ & 25,46 & 26,23 & 18,28 & 23,35 & 6,58 & 20,8 & 3,42 & 0,869 & 0,057 & 0,036 & 0,776 & 0,047 \\
\hline $\begin{array}{ll}11 & 30 \\
12 & 00^{\prime}\end{array}$ & 26,25 & 27,74 & 18,50 & 24,09 & 3,75 & 21,3 & 3,48 & 0,922 & 0,058 & 0,066 & 0,798 & 0,083 \\
\hline $\begin{array}{ll}12 & 00 \\
12 & 30\end{array}$ & 27,08 & 27,85 & 18,06 & 23,66 & 7,27 & 20,9 & 3,42 & 0,895 & 0,055 & 0,034 & 0,806 & 0,042 \\
\hline $\begin{array}{ll}12 & 30 \\
13 & 00^{3}\end{array}$ & 25,37 & 26,92 & 18,15 & 22,33 & 2,70 & 20,2 &, 34 & 0,869 & 0,054 & 0,090 & 725 &, 125 \\
\hline $\begin{array}{l}1300 \\
1330\end{array}$ & 26,83 & 27,38 & 18,86 & 22,70 & 98 & 20,8 & 41 & 853 & 0,056 & 0,033 & 0,764 & 0,044 \\
\hline $\begin{array}{l}1330 \\
1400\end{array}$ & 25,81 & 26,23 & 18,78 & 22,16 & 8,05 & 20,5 & 3,37 & 0,474 & 0,044 & 0,016 & 0,414 & 0,038 \\
\hline $\begin{array}{l}1400 \\
14: 30>\end{array}$ & $-25,12$ & 25,57 & 18,26 & 21,39 & 6,96 & 19,8 & 3,29 & 0,562 & 0,024 & 0,024 & 0,514 & 0,046 \\
\hline $\begin{array}{ll}14 & 30 \\
15 & 00\end{array}$ & 26,04 & 25,89 & 18,45 & 21.02 & $-27,07$ & 19,7 & 3,28 & , 562 & 0,024 & $-0,010$ & 0,548 & $-0,018$ \\
\hline $\begin{array}{ll}15 & 00 \\
15 & 30\end{array}$ & 25,99 & 25,36 & 18,16 & 20,55 & $-3,79$ & 19,4 & 3,23 & 0,424 & 0,020 & $-0,033$ & 0,437 & $-0,075$ \\
\hline $\begin{array}{l}1530 \\
1600\end{array}$ & 25,49 & 23,03 & 17,20 & 20,28 & $-1,25$ & 18,7 & 3,16 & 256 & 0,013 & $-0,061$ & 0,304 & $-0,202$ \\
\hline $\begin{array}{ll}16 & 00 \\
16 & 30\end{array}$ & 24,66 & 22,95 & 17,15 & 19,88 & $-1,60$ & 18,5 & 3,13 & 0,149 & 0,009 & $-0,028$ & 0,168 & $-0,166$ \\
\hline $\begin{array}{l}1630 \\
1700\end{array}$ & 24,55 & 23,49 & 17,21 & 20,11 & $-2,64$ & 28,6 &, 14 & 0,154 & 0,007 & $-0,018$ & 0,165 & $-0,108$ \\
\hline $\begin{array}{l}17.00 \\
1730^{\circ}\end{array}$ & 23,50 & 21,21 & 16,80 & 17,43 & $-0,28$ & 17,1 & 2,97 & 0,036 & 0,002 & $-0,041$ & 0,075 & $-0,546$ \\
\hline $\begin{array}{ll}17 & 30 \\
18 & 00^{>}\end{array}$ & 20,63 & 19,87 & 16,70 & 16,35 & 0,46 & 16,5 & 2,91 & $-0,049$ & $-0,011$ & $-0,028$ & $-0,010$ & 2,940 \\
\hline $\begin{array}{ll}18 & 00 \\
18 & 30\end{array}$ & 19,28 & 18,49 & 16,88 & 16,58 & 0,38 & 16,7 & 2,93 & $-0,089$ & $-0,015$ & $-0,067$ & $-0,007$ & 8,818 \\
\hline $\begin{array}{ll}18 & 30 \\
19 & 00\end{array}$ & 19,10 & 17,66 & 15,78 & 15,09 & 0,48 & 15,4 & 2,79 & $-0,097$ & $-0,020$ & $-0,057$ & $-0,020$ & 2,948 \\
\hline
\end{tabular}


Ápêndice 1.5.b - Resultádos do dia 1.10.86, para o tratamento M75\%

\begin{tabular}{|c|c|c|c|c|c|c|c|c|c|c|c|c|}
\hline Período & $\mathbf{T}_{2}$ & $T_{1}$ & $\mathrm{Tu}_{2}$ & $\mathrm{Tu}_{1}$ & $\Delta \mathrm{Tu} / \Delta \mathrm{T}$ & TuM & $\frac{s+\gamma}{\gamma}$ & $\mathrm{RN}$ & G & H & LE & $B$ \\
\hline $\mathrm{h} \min$ & - & - & \multicolumn{2}{|c|}{${ }^{\circ} \mathrm{C} \ldots \ldots$} & \multicolumn{3}{|c|}{${ }^{\circ} \mathrm{C}$} & \multicolumn{5}{|c|}{ cal. $\mathrm{cm}^{-2} \cdot \mathrm{min}^{-1} \ldots$} \\
\hline $\begin{array}{ll}7 & 00 \\
7 & 30\end{array}$ & 16,48 & $16 ; 79$ & 14,22 & 15,01 & 2,55 & 14,6 & 2,71 & 0,187 & $-0,003$ & 0,027 & 0,163 & 0,169 \\
\hline $\begin{array}{l}730 \\
800^{3}\end{array}$ & 17,51 & 17,72 & 15,01 & 15,32 & 1,48 & 15,2 & 2,77 & 0,296 & 0,004 & 0,071 & 0,221 & 0,323 \\
\hline $\begin{array}{ll}8 & 00 \\
8 & 30\end{array}$ & 18,03 & 18,36 & 15,12 & 16,01 & 2,70 & 15,6 & 2,81 & 0,416 & 0,010 & 0,054 & 0,352 & 0,152 \\
\hline $\begin{array}{l}830> \\
900\end{array}$ & 18,40 & 18,96 & 15,49 & 16,10 & 1,09 & 15,8 & 2,83 & 0,500 & 0,027 & 0,155 & 0,320 & $\cdot 0,480$ \\
\hline $\begin{array}{ll}9 & 00 \\
9 & 30\end{array}$ & 19,60 & 20,23 & 15,43 & 16,67 & 1,97 & 16,1 & 2,86 & 0,647 & 0,036 & 0,109 & 0,502 & 0,216 \\
\hline $\begin{array}{rl}9 & 30 \\
10 & 00\end{array}$ & 21,70 & 22,19 & 16,25 & 17,43 & 2,41 & 16,8 & 2,94 & 0,716 & 0,044 & 0,095 & 0,577 & 0,164 \\
\hline $\begin{array}{ll}10 & 00> \\
10 & 30\end{array}$ & 21,83 & 22,02 & 18,39 & 19,25 & 4,53 & 18,8 & 3,17 & 0,799 & 0,056 & 0,052 & 0,691 & 0,075 \\
\hline $10 \cdot 30>$ & 24,53 & 24,50 & 18,75 & 19,32 & $-19,00$ & 19,0 & 3,19 & 0,844 & 0,057 & $-0,013$ & 0,800 & $-0,016$ \\
\hline 1100 & 24,52 & 24,21 & 18,04 & 19,06 & $-3,29$ & 18,6 & 3,14 & 0,869 & 0,057 & $-0,079$ & 0,891 & $-0,088$ \\
\hline $1230>$ & 26,92 & 26,39 & 17,55 & 20,20 & $-5,00$ & 18,9 & 3,17 & 0,922 & 0,058 & $-0,054$ & 0,918 & $-0,059$ \\
\hline $1200>$ & 27,56 & 27,04 & 27,34 & 20,02 & $-5,15$ & 18,7 & 3,15 & 0,907 & 0,055 & $-0,052$ & 0,904 & $-0,058$ \\
\hline $\begin{array}{l}1230> \\
1300\end{array}$ & 26,94 & 26,20 & 17,43 & 20,42 & $-4,04$ & 18,9 & 3,18 & 0,895 & 0,060 & $-0,065$ & 0,900 & $-0,072$ \\
\hline $\begin{array}{l}1300 \\
1330\end{array}$ & 26,59 & 26,37 & 16,54 & $.17,28$ & $-3,36$ & 16,9 & 2,95 & 0,869 & 0,054 & $-0,082$ & 0,897 & $-0,092$ \\
\hline $1330>$ & 26,72 & 27,19 & 27,60 & 19,04 & 3,06 & 18,3 & 3,11 & 0,853 & 0,056 & 0,084 & 0,713 & 0,117 \\
\hline $14.00>$ & 25,13 & 25,91 & 16,96 & 18,95 & 2,55 & 18,0 & 3,07 & 0,474 & 0,044 & 0,055 & 0,375 & 0,147 \\
\hline $\begin{array}{l}1430 \\
1500\end{array}$ & 27,62 & 28,27 & 27,28 & 19,89 & 4,02 & 18,6 & 3,14 & 0,562 &, 024 & 0,043 & 0,495 & 0,086 \\
\hline $\begin{array}{ll}15 & 00 \\
15 & 30\end{array}$ & 25,51 & 25,75 & 17,47 & 18,86 & 5,79 & 18,2 & 3,09 & 0,424 & 0,020 & 0,023 & 0,381 & 0,059 \\
\hline $\begin{array}{ll}1530 \\
1600\end{array}$ & 25,70 & 26,02 & 17,14 & 19,31 & 6,78 & 18,2 & 3,10 & 0,256 & 0,013 & 0,012 & 0,231 & 0,050 \\
\hline $\begin{array}{ll}16 & 00 \\
16 & 30\end{array}$ & 25,14 & 24,71 & 37,01 & 17,77 & $-1,72$ & 17,4 & 3,00 & 0,149 & 0,009 & $-0,026$ & 0,166 & $-0,159$ \\
\hline $\begin{array}{ll}16 & 30 \\
17 & 00\end{array}$ & 26,31 & 26,98 & 16,93 & 18,24 & 1,96 & 27,6 & 3,02 &, 154 & 0,007 & 0,025 & 0,122 & 0,204 \\
\hline $1730^{>}$. & 24,28 & 23,26 & 17,88 & $i 8,04$ & 0,16 & $18,0^{\circ}$ & 3,07 &, 036 & .002 & $-0,071$ & 0,105 & $-0,675$ \\
\hline $\begin{array}{lll}17 & 30 \\
18 & 00^{>}\end{array}$ & 20,89 & 20,37 & 16,89 & 18,50 & $-3,10$ & 17,7 & 3,04 & $-0,049$ & 0,011 & 0,004 & $-0,042$ & $-0,096$ \\
\hline $18 \cdot 30^{>}$ & 19,89 & 19,13 & 16,17 & 15,31 &, 13 & 15,7 & 2,83 & $-0,089$ & $-0,015$ & $-0,023$ & $-0,051$ & 0,455 \\
\hline $1900^{>}$ & 18,90 & 18,44 & 15,74 & 15,45 & 0,63 & 15,6 & 2,82 & $-0,097$ & $-0,020$ & $-0,043$ & $-0,034$ & 1,288 \\
\hline
\end{tabular}

